University of Louisville

ThinkIR: The University of Louisville's Institutional Repository

Electronic Theses and Dissertations

$12-2017$

\title{
Age-related host factors regulate lung cancer progression.
}

John Caleb Greenwell

University of Louisville

Follow this and additional works at: https://ir.library.louisville.edu/etd

Part of the Pharmacology Commons, and the Toxicology Commons

\section{Recommended Citation}

Greenwell, John Caleb, "Age-related host factors regulate lung cancer progression." (2017). Electronic Theses and Dissertations. Paper 2846.

https://doi.org/10.18297/etd/2846

This Doctoral Dissertation is brought to you for free and open access by ThinkIR: The University of Louisville's Institutional Repository. It has been accepted for inclusion in Electronic Theses and Dissertations by an authorized administrator of ThinkIR: The University of Louisville's Institutional Repository. This title appears here courtesy of the author, who has retained all other copyrights. For more information, please contact thinkir@louisville.edu. 


\title{
AGE-RELATED HOST FACTORS REGULATE LUNG CANCER PROGRESSION
}

\author{
By \\ John Caleb Greenwell \\ B.S., University of Louisville, 2010 \\ M.S., University of Louisville 2015
}

\begin{abstract}
A Dissertation
Submitted to the Faculty of the

School of Medicine of the University of Louisville in Partial Fulfillment of the Requirements for the Degree of

\author{
Doctor of Philosophy \\ in \\ Pharmacology and Toxicology \\ Department of Pharmacology and Toxicology \\ University of Louisville \\ Louisville, KY
}

December 2017 
Copyright 2017 by John Caleb Greenwell

All Rights Reserved 



\title{
AGE-RELATED HOST FACTORS REGULATE LUNG CANCER PROGRESSION
}

\author{
By \\ John Caleb Greenwell \\ B.S., University of Louisville, 2010 \\ M.S., University of Louisville, 2015 \\ A Dissertation Approved on \\ November $14^{\text {th }}, 2017$ \\ by the following Dissertation Committee: \\ Jesse Roman, M.D. Dissertation Director \\ Levi Beverly, Ph.D. \\ Shirish Barve, Ph.D. \\ Ramesh Gupta, Ph.D. \\ Jun Yan, M.D., Ph.D.
}




\section{DEDICATION}

To my beloved and beautiful wife Tricia. Your worth to me is more than precious jewels. You are my trusted companion and my heart rejoices in you. You are my heroine and my greatest asset. There is no one else I would have chosen to be by my side during this race. I truly could not have done it without you. I love you.

To my children: Claire, Calvin, Tucker and Tate. I am overjoyed to be your father and I am so proud of all of you. The joy you have brought your mother and I is unmatched. I love you.

"He who finds a wife finds a good thing and obtains favor from the LORD."

- Proverbs 18:22

"Behold, children are a gift of the LORD, the fruit of the womb is a reward."

- Psalm 127:3 


\section{ACKNOWLEDGEMENTS}

As I ponder the long years spent working on this project, I am truly humbled by the large number of individuals who have sacrificially invested their lives in mine and who have walked this road with me. Nothing in life can be accomplished alone, and graduate school is no exception. First, I would like to thank my mentor, Dr. Jesse Roman, for allowing me to be a part of his lab, where I developed a love and appreciation for the role that tissue remodeling plays in disease. His patience, encouragement, and unwavering support spurred me on when the threat of defeat was upon me. I consider it a great honor to have worked with him. I would also like to thank the members of the lab, where the majority of my time was spent: Jeff Ritzenthaler, Edilson Torres-González, Glenn Vicary, Ryan McAllister, Dr. Watson (Bert), and Dr. Zelko (Igor). Not only did they help me tremendously in the lab, they

made every day lively and enjoyable, and they have become my friends. Lastly, I would like to thank my committee members Dr. Shirish Barve, Dr. Ramesh Gupta, Dr. Levi Beverly, and Dr. Jun Yan, for their comments and guidance. 


\section{ABSTRACT \\ AGE-RELATED HOST FACTORS REGULATE LUNG CANCER PROGRESSION}

John Caleb Greenwell

November $14^{\text {th }}, 2017$

Cancer is largely a disease of the elderly. In the United States alone, $87 \%$ of all cancers in 2017 will be diagnosed in individuals aged 50 years or older. Among them, lung cancer is the deadliest, accounting for 1 in 4 cancer deaths. The 5-year survival rate is below $20 \%$, a number which has not changed substantially over the past several decades. This underscores a desperate need for new strategies in prevention, early detection and treatment of this deadly disease. While tobacco use is unquestionably the number one risk factor for the development of lung cancer, the majority of diagnoses occur in individuals with preexisting lung conditions such as chronic obstructive pulmonary disease and idiopathic pulmonary fibrosis, characterized by inflammation and remodeling of the extracellular matrix. Fibronectin is one matrix protein upregulated in these settings. Fibronectin EDA is a splice variant of fibronectin that is increased with aging and has been shown to be a vascular marker for solid tumors and metastases. 
Moreover, immunization against fibronectin EDA decreases tumor burden and lung metastases in the MMTV-PyMT transgenic model of metastatic mammary carcinoma.

In this dissertation, I explore how age-related host factors regulate lung progression. More specifically, I examine how tissue remodeling and aging act in concert, through increased levels of fibronectin EDA, to render the host susceptible to lung cancer progression. This and other work is described in 5 chapters: 1) background and introduction; 2) the role of aging and tissue remodeling in lung cancer; 3 ) the role of fibroblasts in lung cancer; 4) the role of sex and redox in lung cancer; and 5) summary and discussion. The work described here suggests that age-dependent host factors influence lung cancer progression. Importantly, lung inflammation/tissue remodeling augments pulmonary metastasis in the aging lung, but not in young lungs, through mechanisms involving fibronectin EDA, which perhaps provides a scaffold for tumor cell migration/organization and proliferation. This points to an interplay between lung aging and inflammation/remodeling in lung tumor progression and describes a previously unknown role of fibronectin EDA in lung cancer in the setting of lung injury and aging. Sex also appears to be important, while oxidative stress may play a minor role. Finally, we show that fibroblasts produce factors capable of influencing cancer progression. 
TABLE OF CONTENTS

$\underline{\text { PAGE }}$

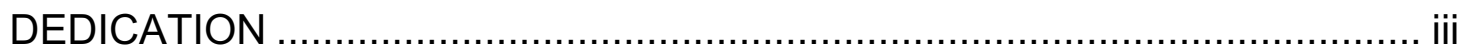

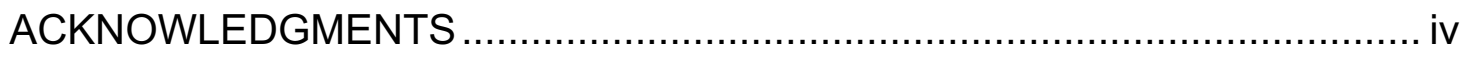

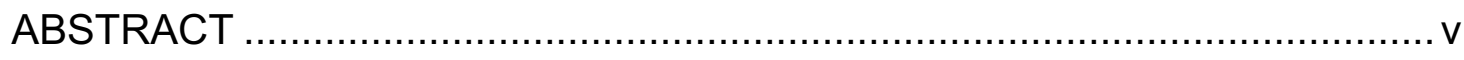

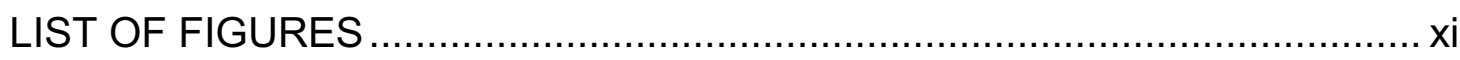

CHAPTERS:

I. BACKGROUND AND INTRODUCTION

1.1 Epidemiology of Lung Cancer .................................................. 1

1.2 Diagnosis, Management, and Treatment of Lung Cancer ................5

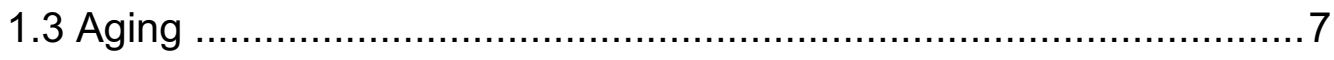

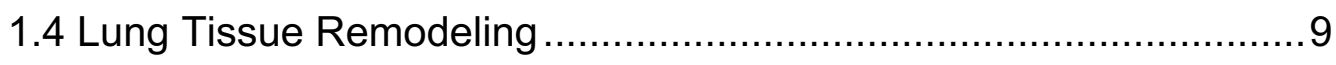

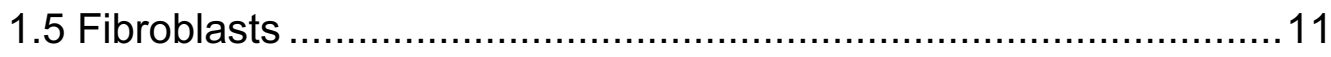

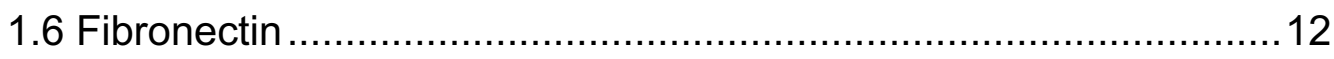

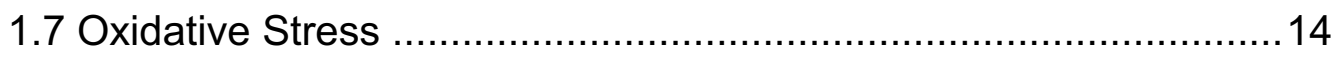

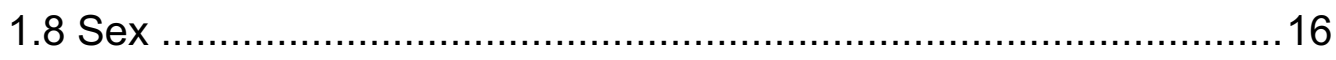

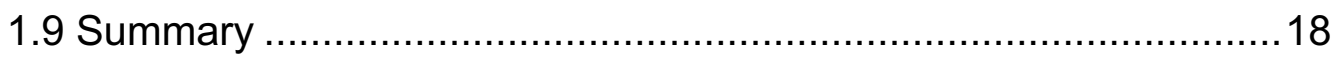




\section{ROLE OF AGING AND TISSUE REMODELING IN LUNG CANCER}

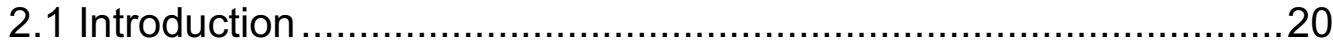

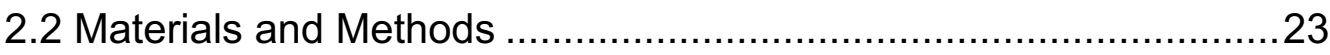

2.3 Results

2.3.1 Aging is Associated with Increased Lung Metastases...........26

2.3.2 Bleomycin Treatment is Associated with Increased

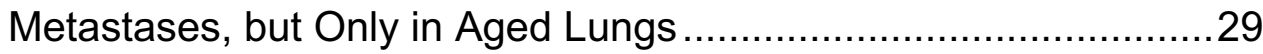

2.3.3 Fibronectin EDA is Dispensable for Age-Related

Lung Cancer Progression, but Required for Bleomycin-Induced

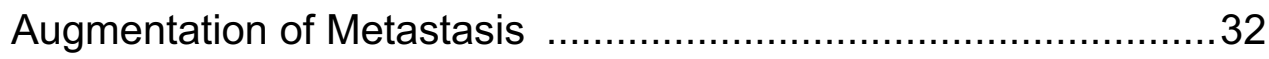

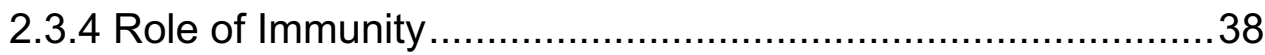

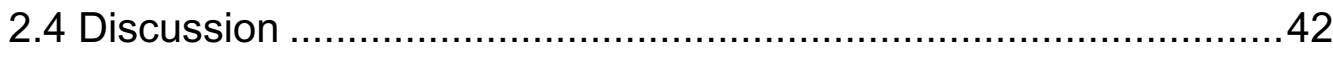

\section{ROLE OF FIBROBLASTS IN LUNG CANCER}

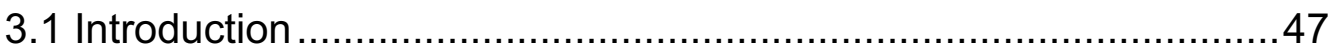

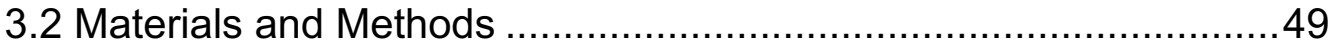

3.3 Results

3.3.1 FCM Alters Morphology of Lung Cancer Cells .....................57

3.3.2 FCM Has Differential Effects on Proliferation, Migration

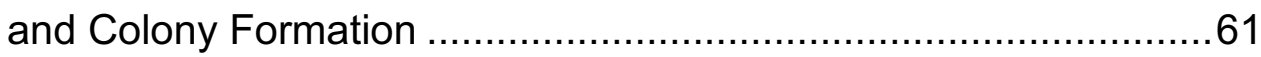

3.3.3 FCM Protects Against Cisplatin-Induced Death ....................66

3.3.4 Fibroblasts Co-Injected with LLC Cells Promote Tumor

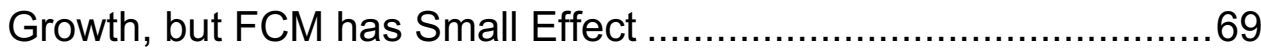




\section{ROLE OF SEX AND REDOX IN LUNG CANCER}

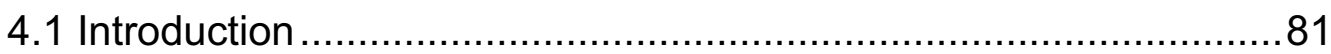

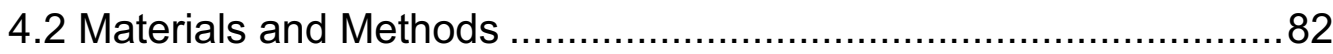

4.3 Results

4.3.1 Plasma Eh Cys/CySS is Unchanged in Aged

Mice but Females are More Oxidized Compared to Males

85

4.3.2 Female Mice are More Susceptible to LLC

Lung Cancer Metastasis

4.3.3 Sulfur Amino Acid Diets and Fasting Affect Plasma

Eh Cys/Cyss

4.3.4 Alterations in Plasma $E_{h}$ Cys/CySS Have No Effect

on LLC Lung Cancer Progression 94

4.4 Discussion 96

\section{SUMMARY AND DISCUSSION}

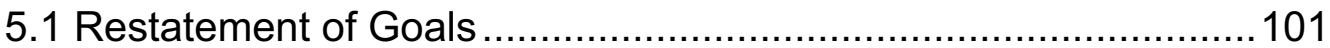

5.2 Main Findings of this Dissertation...........................................102

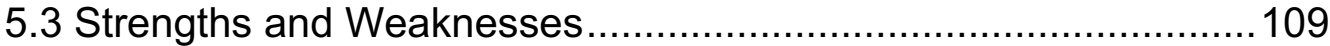

5.4 Future Directions

5.4.1 How does aging impact lung cancer progression? 
5.4.2 What is the identity of soluble factor(s) in FCM that

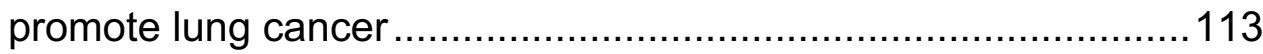

5.4.3 What is the role of sex in lung cancer progression? ............113

5.4.4 Could SAA diets play a role in prevention? .......................115

5.4.5 What is the role of the lung microbiome? .........................115

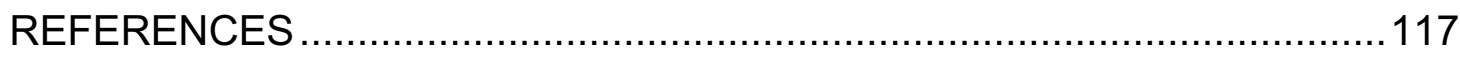

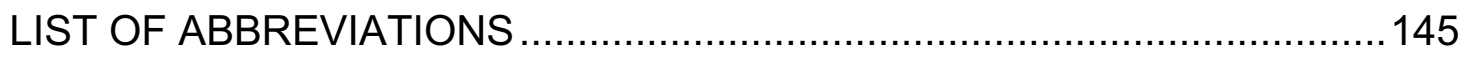

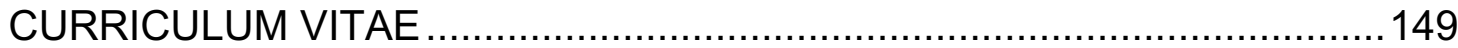




\section{LIST OF FIGURES}

FIGURE $\quad \underline{\text { PAGE }}$

1. Dissertation Hypothesis .................................................................19

2. Aging is Associated with Increased Lung Metastases ........................27

3. Bleomycin Treatment is Associated with Increased Metastases, but

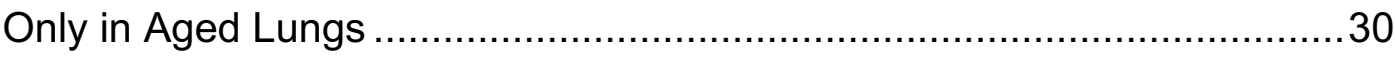

4. Fibronectin EDA is Dispensable for Age-Related Lung Cancer

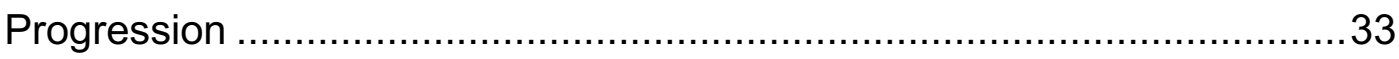

5. Fibronectin EDA is Required for Bleomycin-Induced Augmentation

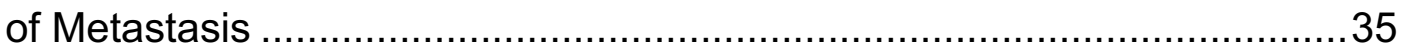

6. Lung Metastases Develop Primarily in Fibrotic Areas ............................36

7. Effect of cFN on LLC Proliferation and Migration .................................37

8. Effect of Immunity on LLC Lung Cancer Progression .............................39

9. LLC Metastases in WT and NSG Mice .............................................. 41

10. FCM Alters Lung Cancer Cell Morphology .........................................58

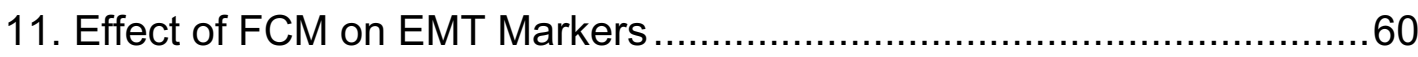

12. FCM Increases Lung Cancer Cell Proliferation ...................................62

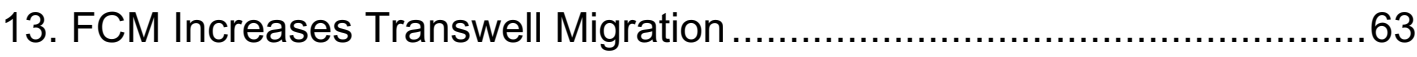

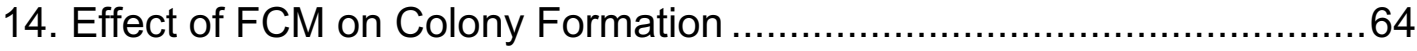

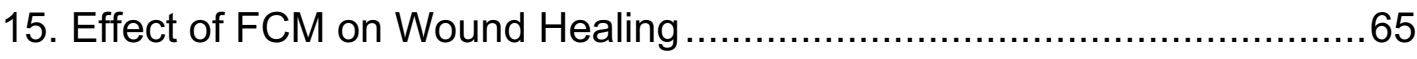


16. FCM Decreases Sensitivity of Lung Cancer Cells to Cisplatin

17. Effect of FCM on Caspase 3/7 Activation...........................................68

18. Effect of PLF and FCM on tumor growth and lung metastasis

in vivo

70

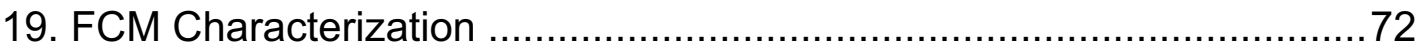

20. Charcoal-Stripped FCM Blocks Protection Against Cisplatin .................74

21. Plasma Eh Cys/CySS and Eh GSH/GSSG are Unchanged

in Old Mice

22. Female Plasma Eh Cys/CySS is More Oxidized Compared

to Males

23. Female Mice are More Susceptible to LLC Lung Cancer Metastasis ....89

24. Diets Containing Excess Sulfur Amino Acids Reduce the Plasma

Eh Cys/Cyss

25. Fasting Alters Plasma Eh Cys/CySS in Male Mice but Not Female

Mice

26. Alterations in Plasma $E_{h}$ Cys/CySS Have No Effect on LLC Lung

Cancer Progression

27. FNA EDA Protein Levels in Female and Male Whole Lung

Homogenates 


\section{CHAPTER I}

\section{BACKGROUND AND INTRODUCTION}

\subsection{Epidemiology of Lung Cancer}

Lung cancer is the leading cause of cancer death in men and women in the Unites States (US). It is largely preventable, as most cases are due to tobacco use. In 2017, there will be over an estimated 220,000 new cases of lung cancer, which accounts for $14 \%$ of all cancer diagnoses [1]. Of those diagnosed, there will be over an estimated 155,000 deaths, which is more than the next 3 major types of cancer (colon, prostate, and breast) combined. Lung cancer is thus responsible for more than one-quarter (27\%) of all cancer deaths [2]. Due to the large number of individuals affected by lung cancer, the national cost of lung cancer care in the US in 2010 was estimated to be $\$ 12.12$ billion, a significant burden on the economy. Lung cancer was also found to be the condition with the highest cost in the last year of life phase of care [3]. These data justify further research and efforts in this area.

Lung cancer is diagnosed primarily in the elderly population. Cancer in general is well known to be a disease of the aged. In the US alone, $87 \%$ of all cancers in 2017 will be diagnosed in individuals 50 years or older. For lung cancer, two-thirds of all new cases will be diagnosed in those older than 65 years, while 
the number of deaths from lung cancer in those under 20 years of age is expected to be $0 \%[1]$.

The number one risk factor for the development of lung cancer is unquestionably tobacco exposure. This was first reported in 1964, when Luther Terry, the ninth Surgeon General of the United States, released his now famous report titled, "Smoking and Health: Report of the Advisory Committee to the Surgeon General of the United States," which concluded that bronchitis and lung cancer were causally related to cigarette smoking. Of all lung cancer deaths, $80 \%$ are caused by smoking. This fact is strengthened by the striking geographic variation in lung cancer deaths by state, where patterns of mortality cluster in areas with the highest prevalence of smoking. Kentucky leads the nation in individuals who smoke, while Utah contains the fewest smokers. Not surprisingly, the number of lung cancer deaths in those states in 2017 is estimated to be 3560 compared to 460 , respectively [1]. While the carcinogenic mechanisms of tobacco use are not completely understood, research over the past 5 decades has revealed that we do indeed know a great deal about how tobacco use causes lung cancer and that there is certainly not a single mechanism, but several, responsible for tobacco carcinogenesis. There have been over 8000 compounds identified in tobacco and tobacco smoke [4]. Among them, the International Agency for Research on Cancer has classified over 70 carcinogens capable of causing cancer in laboratory animals and humans [5]. These carcinogens include the polycyclic aromatic hydrocarbons (PAHs) and the tobacco specific nitrosamines (TSNAs). Many require metabolic activation that then leads to the formation of DNA adducts by covalent binding. For 
example, benzo[a]pyrene diol epoxide has been shown to bind to select regions of the $p 53$ gene [6]. Overtime, DNA repair mechanisms fail, or are evaded, and due to the cumulative nature of these adducts, permanent mutations are formed. If these mutations occur in vital genes, oncogenes (e.g. KRAS) could be activated and tumor suppressor genes (e.g. p53 and $R b$ ) could be deactivated leading to the development of cancer. While the contribution of such mutations in the development of cancer cannot be overstated, mutations alone are not sufficient to cause tumor growth. It has been shown that simultaneous expression of oncogenic KRAS and knockdown of p53 was insufficient to confer a complete malignant phenotype in human bronchial epithelial cells [7].

While lung cancer is often viewed solely as a smoker's disease, not all lung cancers occur in individuals who smoke [8]. This is an important fact to take note of because lung cancers that develop in those who have never smoked differ considerably from lung cancers in smokers. Significant differences in histologic subtypes have been identified, with adenocarcinoma prevailing in never smokers [9]. Exposure to radon gas, which can be trapped in residential homes, has been proposed as the second leading cause of lung cancer after cigarette smoking $[10,11]$. However, others have argued that studies showing an association between radon exposure and lung cancer relied on a linear-no-threshold hypothesis-based, risk assessment paradigm that has recently been invalidated. Instead, using a hormetic relative risk model, radon exposure was shown to actually protect against lung cancer [12]. Regardless, these studies establish the point that a large number of individuals who develop lung cancer are never- 
smokers, and the proportion of individuals who develop lung cancer that have never smoked is going to continually increase as smoking cessation efforts continue, and thus research in this area must continue [13].

The overall incidence of lung cancer has been declining, but this is due largely to smoking cessation efforts. For men, the incidence rate has been declining since the mid 1980s, while for women, the rate did not start declining until the early 2000s [2]. From 1990 to 2011 , lung cancer death rates dropped by $36 \%$ for men and $11 \%$ for women from 2002 to 2011 [14]. This decrease in death rates matched a drop in the number of individuals smoking that began decades earlier. In fact, it has been estimated that the Surgeon General's report in 1964 resulted in 8 million fewer smoking-related deaths, with one-third of those being due to cancer. This was associated with a decline in adult smoking rates from $43 \%$ (1965) to $18 \%$ today [15]. Although this decline in smoking rates is to be celebrated, tobacco use remains a major problem in the US and worldwide. Every day, it is estimated that 3200 youth smoke a cigarette for the first time, and 2100 youth and occasional smokers progress to become daily smokers [15]. There also appears to be a high -risk population of women born after 1950 in several Southern and Midwestern states [16]. Thus, continued efforts in raising awareness of the health hazards of tobacco use and additional interventions must be pursued in all areas of influence.

Unfortunately, the decline in the number of cigarette smokers in the US has been met by an increase in the number of electronic cigarette (e-cig) users. E-cigs are battery-powered devices that use heat to convert liquid nicotine and various flavorings into an inhalable vapor. E-cigs were invented in 2003 and introduced 
into the market the following year as a "safe alternative" to cigarette smoking. Since then, the number of e-cig users has grown at an alarming pace, especially among the nation's youth. Roughly $16 \%$ of current cigarette smokers and $22 \%$ of recent former smokers currently use e-cigs on a regular basis [17]. E-cig sales in the US are estimated to reach $\$ 10$ billion in 2017 , and are expected to surpass the sale of standard cigarettes by 2023 [18]. While e-cigs are marketed as safer alternatives to conventional cigarettes, numerous studies have shown that e-cigs contain carcinogens found in cigarettes, as well as several metals and silicate particles $[19,20]$. Long-term term studies evaluating the harmful effects of e-cigs and the ability of e-cig use to cause or promote lung cancer have not been investigated. However, due to their similar composition to conventional cigarettes (nicotine and carcinogens), the drastic increase of e-cig use is a matter of great concern, and additional studies are warranted in this area.

\subsection{Diagnosis, Management, and Treatment of Lung Cancer}

There are currently 2 major recognized types of lung cancer: small-cell lung cancer (SCLC) and non-small-cell lung cancer (NSCLC), which is further divided into squamous cell carcinoma, adenocarcinoma, and large cell carcinoma [21]. SCLC is highly aggressive, exhibits neuroendocrine characteristics, and accounts for $15 \%$ of lung cancers. Of the remaining $85 \%$ of lung cancers, the vast majority are NSCLC, with adenocarcinoma being the most common, followed by squamous cell carcinoma, and lastly large cell carcinoma [14]. While smoking is associated with every type of lung cancer, the association is strongest for SCLC and 
squamous cell carcinoma. In never smokers, adenocarcinoma is the most the common type identified $[9,22]$.

Symptoms of lung cancer include persistent cough, coughing up blood, shortness of breath, wheezing, hoarseness, weight loss, chest pain, lethargy, and others. A diagnosis is made using one or several of the following methods: physical exam, chest x-ray, CT scan, PET scan, MRI, bone scan, sputum cytology, bronchoscopy, or fine-needle aspiration biopsy of the lung. Once a diagnosis has been made, oncologists use the principles set forth by the American Joint Committee on Cancer for lung cancer staging. There are currently 4 recognized stages of lung cancer, staged 1 - 4, with stages 1, 2 and 3 being further divided into $A$ and $B$ subtypes [23]. Proper staging is of the utmost importance for the determination of the appropriate treatment regimen. For example, surgical resection is beneficial for patients with stages $1-2$, while those with stages 3-4 rarely benefit from surgery [24]. Other treatment options include chemotherapy alone or in combination with radiation.

Despite the steady increase in survival rates for most cancers, the current relative 5 -year survival rate for lung cancer is $18 \%$ and that number has only increased slowly over the past several decades [2]. The survival rate decreases to $4 \%$ if distant metastases are present, which is a devastating reality because over $50 \%$ of all diagnoses are in this category [14]. This is one of the main reasons for the low survival rate, largely due to the lack of symptoms until that time. This underscores the need for early detection in lung cancer. It has been argued that progress is being made in this area through recent developments in screening with 
spiral computed topography, which has been shown to decrease lung cancer deaths in those who have a history of heavy smoking $[25,26]$. These reports, however, as some have warned, must be taken with caution, as they introduce lead time bias in survival rates [27]. Thus, age-adjusted mortality rates and not survival rates might be a better measure of lung cancer incidence.

\subsection{Aging}

Aging is natural process of life that is unavoidable. It is largely due to the progressive accumulation of damage in macromolecules that is marked by a decline in the function of cells, tissues and ultimately organs. This decline in physiological integrity renders organisms vulnerable to cancer, cardiovascular disease, diabetes, and neurodegenerative diseases, among others.

Population aging, a process defined as an increase in the proportion of older people and a decrease in the number of younger people, is becoming a major problem in the US and worldwide. For example, in 1950 only $8 \%$ of the world's population was over the age of 60 . That number grew to $11.2 \%$ by 2011 , and is projected to reach $22 \%$ by 2050 . In contrast, the number of individuals under the age of 15 is projected to decrease from $26.6 \%$ to $20 \%$ in 2050 [28]. The cause of population aging is two-fold: one is a decrease in fertility rates, and two, increased life expectancies. In the US, the fertility rate, defined as births per 1000 women, is now the lowest it has ever been since such records started being kept more than a century ago [29]. Increases in life expectancy in the past have mainly been due to decreases in child mortality rates. Presently, however, increased life expectancy 
is due to decreases in mortality in the elderly. As the population continues to age, the prevalence of chronic diseases, known as noncommunicable diseases (NCDs) will continue to increase. In the US, $65 \%$ of health care costs are due to individuals with at least one NCD [30]. This will become a major threat to our economy, as the high health costs associated with NCDs will need to be sustained by a shrinking working-age population.

While worldwide deaths from most NCDs (cancer and cardiovascular diseases) are continuing to decline, those from chronic obstructive pulmonary disease (COPD) are not and some estimate that they are growing. In fact, diseases of the respiratory system are among the major contributors of the worldwide burden of disease. For example, there are over 1 billion people globally who suffer from chronic respiratory diseases such as asthma (300 million) and COPD (210 million) [31], with COPD expected to become the third leading cause of death by 2030 [32]. These respiratory diseases are disproportionately observed in the elderly population $[33,34]$, and may actually be underrepresented [35].

The association between aging and an increased susceptibility to respiratory diseases has also been noted in several rodent models. For example, old animals were shown to be more susceptible to bleomycin-induced pulmonary fibrosis, and morphologic and functional changes due to chronic cigarette smoke inhalation $[36,37]$. Old animals were also more susceptible to lung injury in the setting of mechanical ventilation [38]. 


\subsection{Lung Tissue Remodeling}

As previously mentioned, historically, lung cancer was thought to be caused directly by mutations in the genome initiated by tobacco carcinogens. However, numerous studies have shown that COPD and fibrotic diseases such as asbestosis and idiopathic pulmonary fibrosis (IPF), characterized by inflammation and lung tissue remodeling, are also risk factors for the development of cancer. For example, as early as 1935, through autopsy studies, Gloyne identified cases of squamous cell carcinoma in individuals with asbestosis [39]. Several decades later, Haddad \& Massaro, again through autopsy studies, found lung cancer lesions in individuals with IPF [40]. More recently, Hubbard and colleagues found a seven-fold increase in the incidence of lung cancer in those with IPF (termed cryptogenic fibrosing alveolitis in their study) compared to controls, even after adjusting for smoking [41]. These studies suggest that alterations in lung structure/function and composition precede the development of lung cancer, which posits one to consider that the normal, healthy lung is able to successfully defend itself against genomic alterations due to genetic mutations.

Lung tissue remodeling can be defined as alterations in the composition and deposition of extracellular matrix (ECM) proteins. While the ECM plays roles consistent with the organs in which it is found, it is usually composed of similar macromolecules; the fibrous proteins like collagens, fibronectins, laminins, and the proteoglycans [42]. These proteins are capable of self-assembling into elaborate and extensive, interconnected three-dimensional networks that have several roles. The ECM provides structural support for tissues, acting as a glue and/or scaffold 
that holds cells together, but it is also has regulatory and functional roles that determine cell shape, activity, and differentiation [43]. It is thus crucial in maintaining tissue homeostasis. It is not surprising then that alterations in the ECM (i.e. lung tissue remodeling) have been linked with several diseases. For example, Ehlers-Danlos syndrome, an inherited disease marked by joint, skin, and blood vessel problems, is caused by mutations in one or more genes that results in defects in processing and structure of collagen. Additionally, Marfan's syndrome is caused by an absence of fibrillin, which leads to a lack of elastic recoil in the aorta, predisposing individuals who suffer from this disease to aortic rupture. In terms of the lung, tissue remodeling is one of the key features of both COPD and IPF, diseases that are distinct, and yet that share many similarities [44,45]. For example, in IPF, one of the main problems is excessive collagen type 1 deposition, mainly caused by increased TGF $\beta$ signaling, which leads to impaired gas exchange $[46,47]$. This is also true of COPD, where ECM composition in the airway wall has been shown to be altered compared to normal, healthy subjects $[44,48]$. While excessive collagen deposition is hallmark of tissue remodeling, fibronectins are also present in large quantities in areas of fibrosis [49] and tissue repair/wound healing $[50,51]$. Interestingly, alterations of the ECM have also been shown to occur with aging, with chronic inflammation and/or oxidative stress suggested as the possible cause [52].

Thus, while lung tissue remodeling is characteristic of COPD and IPF, both risk factors for lung cancer, the true role that lung issue remodeling plays in lung cancer remains undefined and further research in this area is warranted. 


\subsection{Fibroblasts}

Fibroblasts were first identified in the late 1800's by their location and appearance $[53,54]$, and yet they remain poorly defined in molecular terms. They are usually identified by their elongated, spindle-shaped appearance. While certain markers in the literature are used to identify fibroblasts, there are none to date that are known to be exclusive to fibroblasts, and there is a large variation in fibroblasts isolated from different anatomical areas of the body. For example, desmin appears to be a good marker for identifying fibroblasts isolated from the skin, while discoidin-domain receptor 2 can be used to identify cardiac fibroblasts $[55,56]$.

Fibroblasts are the predominant cell type of tissue stroma. In normal tissue homeostasis, they are largely responsible for the production and function of the ECM, in which they are embedded. The ECM, as described previously, functions as a scaffold that holds cells together, but also has regulatory and functional roles that determine cell shape and activity. Thus, fibroblasts are key players in tissue remodeling, and have prominent roles in the development and progression of COPD and IPF. Increased TGF $\beta$ signaling is a main driver of tissue remodeling that has proven difficult to target in diseased states due to the roles of TGF $\beta$ in the functioning of normal cells. However, it has recently been reported that specific inhibition of TGF $\beta$ signaling in lung fibroblasts could inhibit lung and tumor fibrosis [57]. As key drivers of the development and progression of COPF and IPF, both risk factors for lung cancer, fibroblasts also play roles in lung cancer progression although the exacts roles and mechanisms are undefined, with contradictory reports in the literature. For example, Yamauchi et al., showed that TIG-3 
fibroblasts, when co-implanted with lung cancer cells, increased tumor growth at the site of injection and metastases to the lung, and that this effect was due, at least partly, to TGF $\beta$-mediated interactions [58]. These experiments, however, were performed in NOG mice, which are highly immunodeficient and thus must be interpreted carefully. In contrast, others have shown that normal lung fibroblasts play a role in inhibiting lung cancer progression. For example, Mishra et al., showed significantly fewer metastatic lesions in an ex vivo 4D acellular lung model when $\mathrm{H} 460$ cells were seeded with normal lung fibroblasts compared to carcinoma-associated fibroblasts (CAFs) [59]. These data, among others, point to the complicated nature of tumor-stromal cell interactions, and warrant further research in this area, particular in the lung.

\subsection{Fibronectin}

Fibronectin is a large, ubiquitously expressed, multi-domain glycoprotein located primarily in extracellular fluids, connective tissues and on many cell surfaces. It exists in the body in two forms: a circulating, soluble dimer form produced mainly by hepatocytes and found in the plasma [60] (referred to as "plasma fibronectin") and an insoluble form produced by fibroblasts and other cells (referred to as "cellular fibronectin") that is embedded in fibrils in the ECM [61]. One crucial feature that distinguishes these two forms from each other is accomplished by alternative splicing and is characterized by the inclusion of at least one of two extra exons termed Extra Domain A (EDA) and/or Extra Domain $B(E D B)$ [62-64]. One or both of these domains are present in cellular fibronectin 
(cFN), but absent in plasma fibronectin $(\mathrm{pFN})$. While the primary structure and alternative splicing of fibronectin has been known for decades, the specific functions of these isoforms have been difficult to study in vivo until recently, when animals lacking these isoforms were developed.

Fibronectin itself plays a crucial role in embryogenesis and lung development, evidenced by its high expression in embryonic tissues and by the fact that animals lacking fibronectin are embryonic lethal $[65,66]$. Fibronectin has roles in several cellular processes, such as hemostasis, wound healing, and host defense. One of its most basic functions in these instances is in promoting adhesion to and the spreading of cells on various solid substrates, such as, collagen, fibrin, and gelatin [67-70]. For example, during wound healing, pFN exits the damaged blood vessels, and together with other molecules and cells (e.g. fibrin and platelets), forms a hemostatic plug that serves as a scaffold or net that supports cell migration and re-epithelialization. Mice lacking pFN however, are still able to heal skin wounds [71], while mice lacking fibronectin EDA are not [72], suggesting that fibronectin EDA produced locally at the site of injury is sufficient for wound healing. Although fibronectin has been shown to have roles in normal wound healing, excessive fibronectin levels have been shown to promote disrepair [36].

More recently, fibronectin has been implicated in several types of cancer $[73,74]$. While fibronectin EDA has been shown to be a vascular marker for solid tumors and metastases of the liver [75], and immunization against fibronectin EDA in a therapeutic setting has been shown to decrease tumor burden and lung 
metastases in the MMTV-PyMT transgenic model of metastatic mammary carcinoma [76], little is known about its role in cancer and more specifically lung cancer.

\subsection{Oxidative Stress}

The term "oxidative stress" was first proposed by Helmut Sies in 1985 as "a disturbance in the pro-oxidant-antioxidant balance in favor of the former" [77]. This disturbance can be due to high levels of oxidants, or low levels of antioxidants. This definition has been useful and has led to the discovery of a number of diseases that are associated with oxidative stress, such as cancer, diabetes, and neurodegeneration. The main drivers of oxidative stress in these instances are superoxide anion, hydrogen peroxide, and the hydroxyl radical, collectively termed reactive oxygen species (ROS). There are a variety of sources of ROS in the body: $\mathrm{NADPH}$ oxidases, cytokine and growth factor receptors, the electron transport chain, and phase 2 drug metabolizing enzymes, such as xanthine oxidases and cytochrome p450s, among others. ROS can cause reversible modifications to protein side chains on methionine and cysteine residues. These have important regulatory and signaling functions in the body. However, ROS can also cause irreversible damage to macromolecules, so the body contains numerous enzymatic (glutathione and thioredoxin) and non-enzymatic (catalase, superoxide dismutase, glutathione peroxidase) cellular defenses to protect against these deleterious effects. Many of these defenses are thiol-dependent. As such, oxidative stress can now be quantified in humans as the redox state of plasma 
glutathione/glutathione disulfide (Eh GSH/GSSG) and plasma cysteine/cystine (Eh CyS/CySS). These thiol/disulfide couples becomes oxidized with age [78], in response to smoking, and in various diseases [79]. However, we now know that plasma GSH redox is not in equilibrium with thioredoxin-1 or the larger cysteine/cystine (Cys/CySS) pool. These systems also respond differently to physiologic and chemical stimuli. These data, along with the inconsistencies of several antioxidant trials [80-83] indicate that oxidative stress cannot be defined by a single entity, suggesting we need to redefine the term oxidative stress. Dean Jones at Emory University has done just that and has proposed a new definition of oxidative stress as "a disruption of redox signaling and control." [84] This definition should redirect our efforts to identify key alterations in redox signaling in oxidative stress-related diseases that will then lead to new targets for treatment.

Jones has also shown that the physiological redox potential of Cys/CySS found in the plasma of healthy subjects is around $-80 \mathrm{mV}$. In aged individuals, and those with disease, this redox potential may be oxidized to values between -62 to $-20 \mathrm{mV}$. Our lab has previously shown that this type of oxidant stress promotes lung fibroblast proliferation, myofibroblast transdifferentiation, and increased expression of TGF $\beta$ in vitro [85], all of which act to create a pro-fibrotic phenotype in the lung. These observations suggest that oxidant stress could act to create an oncogenic microenvironment, that renders the aging host susceptible to lung cancer progression. 


\subsection{Sex}

The National Institutes of Health (NIH) recently (June 2015) released a Guide notice (NOT-OD-15-102) indicating that researchers should consider sex a biologic variable in their studies. A quick literature review will reveal that prior to 2015, methodology detailing sex and age of most animal studies is severely lacking. Moreover, males have been the predominant sex used in animal models of biomedical research [86]. This has serious implications for health-care in both men and women, as animal models in research are the predominant basis for human clinical trials. This is unfortunate, as sex in both animals and humans has been shown to be a determining factor in several outcomes of disease. For example, Alzheimer's disease and osteoporosis are more prevalent in women than men $[87,88]$. In terms of pulmonary diseases, mortality from COPD in females surpassed that of males in the year 2000 for the first time, likely due to the increased number of females who smoke [89]. However, females do appear to be at a greater risk of the harmful effects of tobacco smoke, when compared to males, although this has only recently begun to be investigated [90]. Interestingly, of the $5-12 \%$ of non-smokers who are diagnosed with COPD, the vast majority are also female [91]. These sex differences in pulmonary diseases are also observed in several animal models. For example, in a murine model of pulmonary fibrosis, while no differences were observed in fibrotic development, males were found to have higher basal static lung compliance compared to females, and a significant decline in static compliance after bleomycin instillation [92]. In rats, females were more susceptible to mortality and fibrotic development, determined by collagen 
deposition, when compared to males [93]. This effect was abolished in ovariectomized females without hormone replacement, and was rescued in females given estradiol, suggesting an important role for sex hormones in the development of pulmonary fibrosis. In contrast, female mice were found to develop less fibrosis, as determined by hydroxyproline content, in a silica-induced lung fibrosis model, when compared to males. This effect was again abolished in ovariectomized females [94].

Among cancers, it is well known and descriptive epidemiological studies have shown, that males are more prone to develop cancers, when compared to females $[95,96]$. This is also true for childhood cancers, where prognosis is worse for boys than for girls [97]. Additionally, boys who have survived cancer are at a greater risk of secondary malignancies [98]. Among lung cancers, it has been noted previously, that historically, men were shown to have a higher incidence rate, but this was due to a higher frequency of smoking. It now appears that women are actually at a greater risk of developing lung cancer compared to males [99]. For example, women have been shown to be more susceptible to tobacco carcinogens compared to males [100]. Although it appears that women are at a greater risk of developing lung cancer in both smokers and nonsmokers, it has been argued that among nonsmokers, the increased incidence among women is skewed due to a high prevalence of lung cancer among women in Asian countries [101]. 


\subsection{Summary}

Taken together, these data portray that population aging in the US and worldwide is a matter of great concern and one that simply cannot be ignored. NCDs (for the purpose of this dissertation, specifically lung cancer, IPF, and COPD) occur almost exclusively in the elderly. Moreover, the vast majority of lung cancers, the leading cause of cancer death in the US, also occur in the elderly and frequently in individuals with COPD and/or IPF, diseases marked by inflammation/tissue remodeling and oxidation of both Eh Cys/CySS and Eh GSH/GSSG. Tissue remodeling in the elderly is marked by alterations in the composition and deposition of extracellular matrix proteins, including fibronectin and one of its splicing variants fibronectin EDA, which has also been shown to be increased with aging. This dissertation explores how aging and tissue remodeling act in concert to render the host susceptible to lung cancer progression. As the main source of fibronectin and fibronectin EDA, we also examined what role fibroblasts of the lung play. Finally, we examined the role of sex and oxidative stress. These data led to the development of the following hypothesis: While smoking and other environmental exposures can lead to lung cancer development in a genetically susceptible individual, increased oxidation of the Eh Cys/CySS in the aging lung creates an oncogenic microenvironment, specifically by increased fibronectin EDA levels, that renders the host susceptible to lung cancer progression (Figure 1). 


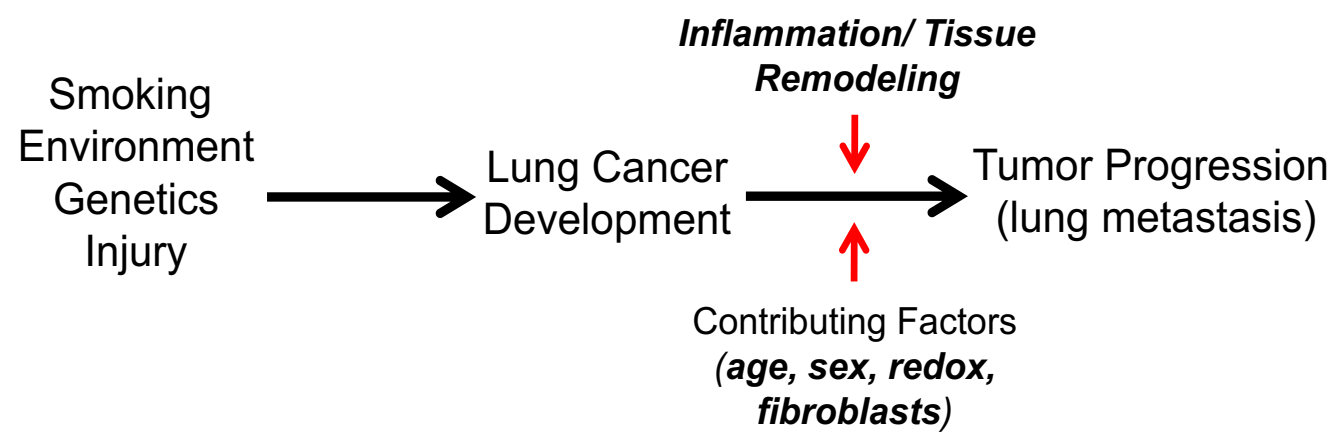

\section{Figure 1. Dissertation Hypothesis}

While smoking and other environmental exposures can lead to lung cancer development in a genetically susceptible individual, we hypothesized that increased oxidation of the Eh Cys/CySS in the aging lung creates an oncogenic microenvironment, specifically by increased fibronectin EDA levels, that renders the host susceptible to lung cancer progression. These events could be exacerbated in females. 


\section{CHAPTER II}

\section{ROLE OF AGING AND TISSUE REMODELING IN LUNG CANCER}

\section{$\underline{2.1 \text { Introduction }}$}

Cancer develops most commonly in the elderly with $78 \%$ of cancers occurring in patients over 55 years of age [102]. This is also the case for lung cancer, which remains the leading cause of cancer death in men and women in the US and worldwide [2]. How exactly aging promotes cancer is unclear, but compared to young individuals, aging is characterized by oxidant stress, mitochondrial dysfunction, immunologic deficiencies, stem cell exhaustion, and accumulation of damage in cells, tissues, and organs, among other things [103106]. Aging has also been characterized by a reduced capacity to respond to environmental injury [107]. Yet, exactly how these processes contribute to carcinogenesis is unknown. Interestingly, most lung cancers occur in individuals with chronic lung disorders characterized by inflammation and tissue remodeling such as COPD and IPF [108]. Considering the emerging data linking inflammation and the tumor microenvironment in cancer development and progression [109], it is not surprising that lung cancer develops most commonly in such settings.

Since the discovery of the first oncogene, Src, in 1970, and later of cellular proto-oncogenes, the prevailing paradigm of cancer development for decades was 
that cancer arises due to mutations in oncogenes and tumor suppressor genes of single cells. However, numerous studies performed in vitro and in vivo have now shown that, despite malignant cell transformation, tumor growth is dependent on processes such as inflammation and angiogenesis in the microenvironment. In fact, it has been shown that a malignant phenotype can be reversed by using integrin blocking antibodies $[110,111]$. Thus, it can be said that genetic mutations are necessary, but not sufficient, to cause tumor growth [7]. It has been known for some time that chronic inflammatory diseases such as COPD, asbestosis and silicosis increase the risk of lung cancer [112]. For example, exposure to asbestos, and the resulting inflammatory response, have been linked to lung cancer and mesothelioma [113]. Indeed, a link between chronic inflammation and many cancers is now well established [114] and several studies have demonstrated a protective effect of non-steroidal anti-inflammatory drugs in cancer development [115]. Others have found that the ability of Rous sarcoma virus to form tumors in newly hatched chicks is dependent upon wounding and inflammation, and that the pro-fibrotic growth factor, transforming growth factor $\beta$ (TGF $\beta$ ), can replace wounding as a promoter of tumor development [116].

Despite the above, the contribution of chronic tissue inflammation and remodeling and their interaction in lung cancer have been difficult to study in humans considering the many confounding factors present, not the least of which is exposure to tobacco, perhaps the best known pro-oncogenic agent. It is for this reason that scientists have turned their attention to experimental models of lung cancer which, even though they do not exactly resemble the human condition, they 
allow for the more careful exploration of the role of individual factors. We hypothesized that aging and tissue inflammation/remodeling act in concert to promote lung cancer progression, and set out to test this in a syngeneic model of lung cancer. For this, we used aged mice, which have been shown to display alterations in inflammatory and tissue remodeling markers [117]. Aged lungs are characterized by, among other things, increased mRNA expression for TGF $\beta$, matrix metalloproteinases, plasminogen activator inhibitor-1, and matrix molecules fibronectin and collagen I $[36,118]$. These changes explain, at least in part, the alterations observed in the structure of the aging lung.

One of the matrix molecules upregulated in the setting of aging is a fibronectin splicing variant, which is characterized by the inclusion of an extra exon termed Extra Type III Domain A (EDA). This is intriguing considering that data generated over the past three decades have linked fibronectin with cancers including breast, prostate, liver, and lung [119-121]. However, it has been difficult to study the role of fibronectin in vivo mainly because animals with knockout mutations in fibronectin are embryonic lethal [122]. More recently, animals with knockout mutations targeting fibronectin EDA were generated and their investigation suggests a role for this molecule in wound healing and aging [72]. Moreover, fibronectin EDA has been linked to lung inflammation and remodeling since its deletion is protective in the bleomycin model of lung injury and repair [123]. Considering these observations, we also tested animals lacking fibronectin EDA. 
Our studies revealed that aged lungs were more susceptible to metastasis when compared to young lungs. Importantly, studies in young and aged animals exposed to bleomycin suggest that tissue remodeling/inflammation augment pulmonary metastasis, but only in the aging lung and not in the young lung. The effect of bleomycin was abolished in studies performed in fibronectin EDA KO mice, despite the presence of fibrosis. Together, these observations suggest an interplay between lung aging and inflammation/remodeling in tumor progression, and that fibronectin EDA is an important molecule in this setting.

\subsection{Materials and Methods}

\subsubsection{Reagents and Cell Culture}

Lewis Lung Carcinoma (LLC) cells were purchased from ATCC (CRL-1642; ATCC, Rockville, MD) and grown in Dulbecco's modified Eagle's medium (DMEM) with $10 \%$ fetal bovine serum (Atlanta Biologicals, Lawrenceburg, GA) at $37^{\circ} \mathrm{C}$ in a humidified 5\% CO2 incubator. Cells were used within 3 months of resuscitation. Bleomycin (catalog \#8416) and cellular fibronectin (cFN; catalog \#F2518) were purchased from Sigma (St. Louis, MO). Sutures for surgery were purchased from Ethicon (catalog \#K833).

\subsubsection{Young and Aged Animals}

C57BL/6 and NOD.Cg-Prkdc ${ }^{\text {scid }} \| 12 \mathrm{rg}^{\text {tm1Wj//SzJ }}$ (NOD scid gamma, NSG) mice

were obtained from Jackson Laboratories and housed in pathogen-free facility at the University of Louisville (Louisville, KY), with access to food and water ad 
libitum. Fibronectin EDA knockout mice were obtained from Dr. Eric White (University of Michigan) and verified by PCR analysis and sequencing. All experiments were approved by the Institutional Animal Care and Use Committee (IACUC) of the University of Louisville.

\subsubsection{LLC Model of Lung Cancer}

LLC cells were split 24 hours prior to injections and were harvested in growth phase. LLC cells were injected (1E6/100 $\mu \mathrm{L}$ sterile PBS) subcutaneously into the hind flank of mice. In parallel experiments, animals were injected with LLC cells intravenously (1E5/100 $\mu$ L sterile PBS). Afterwards, tumors were monitored and the length, width, and height, measured weekly, using digital calipers. A tumor size $>15 \mathrm{~mm}$ in any direction was considered the endpoint, per IACUC regulations. All animals were then sacrificed and tissues were harvested for analysis. The same procedure and number of cell were performed for injections into NSG mice.

\subsubsection{Bleomycin Model of Lung Injury and Repair}

Bleomycin sulfate was reconstituted in sterile PBS at $1 \mathrm{mU} / \mathrm{g}$ of body weight. Animals were anesthetized by using a mixture of ketamine and xylazine. Under aseptic technique, the neck of the mouse was dissected and the trachea was visualized. Bleomycin or PBS was instilled in the trachea, using a $27 \mathrm{G}$ needle, in a total volume of $40 \mu \mathrm{L}$. The wound was sutured with black braided silk and animals were monitored and allowed to recover on a heated pad. 


\subsubsection{Tissue Processing and Histological Analysis}

Per IACUC regulations, once subcutaneous tumors reached a size of 15 $\mathrm{mm}$ in any direction, all animals were sacrificed by $\mathrm{CO}_{2}$ administration in a closed chamber. Lungs were flushed with PBS, inflated at standard pressure with formalin, removed, and formalin-fixed for 48 hours. Lungs were then processed through increasing ethanol solutions in an STP 120 Spin Tissue Processor (ThermoFisher Scientific, Waltham, MA), paraffin-embedded, and sectioned (6 $\mu \mathrm{m}$ ) using a JUNG RM2055 microtome (Leica, Buffalo Groce, IL). Lung sections were then transferred onto charged, glass Colorfrost microslides (VWR Sciences, Radnor, PA) for histological analysis. Sections were deparaffinized, rehydrated, and stained with hematoxylin and eosin (HE) to evaluate lung tumors, or Masson's trichrome (American MasterTech, catalog \#KTMTR2PT) to evaluate collagen content for lung fibrosis determination. Five blinded reviewers used the semiquantitative Ashcroft scoring scale to score pulmonary fibrosis [124].

\subsubsection{Wound Healing (Scratch Assay)}

LLC cells (2.5E5) were plated in 24-well plates coated with cellular fibronectin $(10 \mu \mathrm{g} / \mathrm{mL})$ or plastic alone for 24 hours. A scratch was then created using a $1 \mathrm{~mL}$ pipette tip. Media $(2 \mathrm{~mL})$ was then replaced and photographs taken at 0 and 24 hours using an EVOS ${ }^{\mathrm{TM}}$ XL Core Cell Imaging System (AMG). Quantification was performed using ImageJ software by measuring the distance of the scratch in 6 separate locations at 0 and 24 hours. 


\subsubsection{Analysis of Data}

Means plus standard deviations of the mean were calculated for all experimental values. Significance was assessed by using the Student's $t$ test.

\section{$\underline{2.3 \text { Results }}$}

\subsubsection{Aging is associated with increased lung metastases}

While studying a syngeneic model of lung cancer, we noticed a significant variability in the development of lung metastasis. A retrospective analysis of the data revealed that the age of the animals represented an important variable (not shown). To test the role of aging prospectively, wildtype C57BL/6 mice at ages $3,5,7,9$ and 12 months of age were injected subcutaneously with 1E6 LLC cells. Tumor growth was followed until tumors reached a size of $\geq 15 \mathrm{~mm}$, after which time, all animals were sacrificed and lungs harvested and formalin fixed. As depicted in Fig. 2A and 2B, mice failed to develop lung metastases until 7 months of age or older. We observed small differences in the size of the primary tumors, but these were not statistically significant (not shown).

To circumvent the potential confounding effects of skin immunity, we repeated similar experiments in animals injected intravenously with the tumor cells. In these experiments, we observed that only $50 \%$ of young ( $\sim 3.5$ months) mice developed lung tumors compared to $100 \%$ of old ( 12 months) mice (Fig. 2C). Aged mice also developed a greater number of lung tumors when compared to the number of tumors developed in the few affected young mice (Fig. 2D). Thus, aged lungs are more susceptible to lung metastasis compared to young lungs. 

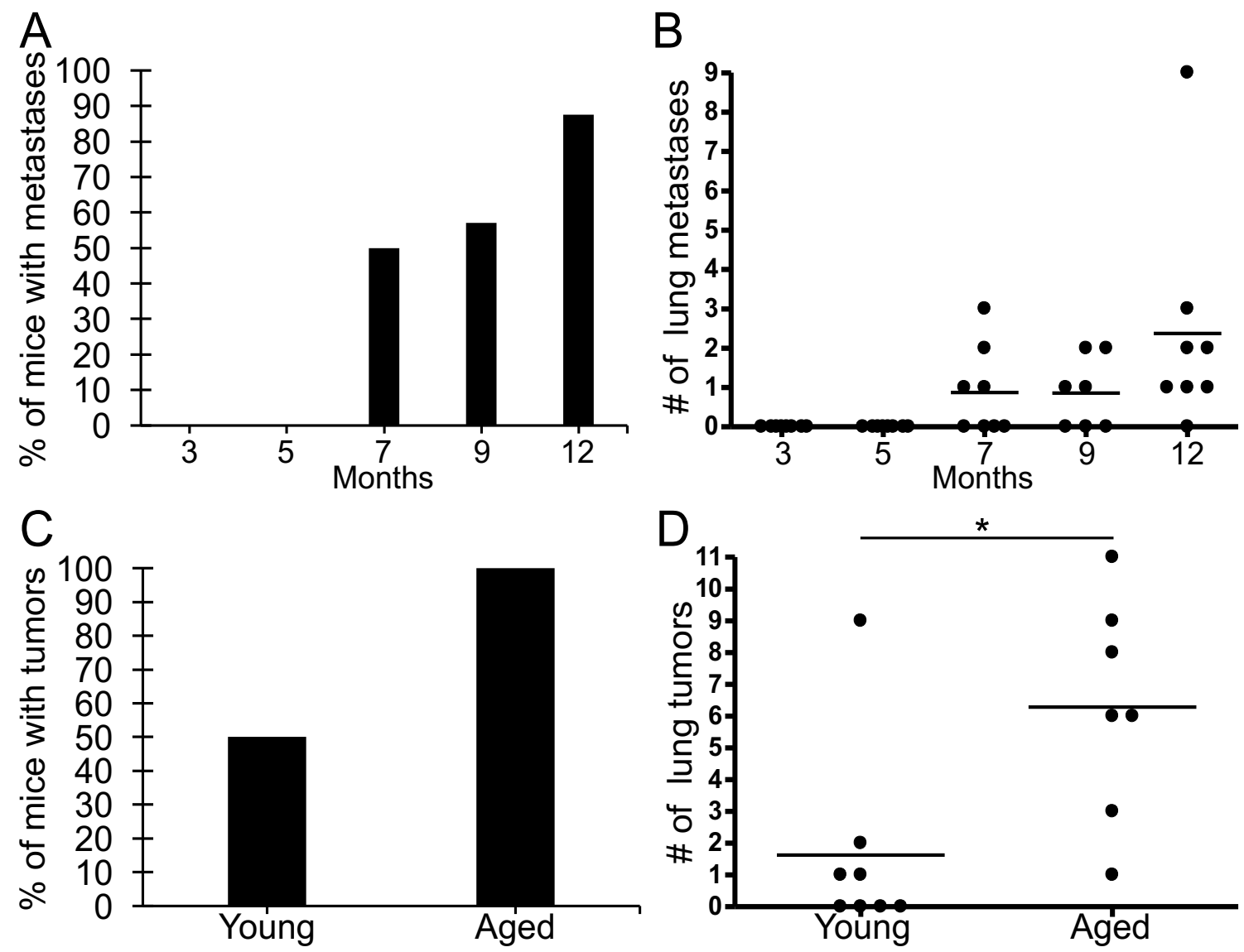

Figure 2. Aging is Associated with Increased Lung Metastases

(A,B) WT C57BL/6 mice, ages 3, 5, 7, 9 and 12 months old were injected with 1E6 WT LLC cells into the hindflank. Per IACUC regulations of endpoints, tumor formation and size were followed until a tumor size of $\geq 15 \mathrm{~mm}$ in length or width was established. All mice were then sacrificed and lungs harvested and processed for examination of metastases. All mice developed tumors at the site of injection, with no differences in size observed at day 17. (A) Percentage of mice in each group where lung metastases were identified. (B) Number of lung metastases in each animal in each group. (C,D) Young (3.5 months) and aged (12 months) WT C57BL/6 mice were injected intravenously with 1E5 WT LLC cells and sacrificed 
at day 13. (C) Percentage of mice in each group where lung tumors were identified. (D) Number of intravenous lung tumors in each animal in each group. Aged mice developed more tumors in the lung $(6.3+/-3.4)$ compared to young mice $(1.6+/-3.1),{ }^{*} P<0.05$. 


\subsubsection{Bleomycin treatment is associated with increased metastases, but only in aged lungs}

To examine the role of lung inflammation/remodeling in lung cancer progression, young ( $\sim 3.5$ months) and aged ( 9.5 months) animals were instilled with bleomycin $(1 \mathrm{mU} / \mathrm{g} \mathrm{BW})$ followed by injection of LLC cells 14 days after bleomycin treatment. As expected, bleomycin induced weight loss (Fig. 3A) and lung inflammation/remodeling (Fig. 3B) in both young and aging mice. In animals injected with LLC cells after bleomycin treatment, we again observed small differences in the size of subcutaneous tumors at the time of euthanasia, but these were not statistically significant (data not shown). However, interestingly, bleomycin augmented the number of lung metastases in the aged murine lungs, but not in young lungs (Fig. 3C), despite the presence of inflammation/remodeling in both groups. 


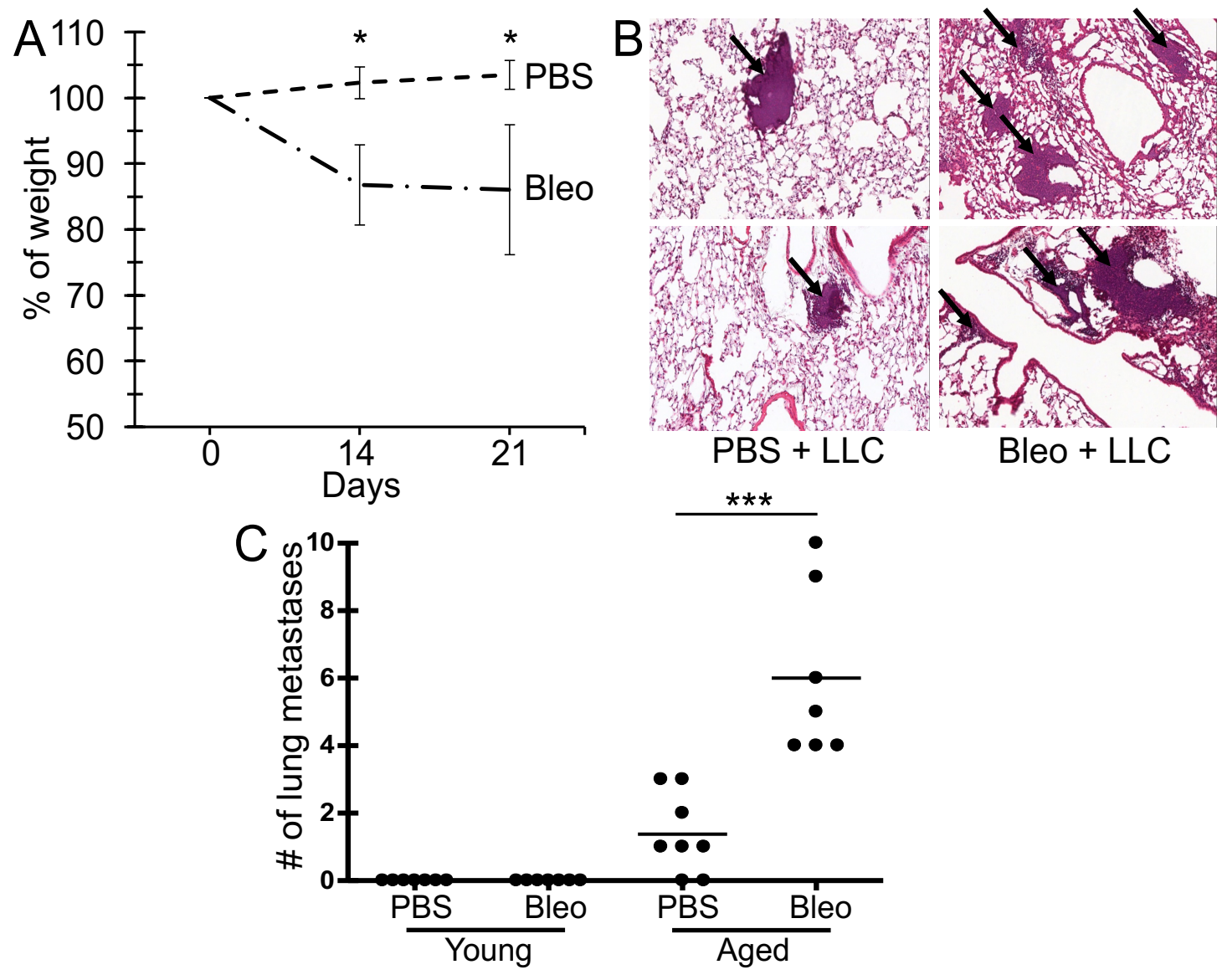

Figure 3. Bleomycin Treatment is Associated with Increased Metastases, but

\section{Only in Aged Lungs}

Young ( $\sim 3.5$ months) and aged ( 9.5 months) WT C57BL/6 mice were instilled intratracheally with PBS (young, $n=7$; aged, $n=8$ ) or bleomycin (Bleo; young, $n=7$; aged, $n=7$ ). At day 14, 1E6 LLC cells were injected subcutaneously into the hindflank. (A) Change in weight in aged mice is shown. Bleomycin significantly induced weight loss in all mice at day 14 and day 21 post-instillation. There were no statistically significant differences in weight loss between young and aged mice. Mice instilled with PBS did not experience weight loss. (B) Representative HE images depict PBS- and bleomycin-treated aged mice at 14x magnification. Tumor 
metastases are observed in all images (indicated by arrows), while fibrosis is readily apparent in the bleomycin treated lungs. (C) Number of lung metastases in aged mice are shown. Young mice failed to develop lung metastases in either group, while bleomycin instillation in aged mice increased the number of lung metastases compared to PBS $(6.0+/-2.5$ vs $1.4+/-1.2),{ }^{*} P<.05,{ }^{* \star *} P<.001$. 


\subsubsection{Fibronectin EDA is dispensable for aged-related lung cancer}

progression, but required for bleomycin-induced augmentation of metastasis

Since aged lungs show alterations in the expression of fibronectin EDA, and fibronectin is implicated in carcinogenesis, we hypothesized that this matrix molecule contributes to the aging effect. To test this, untreated aged wildtype and aged fibronectin EDA knockout mice were injected with LLC cells, both subcutaneously and intravenously. For subcutaneous tumors, growth was followed until tumors reached a size of $\geq 15 \mathrm{~mm}$, after which time, all animals were sacrificed and lungs harvested and formalin fixed. In the subcutaneous model, no differences were observed in the growth of the primary tumor (data not shown) or in the number of lung metastases (Fig. 4A) when comparing aged wildtype and aged fibronectin EDA knockout animals. Likewise, when animals were injected intravenously, no differences were observed in the number of lung tumors when comparing aged wildtype and aged fibronectin EDA knockout animals (Fig. 4B). Thus, despite being increased in aged lungs and being implicated in carcinogenesis and cancer progression, the absence of fibronectin EDA did not inhibit cancer progression in aged lungs in the LLC model.

To test the role of fibronectin EDA in cancer progression in the setting of tissue remodeling/inflammation, we repeated experiments with bleomycin in aged fibronectin EDA KO animals. Although others have reported fibronectin EDA to be essential for the development of lung fibrosis in the bleomycin model [123], we observed no differences in the development of bleomycin-induced fibrosis in WT 


\section{Subcutaneous}

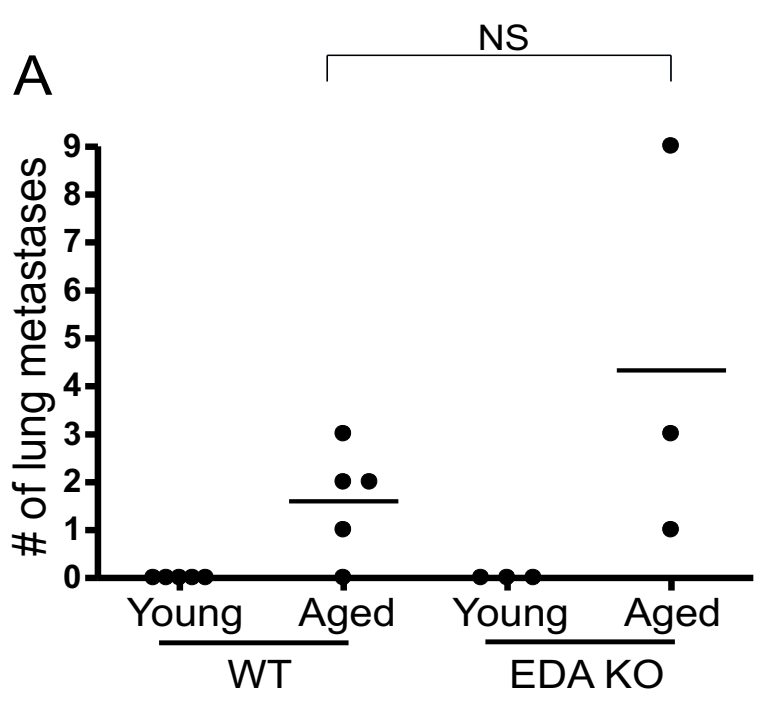

\section{Intravenous}

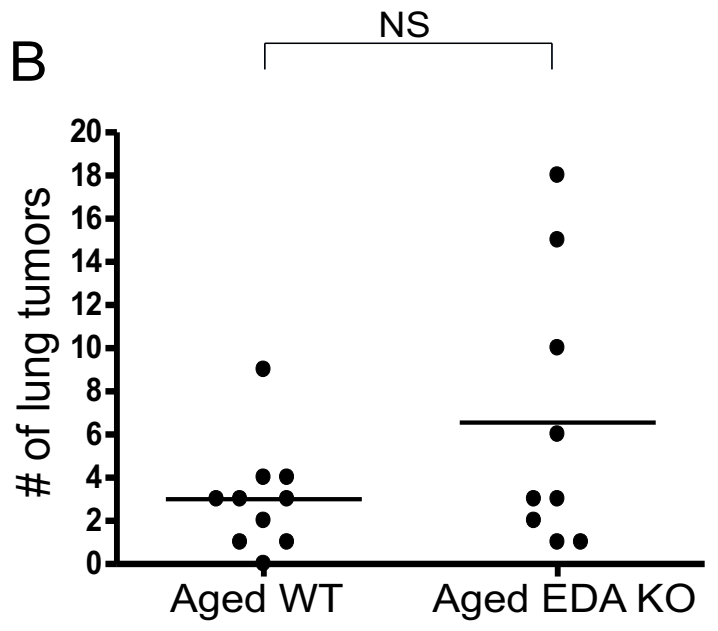

Figure 4. Fibronectin EDA is Dispensable for Age-Related Lung Cancer

\section{Progression}

WT C57BL/6 and FN EDA KO mice were injected with 1E6 WT LLC cells into the hindflank or 1E5 LLC intravenously. (A) Number of metastases in young WT ( 2.5 months, $n=5$ ) and EDA KO (2 months, $n=3$ ) mice and in aged WT (10 months, $n=5$ ) and EDA KO (10 months, $\mathrm{n}=3$ ) mice. Young mice in both groups failed to develop metastases. There were no statistically significant differences in the number of metastases between aged WT $(1.6+/-1.1)$ and aged EDA KO $(4.3+/-4.2)$ mice. (B) Number of intravenous lung tumors in aged WT and EDA KO mice are shown. There were no statistically significant differences in the number of lung tumors between aged WT (3.0 +/- 2.5) and aged EDA KO (6.5 +/- 6.3) mice. 
and fibronectin EDA KO mice (Fig. 5A and 5B). However, interestingly, when injected with LLC cells, the augmentation of pulmonary metastases due to bleomycin was abolished in fibronectin EDA KO mice (Fig. 5C).

Considering the above, we hypothesized that fibronectin EDA provides a scaffold for the proliferation, migration and organization of tumor cells within remodeled lung tissue. This is consistent with data showing that over $75 \%$ of tumor cells metastasizing to the lung co-localized to areas of inflammation/fibrosis (Fig. 6A and 6B). Consistent with this, LLC migration was increased on plates coated with cellular fibronectin compared to plastic (Fig. 7A-B), and LLC proliferation was increased when the cells were cultured in the presence of cellular fibronectin (Fig. 7C). 

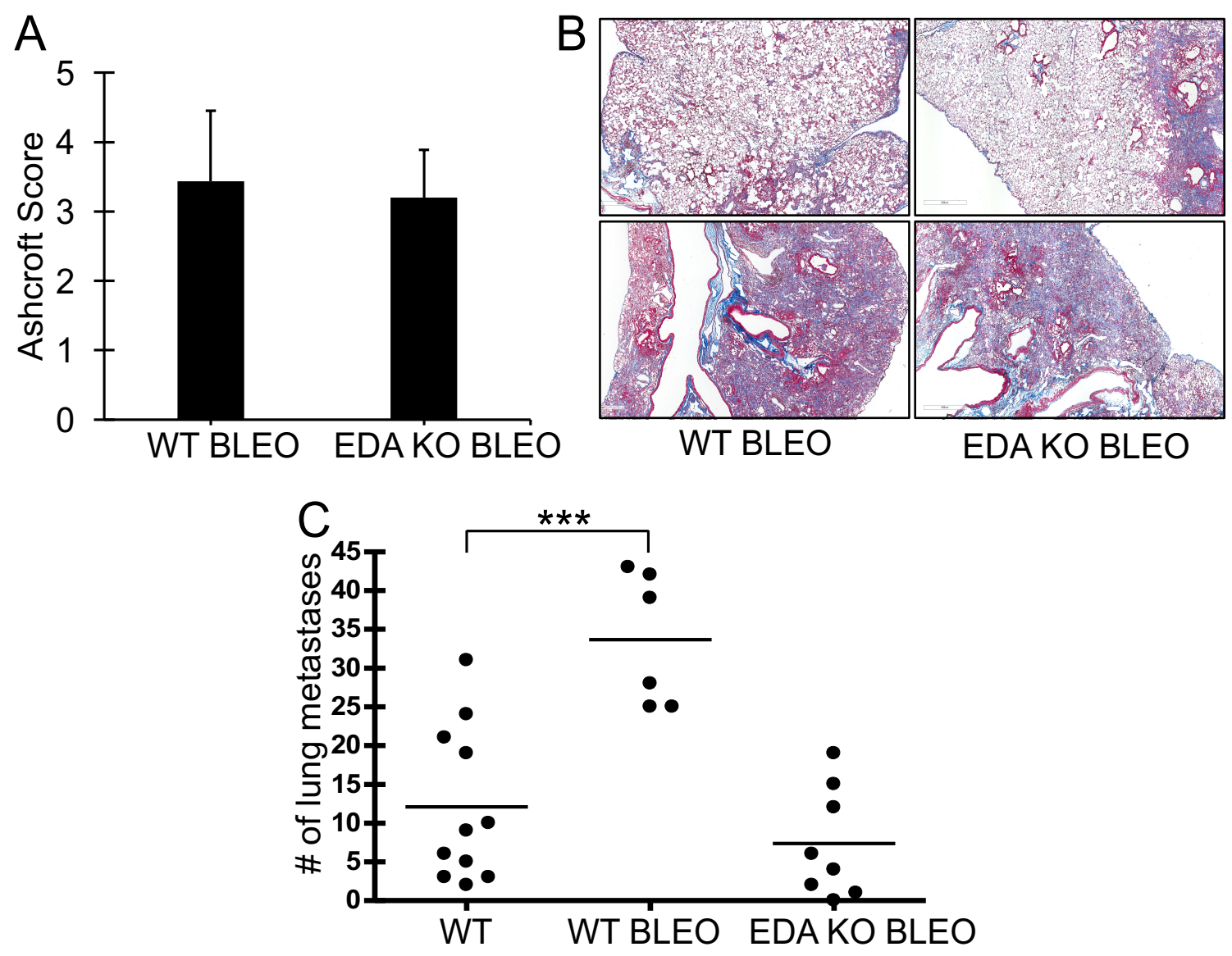

Figure 5. Fibronectin EDA is Required for Bleomycin-Induced Augmentation of Metastasis

WT C57BL/6 ( 10 months) and FN EDA KO ( 9 months) mice were instilled intratracheally with PBS or bleomycin. At day 14, 1E6 LLC cells were injected subcutaneously into the hindflank. (A) Ashcroft scores of 5 blinded reviewers. (B) Representative trichrome stained images at $4 x$ magnification depict lung fibrosis of varying severity in both bleomycin treated WT and EDA KO mice. (C) Number of lung metastases in aged mice are shown. Bleomycin increased the number of lung metastases in WT mice $\left(12.1+/-10.0\right.$ vs $\left.33.7+/-8.6,{ }^{* * *} P<.001\right)$ but not in EDA KO mice $(7.5+/-7.0)$. 

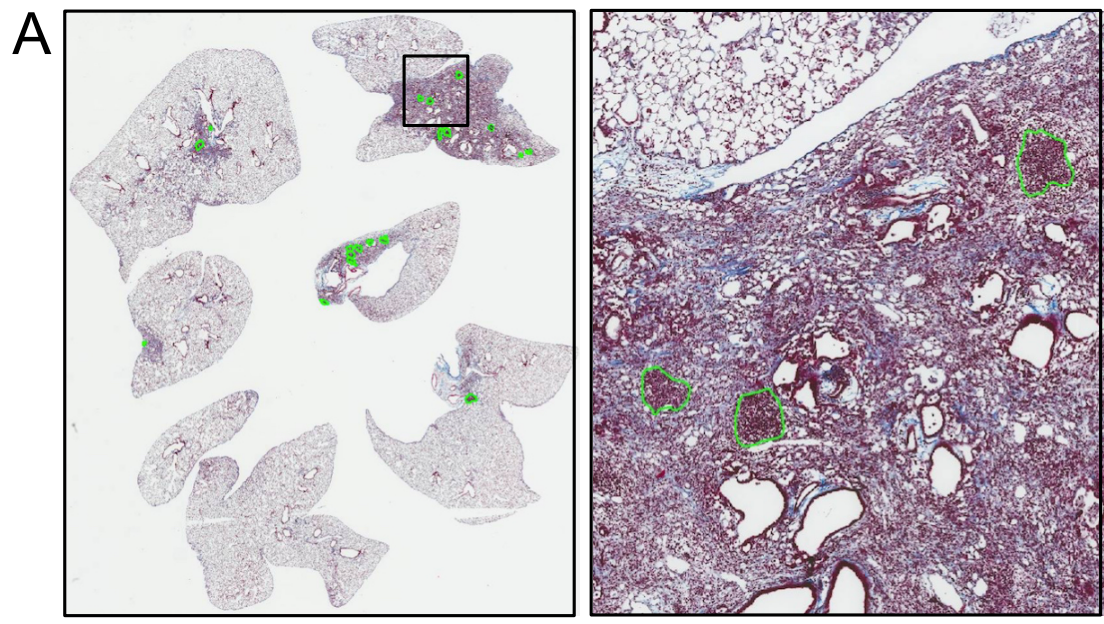

B

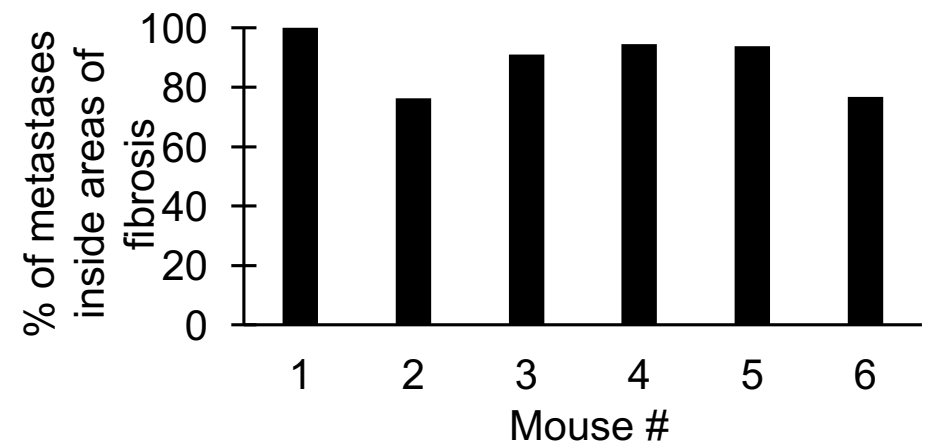

Figure 6. Lung Metastases Develop Primarily in Fibrotic Areas

Paraffin embedded sections from WT C57BL/6 mice from figure 5C were stained with Masson's Trichrome. (A) Representative Masson's Trichrome stained images at .4x and $4 \mathrm{x}$ magnification depict prominent lung fibrosis and LLC metastases (green circles). (B) Percentage of LLC metastases in areas of lung fibrosis in each individual mouse. The $\%$ of metastases that developed in fibrotic areas was greater than $75 \%$ in all mice. 

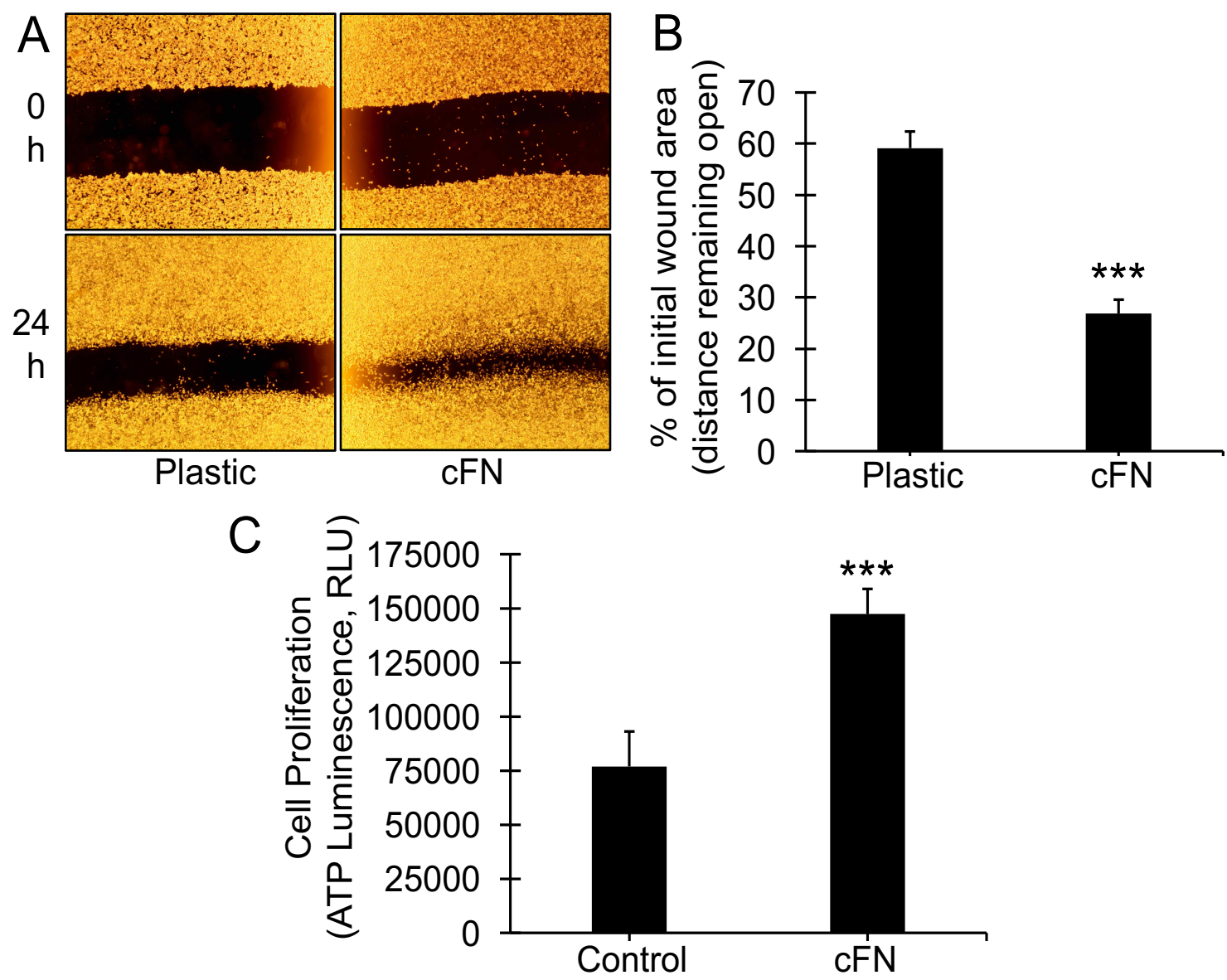

Figure 7. Effect of cFN on LLC Proliferation and Migration

(A) LLC cells were plated on plastic or cellular fibronectin (cFN; $10 \mu \mathrm{g} / \mathrm{mL}$ ) coated 24-wellplates. (B) After 24 hours $59.1+/-3.2 \%$ of the initial wound area remained on plastic vs $26.9+/-2.7 \%$ on cFN. ${ }^{* *} P<.001$. (C) LLC cells were plated in $48-$ well plates in control DMEM or DMEM with $10 \mu \mathrm{g} / \mathrm{mL} \mathrm{cFN.}{ }^{* * *} P<.001$ 


\subsubsection{Role of Immunity}

Finally, we wanted to test the role of immunity in our model to examine if it mediated the age-related effect on lung metastasis. For this, we injected LLC cells into young and aged NOD scid gamma (NSG) mice, which are extremely immunodeficient, lacking B and T cells, as well as functional NK cells. Both young and aged mice developed tumors at the site of injection within 2 weeks, although no differences were observed between the groups when the animals were sacrificed at day 17 (Fig. 8A). Although the number of metastases to the lung was greater in the aged mice, this was not statistically significant (Fig. 8B). However, aged NSG mice developed larger metastases to the lung compared to young NGS mice (Fig. 8C-D). The location of the lung metastases in the NSG mice also differed from those observed in WT animals. While metastases in WT mice developed in areas adjacent to blood vessels, this was not the case in NSG mice, where the majority of metastases developed in the periphery of the lung (Fig 9). These data suggest a role for innate immunity in tumor progression beyond the primary site in the syngeneic model. 

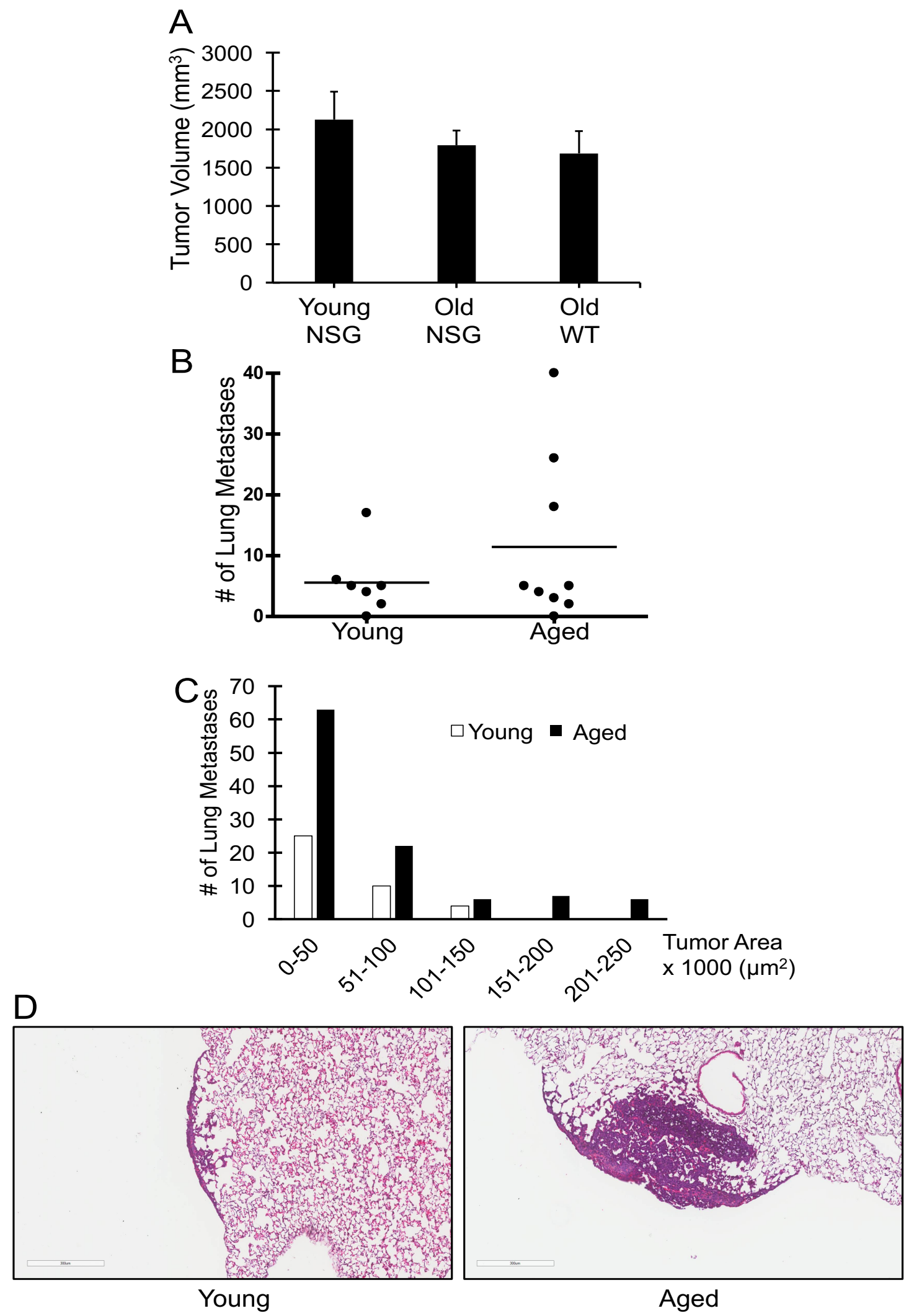


\section{Figure 8. Effect of Immunity on Lung Cancer Progression}

(A-C) Young (2 months) and Aged (9 months) NSG mice were injected subcutaneously into the hindflank with 1E6 LLC cells, and followed for tumor formation. Aged WT C57BI/6 mice were used as a third group as a positive control. Mice were sacrificed at day 17 and lungs removed and processed for examination of metastasis. There were no differences between groups in tumor volume at the site of injection (A), or the number of metastases to the lung (B). Although the number of metastases to the lung between groups was statistically unchanged, aged NSG mice developed larger metastases (in size) to the lung (C). Graph shows numbers of metastases in 5 groups of varying tumor size. 

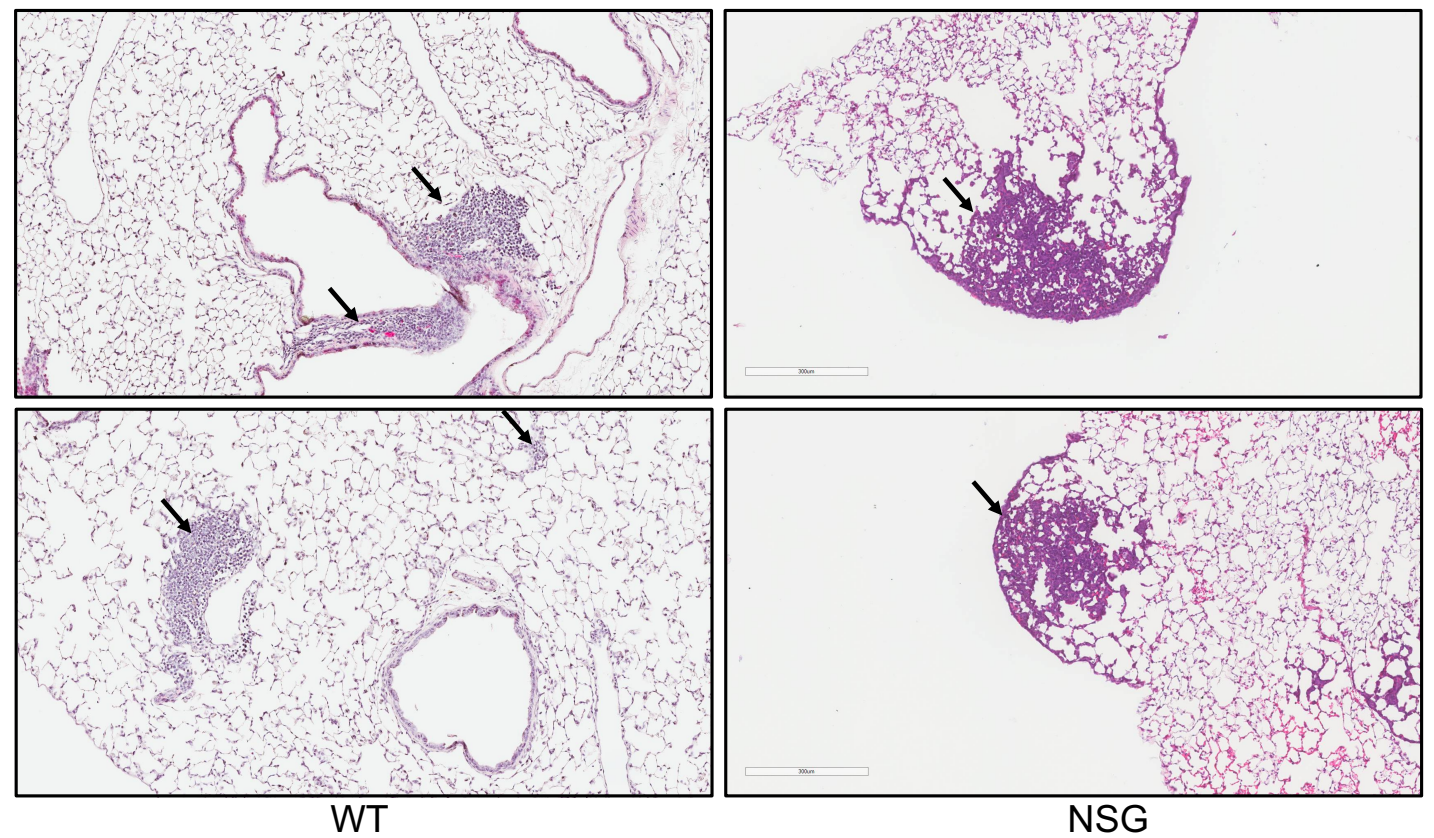

Figure 9. LLC Metastases in WT and NSG Mice

Female WT C57BL/6 and female NSG mice were injected with LLC cells subcutaneously (1E6/100 $\mu \mathrm{L}$ PBS) and then followed for tumor progression. A tumor size $>15 \mathrm{~mm}$ in any direction was considered the endpoint. Mice were then sacrificed and lungs harvested and processed for examination of metastases. Representative HE-stained lung images showing lung metastases at 10X are shown. Black arrows indicate metastases. 


\subsection{Discussion}

By the year 2020 , it is estimated that $70 \%$ of all neoplasms will occur in individuals aged 65 years or older [125]. Among them, lung cancer remains the deadliest and occurs most commonly in individuals with chronic lung disorders characterized by inflammation and tissue remodeling such as chronic obstructive pulmonary disease and fibrosis [108]. The relative contribution of these processes to the pathogenesis of lung cancer, especially metastatic disease, has been difficult to study in part because of the concomitant exposure to tobacco, a wellknown carcinogen [126]. Thus, we set out to study the role of aging and lung tissue inflammation/remodeling in an experimental syngeneic model of lung cancer. Several observations were made as summarized below.

First, we observed that aged lungs develop more metastatic lesions than young lungs, resembling the human condition. This was observed when LLC cells were injected subcutaneously or intravenously, which suggests that some inherent factor(s) in the aged lungs is responsible for this susceptibility, and not tumor implantation, growth, or metastasis from the primary tumor, nor does it relate to the ability of cancer cells to escape the immune system in the periphery. These data contribute to the notion that malignant cell transformation alone is not sufficient for tumor growth and progression. Young, healthy, immunocompetent animals are able to mount a successful defense in the lung to protect against lung lesions. However, aging appears to render the lung vulnerable to cancer progression. 
Second, we showed that lung tissue inflammation/remodeling was associated with increased lung metastases, but only in aged animals suggesting an interplay between aging and lung injury. In our hands, bleomycin induces fibrosis in both young and aged mice, with aged mice showing greater injury [36]. Young mice, however, still failed to develop lung metastases, which suggests that inflammation and/or tissue remodeling is not sufficient for cancer progression in our model. In light of the fact that aged mice show greater injury in response to bleomycin, it remains to be determined if increased inflammation or increased fibrosis contributes to the increased susceptibility to lung cancer. Independent of its role, the amount of fibrosis detected cannot fully explain the differences observed.

Third, we observed that, even though fibronectin EDA is increased in aging lungs and has been implicated in cancer, this matrix molecule was not required for cancer progression in normal lungs. Fibronectin EDA has been shown to be a vascular marker for solid tumors and metastases [75], and immunization against fibronectin EDA in a therapeutic setting has also been recently shown to decrease tumor burden and lung metastases in the MMTV-PyMT transgenic model of metastatic mammary carcinoma [76]. Based on these observations, we hypothesized that the aging lung contains a pro-oncogenic microenvironment due to increased levels of fibronectin EDA that renders the host susceptible to lung cancer progression. However, this was not found to be the case in our model. We found tumors in lung even in fibronectin EDA knockout mice suggesting that this matrix molecule is not required for lung metastasis. 
Fourth, although fibronectin EDA could not explain the increased susceptibility to lung metastasis in the aging lung, it was required for the augmentation of lung metastasis in response to tissue injury induced by bleomycin. Of interest was the fact that, despite a report in the literature that fibronectin EDA is essential for bleomycin induced lung fibrosis, in our hands, fibronectin EDA KO mice developed as much bleomycin-induced lung fibrosis as WT animals. This might be related to differences in the age of animals used, and dose and batch of bleomycin administered. Nevertheless, we did not observe an augmentation of lung metastasis in response to bleomycin in fibronectin EDA KO animals, which suggests that this matrix molecule plays an important role in lung cancer progression in the setting of aging coinciding with tissue remodeling/inflammation. Several mechanisms may explain the pro-oncogenic effects of fibronectin EDA as it may serve as a scaffold for the proliferation, organization, and migration of tumor cells.

Finally, we observed that both young and aged NSG mice developed tumors at the site of injection, and metastases to the lung in the LLC model. Although there were a greater number of metastases in the aged NSG mice, this was not statistically significant. However, aged NSG mice had larger tumors in their lungs compared to young NSG mice. The location of metastases in the NSG mice also differed from those observed in WT mice. These data suggest that the increased number of metastases observed in aging WT mice is somehow dependent on alterations in immune responses involving B, T and NK cell - related mechanisms. This could possibly be due to decreased T-cell dependent functions, 
which have been shown to decline with aging $[105,127,128]$. This will require further investigation.

Overall, we report that aging acts in concert with lung injury to further increase the risk of lung cancer progression. This work adds to a growing body of literature implicating both aging and lung injury as risk factors for lung cancer development and progression [129]. While aging is thought to promote lung cancer progression through immune-mediated factors, the amplifying effects of lung injury in aging appear dependent on fibronectin EDA. These data, along with those of Sueblinvong, et al. [36], suggest that young mice are able to successfully repair bleomycin-induced lung injury, while old mice are predisposed for disrepair, and thus more susceptible to lung cancer progression. Our data suggest that this aberrant repair in the aged lung is facilitated by fibronectin EDA, which is not only increased in the aging lung, but also increased in the aging lung in response to bleomycin, when compared to young lungs. It is important to note that these mechanisms may vary in different cancers as aging does not appear to affect tumor progression similarly when different tumors are tested [130].

Taken together, our data suggest that age-dependent host immune factors influence lung cancer progression. Importantly, lung inflammation and tissue remodeling augment pulmonary metastasis in the aging lung, but not in young lungs, through mechanisms involving fibronectin EDA, which perhaps provides a scaffold for tumor cell migration, organization, and proliferation. This points to an interplay between lung aging and inflammation/remodeling in lung tumor progression. Admittedly, strategies for targeting fibronectin in the clinic would be 
limited due to the high concentration of fibronectin in the plasma and other organs, but much work is being done in this area [131]. Perhaps a better approach would be to target fibronectin recognition by blocking its association with its various integrins [132]. This report underscores the need for further studies in this area to unveil new anti-lung cancer therapies. 
CHAPTER III

\section{ROLE OF FIBROBLASTS IN LUNG CANCER}

\subsection{Introduction}

Although the incidence of lung cancer has decreased over the past decade, it still remains higher than that of breast cancer, prostate cancer, and colon cancer combined [2], and remains a significant threat worldwide [133]. Tobacco use remains the number one risk factor, exposing an individual to a myriad of carcinogens, among other harmful compounds [126]. The prevailing paradigm for decades has been that cells, when exposed to these and other carcinogens, acquire mutations in vital genes that over time lead to the development of tumors [134]. However, it is now well-documented that mutations alone are not sufficient to account for tumor development and progression [7]. In fact, a decreased incidence of colon and breast cancer has been observed through the use of nonsteroidal anti-inflammatory drugs $[135,136]$, which suggests that factors other than cellular transformation are needed to cause tumor growth. This concept was first proposed in 1889, when Stephen Paget revealed his seed and soil hypothesis, which described a non-random pattern of metastasis in which cancer cells ("seeds") depend on crosstalk with the microenvironment ("soil") for growth and progression. In other words, metastasis from a primary tumor to distant organs is 
site specific, where the soil produces molecular factors appropriate and necessary for the seed's survival. Since then, it has been shown that processes such as inflammation, angiogenesis, and paracrine signaling from stromal cells in the tumor microenvironment are vitally important for tumors to survive and progress [137].

Fibroblasts are a predominant cell type in the tissue microenvironment and are largely responsible for the production of the extracellular matrix, in which they are embedded. Much attention has been given to the role of cancer-associated fibroblasts, which have been termed activated fibroblasts, identified by their expression of alpha-smooth-muscle actin [138]. It is well-known that these activated fibroblasts can promote tumor progression. However, the role that normal lung fibroblasts play in the progression of lung cancer has been difficult to ascertain, with conflicting reports in the literature. For example, Yamauchi et al., showed that TIG-3 fibroblasts, when co-implanted with lung cancer cells, increased tumor growth at the site of injection and metastases to the lung, and that this effect was due, at least partly, to TGF $\beta$-mediated interactions [58]. These experiments, however, were performed in NOG mice, which are highly immunodeficient and thus must be interpreted carefully. In contrast, others have shown that normal lung fibroblasts play a role in inhibiting lung cancer progression. For example, Mishra et al., showed significantly fewer metastatic lesions in an ex vivo 4D acellular lung model when $\mathrm{H} 460$ cells were seeded with normal lung fibroblasts compared to carcinoma-associated fibroblasts [59]. Others have shown an important role of fibroblast-derived hepatocyte growth factor (HGF) in lung cancer progression $[139,140]$. This has largely been shown in the setting of resistance to epidermal 
growth factor receptor tyrosine kinase inhibitors [141,142]. These data, among others, point to the complicated nature of tumor-stromal cell interactions, and warrant further research in this area. Even fewer studies have examined the role of young versus aged fibroblasts in terms of lung cancer. With the emerging practice of personalized medicine based on a patient's genetic profile, perhaps the conflicting reports in the literature could be explained, at least in part, to differences in the genetic profile of the host and/or the various lung cancer cell lines used.

Here, we attempt to assess the role that normal, untransformed fibroblasts of the lung play in lung cancer progression in vitro and in vivo in immunocompetent animals using human and murine lung fibroblast and lung cancer cell lines. We also explore the effect of aging, by using primary lung fibroblasts isolated from old animals.

\subsection{Materials and Methods}

\subsubsection{Reagents}

Transwell inserts with an $8.0 \mu \mathrm{m}$ pore size were purchased from Corning (Costar, catalog \#3464). All chemical reagents were purchased from Tocris Bioscience (Ellisville, MO) unless otherwise specified. The cell transformation detection assay (colony formation) kit was obtained from Millipore (Temecula, CA, catalog \#ECM570). The Cell Titer-Glo® Luminescent Cell Viability Assay (catalog \#G7572) and Caspase-Glo® 3/7 Assay (catalog \#G8091) were obtained from Promega (Madison, WI). 


\subsubsection{Cell Culture}

Lewis Lung Carcinoma (LLC) (CRL-1642), A549 (CCL-185), H1792 (CRL5895), H460 (HTB-177), WI38 (CCL-75), and IMR90 (CCL-186) cells were purchased from ATCC (Rockville, MD). Primary murine lung fibroblasts (PLF) were isolated by harvesting lungs from 3-month-old (young) or 24-month-old (old) C57BL/6 mice. Lungs were minced and allowed to attach to a p100 dish by air drying for 5 minutes. Five $\mathrm{mL}$ of DMEM were then gently added. All cells were grown in DMEM supplemented with $10 \% \mathrm{FBS}$, at $37^{\circ} \mathrm{C}$ in a humidified $5 \% \mathrm{CO}_{2}$ incubator.

\subsubsection{Fibroblast Conditioned Media}

Primary murine lung fibroblasts (1.5E6) were plated in p150 dishes in 25 $\mathrm{mL}$ DMEM with $10 \%$ FBS, and allowed to grow for 3 days. For controls, $25 \mathrm{~mL}$ DMEM was added to $p 150$ dishes with no cells and incubated for 3 days. Media was then collected from all groups into $50 \mathrm{~mL}$ conical tubes and spun at $1000 \mathrm{RPM}$ for 5 minutes, filtered $(0.2 \mu \mathrm{M})$, and then transferred to new $50 \mathrm{~mL}$ conical tubes and stored at $-70^{\circ} \mathrm{C}$ until future use. The same protocol was used from IMR90 and WI38 fibroblasts, but 1.5E6 and 1E6 cells were plated in p100 dishes in $15 \mathrm{~mL}$ DMEM, respectively.

\subsubsection{Morphology}

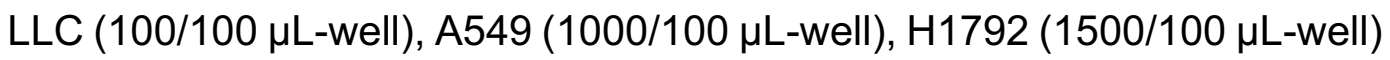
and H460 (1000/100 $\mu \mathrm{L}$-well) cells were plated in clear 96-well plates and cultured 
in control DMEM or FCM for 5 days. Cells were then formalin fixed by adding warm 4\% paraformaldehyde for 10 minutes. Cells were washed with PBS and permeabilized with $1 \%$ Triton X-100 (PBS) for 5 minutes. Cells were again washed with PBS. Cells were stained with phalloidin for 1 hour at room temperature, followed by DAPI staining for 1 minute. Cells were then photographed using an EVOS $^{\mathrm{TM}} \mathrm{FL}$ digital inverted fluorescence microscope (AMG, AMEFC-4302).

\subsubsection{Western Blot Analysis}

For protein isolation, all cells were plated in 6-well plates and incubated 24 - 120 hours. Some experiments included a 24-hour serum starvation period prior to treatment. After treatment, cells were washed with PBS and collected into $1.5 \mathrm{~mL}$ Eppendorf tubes in PBS via scraping. No trypsin was used. Cells were then centrifuged at $750 \times \mathrm{g}$ and resuspended in homogenization buffer containing 50 mM NaCl, 50 mM NaF, $50 \mathrm{mM} \mathrm{NaP}_{2} \mathrm{O}_{7}-10 \mathrm{H}_{2} \mathrm{O}, 5 \mathrm{mM}$ EDTA, $5 \mathrm{mM}$ EGTA, 2 mM $\mathrm{Na}_{3} \mathrm{VO}_{4}, 0.5 \mathrm{mM}$ PMSF, $0.01 \%$ Triton X-100, $10 \mathrm{mM}$ HEPES, pH 7.4. Samples were placed on ice and then sonicated with 3 quick pulses using a Sonifier 450 (Branson, Danbury, CT). Protein concentrations were determined using Bradford reagent (Sigma) readings in DU-800 Spectrophotometer (Beckman Coulter, Brea, CA $)$ in a 96 -well format. Protein $(20 \mu \mathrm{g})$ was mixed with $5 \mathrm{X}$ sample buffer and water to an equal volume for all samples, heated at $90{ }^{\circ} \mathrm{C}$ for 5 minutes, briefly centrifuged, and then loaded into 10 -well, $10 \%$ SDS polyacrylamide gels $(8 \%$ for FN). Gels were run in a mini trans-blot system (Bio-rad), on ice, at 100-150V for 2 hours, using a Powerpack HC power supply (Bio-rad). Gels were then soaked in 
Pierce Transfer Buffer (Thermo Scientific) for 15 minutes. Protein was transferred to $0.2 \mu \mathrm{m}$ Nitrocellulose Membranes (Bio-rad) using a Trans-Blot SD semi-dry transfer cell (Bio-rad) at $25 \mathrm{~V}$ for 1.5 hours. Membranes were then air dried for 15 minutes and blocked for 1 hour at RT in Odyssey Blocking Buffer (PBS, Li-Cor). Membranes were then incubated overnight at $4^{\circ} \mathrm{C}$ with the primary antibodies against GAPDH (Sigma; 1:10,000), fibronectin (Sigma, 1:1000), e-cadherin (CellSignaling, 1:500), vimentin (Cell-Signaling, 1:500), alpha smooth muscle actin (Abcam, 1:1000). Membranes were washed ( $3 \times 10$ minutes) with PBST and then incubated with the appropriate secondary antibody $(1: 20,000)$ for 1 hour at RT. Membranes were again washed in PBST ( $3 \times 10$ minutes). Florescent blots were then scanned on a LI-COR Odyssey CLx imaging system and analyzed in Image Studio (LI-COR).

\subsubsection{Proliferation Assay}

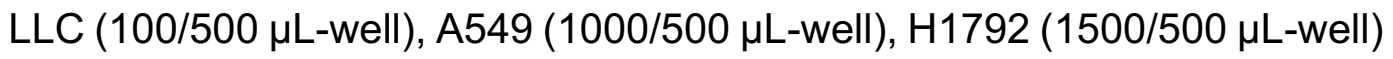
and H460 (1000/500 $\mu \mathrm{L}$-well) cells were plated in clear 48-well plates and cultured in control DMEM or FCM, and allowed to grow up to 7 days. Media was replaced every 2-3 days. Cell proliferation was then evaluated using the CellTiter-Glo $®$ Luminescent Cell Viability Assay. Briefly, media was aspirated and $100 \mu \mathrm{L}$ CellTiter-Glo lysis buffer was added. Plates were shaken for 1 minute, incubated for 8 minutes at room temperature, and then shaken an additional minute. Seventy-

five $\mu \mathrm{L}$ was then transferred to an all-white 96-well plate and read using a Luminoskan Ascent Luminometer (Beckman Coulter). 


\subsubsection{Transwell Migration Assay}

LLC, A549, H1792, and $\mathrm{H} 460$ cells (all at 50,000/200 $\mu \mathrm{L}$ ) were plated into Transwell inserts in $200 \mu \mathrm{L}$ serum free DMEM in 24-well plates. Complete DMEM or FCM $(700 \mu \mathrm{L})$ was pipetted into the bottom of the well to act as a chemoattractant. Inserts were removed 16 hours later ( 24 hours for LLC cells) and cells were fixed and stained using Thermo Scientific's Kwik-Diff kit (catalog \#9990700), per the manufacturer's instructions. Inserts were then rinsed in $\mathrm{dH}_{2} \mathrm{O}$ and non-adherent cells on the inside of the insert were removed with a cotton swab. Cells were then photographed using an EVOS ${ }^{T M}$ XL Core Cell Imaging System (AMG).

\subsubsection{Colony Formation Assay}

The colony formation assay was performed according to Millipore's instructions (Cell Transformation Detection Assay, ECM570). Briefly, a 0.8\% base agar layer was prepared ( $500 \mu \mathrm{L} / 24$-well) by boiling the agar in $\mathrm{dH}_{2} \mathrm{O}$ and allowed to cool for 5 minutes. An equal amount of DMEM was then added and plated out. Plates were placed at $4^{\circ} \mathrm{C}$ for at least $30 \mathrm{~min}$ to allow the base agar layer to gel. The top agar $(0.4 \%)$ layer $(200 \mu \mathrm{L})$ was prepared by mixing $0.8 \%$ solution with equal amount of culture media. Plates were incubated at $37^{\circ} \mathrm{C}$ for 5 minutes prior to addition of cells (500-1000/well) followed by incubation for up to 21 days. Control media or FCM $(250 \mu \mathrm{l} /$ well $)$ was added and then replaced every 3-4 days, after

aspiration of old media. Afterwards, colonies were photographed and counted using ImageJ software. 


\subsubsection{Wound Healing (Scratch) Assay}

LLC (5E5/5 mL DMEM), A549 (7.5E5/5 mL DMEM), H1792 cells (1E6/5 $\mathrm{mL}$ DMEM) and H460 cells (1E6/5 mL DMEM) were plated into 6-well plates. After 24 hours, cells were scratched with a sterile $1 \mathrm{~mL}$ pipette tip. Media was then aspirated and replaced with $5 \mathrm{~mL}$ control DMEM or FCM. Media was replaced at 24 hours. Photographs were taken at 0 and 48 hours using an EVOS $^{\mathrm{TM}}$ XL Core Cell Imaging System (AMG). Quantification was accomplished using ImageJ software, by measuring the distance of the scratch area in three separate locations at 0 and 48 hours.

\subsubsection{Caspase 3/7 Activation Assay}

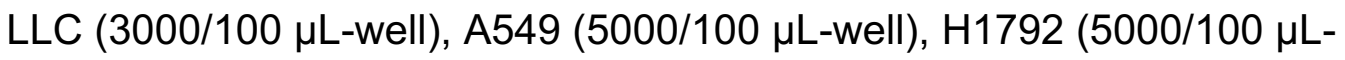
well) and H460 (5000/100 $\mu \mathrm{L}-$-well) cells were plated in white-walled, clearbottom, 96-well plates and cultured in control DMEM or FCM for 24 hours. Media was then aspirated and $50 \mu \mathrm{L}$ of control DMEM or FCM with or without cisplatin was added. Final concentrations of cisplatin were 10, 30, 30 and $100 \mu \mathrm{M}$ for LLC, A549, $\mathrm{H} 460$ and $\mathrm{H} 1792$, respectively. Apoptosis was then evaluated using the Caspase-Glo® 3/7 Assay. Briefly, $50 \mu \mathrm{L}$ Caspase-Glo® lysis buffer was added. Plates were shaken for 2 minutes, incubated for 1 hour at RT, shaken an additional 2 minutes, and then read using a Luminoskan Ascent Luminometer (Beckman Coulter). Cell viability was evaluated using the CellTiter-Glo® Luminescent Cell Viability Assay as described above. 


\subsubsection{Animal Studies}

All experiments were approved by the Institutional Animal Care and Use Committee of the University of Louisville. LLC cells and primary lung fibroblasts were plated out 24 hours prior to injections and were harvested at $\sim 50 \%$ confluence to ensure cells were in growth phase. LLC cells (1E6/100 $\mu$ sterile PBS) were injected alone or together with primary lung fibroblasts (1E6 /100 $\mu \mathrm{l}$ sterile PBS) subcutaneously into the hind flank of wildtype C57BL/6 mice. Afterwards, tumors were monitored and measured weekly. A tumor size $>15 \mathrm{~mm}$ in any direction was considered the endpoint, per IACUC regulations. Animals were then sacrificed and tissues were harvested for analysis. In separate experiments, LLC cells (1E6) that had been grown in control DMEM or FCM for 24 hours were then injected into the hindflank in control DMEM or FCM and followed as described above.

\subsubsection{Tissue Processing and Histological Analysis}

Animals were sacrificed by $\mathrm{CO}_{2}$ administration in a closed chamber. Lungs were flushed with PBS, inflated at standard pressure with formalin, removed, and formalin-fixed for 48 hours. Lungs were then processed through increasing ethanol solutions in an STP 120 Spin Tissue Processor (ThermoFisher Scientific, Waltham, MA), paraffin-embedded, and sectioned (6 $\mu \mathrm{m})$ using a JUNG RM2055 microtome (Leica, Buffalo Groce, IL). Lung sections were then transferred onto charged, glass Colorfrost microslides (VWR Sciences, Radnor, PA) for histological 
analysis. Sections were deparaffinized, rehydrated, and stained with hematoxylin and eosin (HE) to evaluate lung tumors.

\subsubsection{FCM Characterization via Antibody Array}

A RayBio label-based (L-series) mouse antibody array L-308 membrane kit (\# AAM-BLM-1-4) was used for FCM characterization, per the manufacturer's instructions. Briefly, samples were dialyzed by loading $3 \mathrm{~mL}$ control DMEM and $3 \mathrm{~mL}$ FCM each into 2 dialysis vials, and then placed in $4 \mathrm{~L} \mathrm{PBS}$ overnight at $4^{\circ} \mathrm{C}$. Samples were then transferred to $5 \mathrm{~mL}$ Eppendorf tubes and spun at 10,000 RPM for 5 minutes and transferred to new Eppendorf tubes. Labeling reagent was added and samples were incubated at room temperature for 30 minutes with gentle shaking. Stop solution was then added and samples were spun at $1000 \times \mathrm{g}$ for 3 minutes using the provided spin columns. Membranes were blocked in provided blocking buffer for 1 hour at room temperature with gentle shaking. Samples were diluted $1: 2$ by mixing $5 \mathrm{~mL}$ sample with $5 \mathrm{~mL}$ blocking buffer. Membranes were then incubated at room temperature for 2 hours with gentle shaking. Membranes were washed three times per ten minutes with wash buffer \#1 and three times per ten minutes with wash buffer \#2. 500x HRP-conjugated streptavidin was diluted with $10 \mathrm{~mL}$ blocking buffer and membranes were incubated for 2 hours at room temperature. Membranes were then washed and exposed to detection buffer for 2 minutes with gentle shaking. Membranes were placed between provided plastic sheets and imaged using Biorad's ChemiDoc ${ }^{\mathrm{TM}}$ XRS+ System. 


\subsubsection{Analysis of Data}

Means plus standard deviations of the mean were calculated for all experimental values, unless otherwise noted. Significance was assessed by using the Student's $t$ test, unless otherwise noted. All experiments were repeated a minimum of 3 times with each sample group containing a minimum number of three experimental groups.

\subsection{Results}

\subsubsection{FCM alters morphology of lung cancer cells}

Lung cancer cells were cultured in complete DMEM versus fibroblastconditioned media (FCM) for 5 days. FCM was obtained from IMR90 and WI38 human lung fibroblasts when testing human cancer cells, and from primary murine lung fibroblasts when testing LLC cells. Afterwards, cells were formalin fixed, permeabilized, and stained with phalloidin and DAPI. FCM altered the morphology of A549, H1792, and LLC cells, but not $\mathrm{H} 460$ cells (Fig. 10A-D). This change in morphology was characterized by a spindle shape appearance, and was accompanied by cell scattering, both of which suggested the possibility of epithelial-mesenchymal transition (EMT), a marker of increased metastatic potential. To test this, cells were serum starved for 24 hours and then cultured in complete DMEM or FCM for 48 hours. Protein was then isolated, followed by 


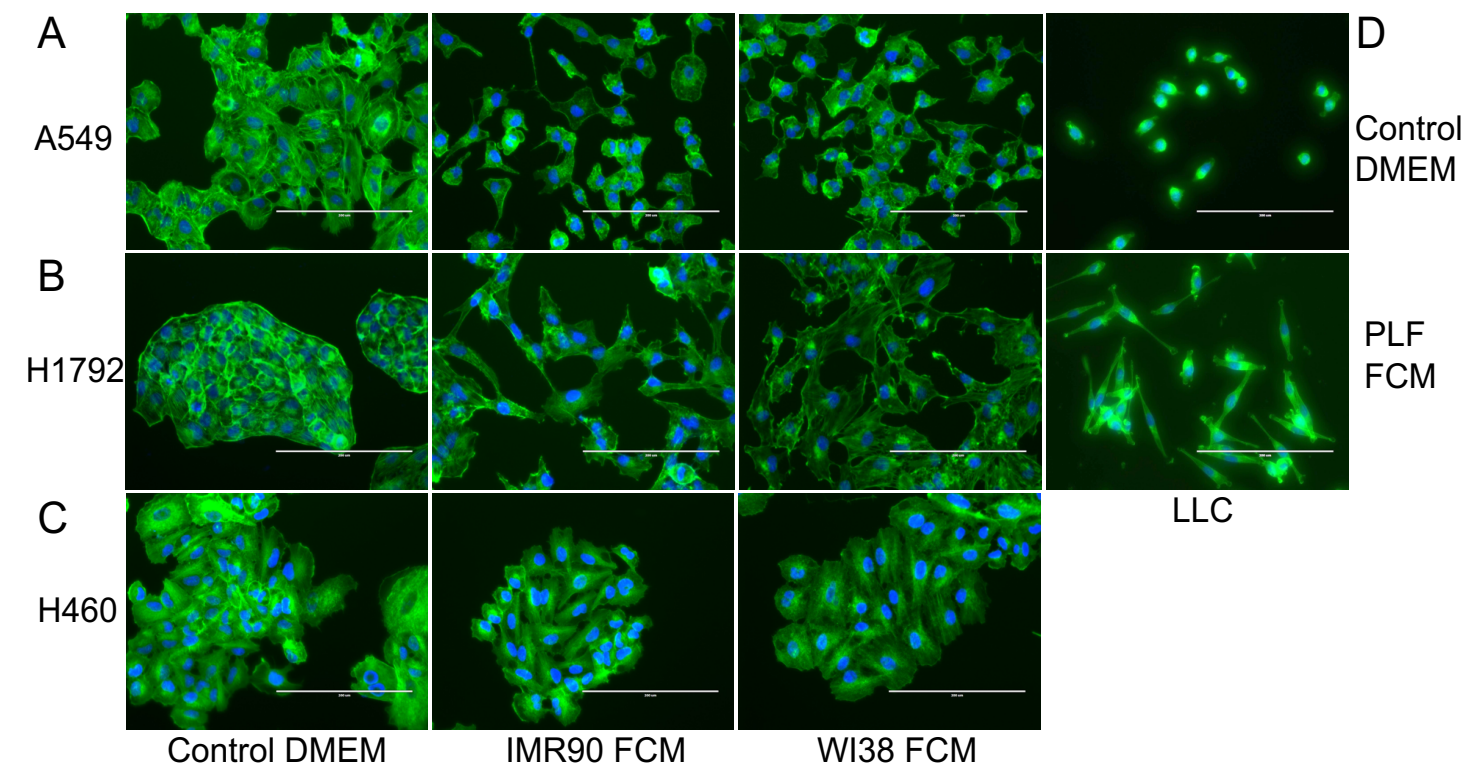

Figure 10. FCM Alters Lung Cancer Cell Morphology

A549, H1792, H460, and LLC cells were grown in 96-well plates in control DMEM or FCM for 5 days, formalin fixed, permeabilized and stained with phalloidin and DAPI. FCM altered the morphology of all cell lines, with the exception of $\mathrm{H} 460$ cells. Cell-scattering and a spindle-shaped morphology was observed. 
Western Blot analysis for vimentin, E-cadherin, alpha smooth-muscle actin, and fibronectin. Very small changes were noted in all cell lines, except for $\mathrm{H} 1792$ cells, were alpha smooth-muscle actin, vimentin, and fibronectin levels were all increased in response to FCM (Fig. 11A-D). 

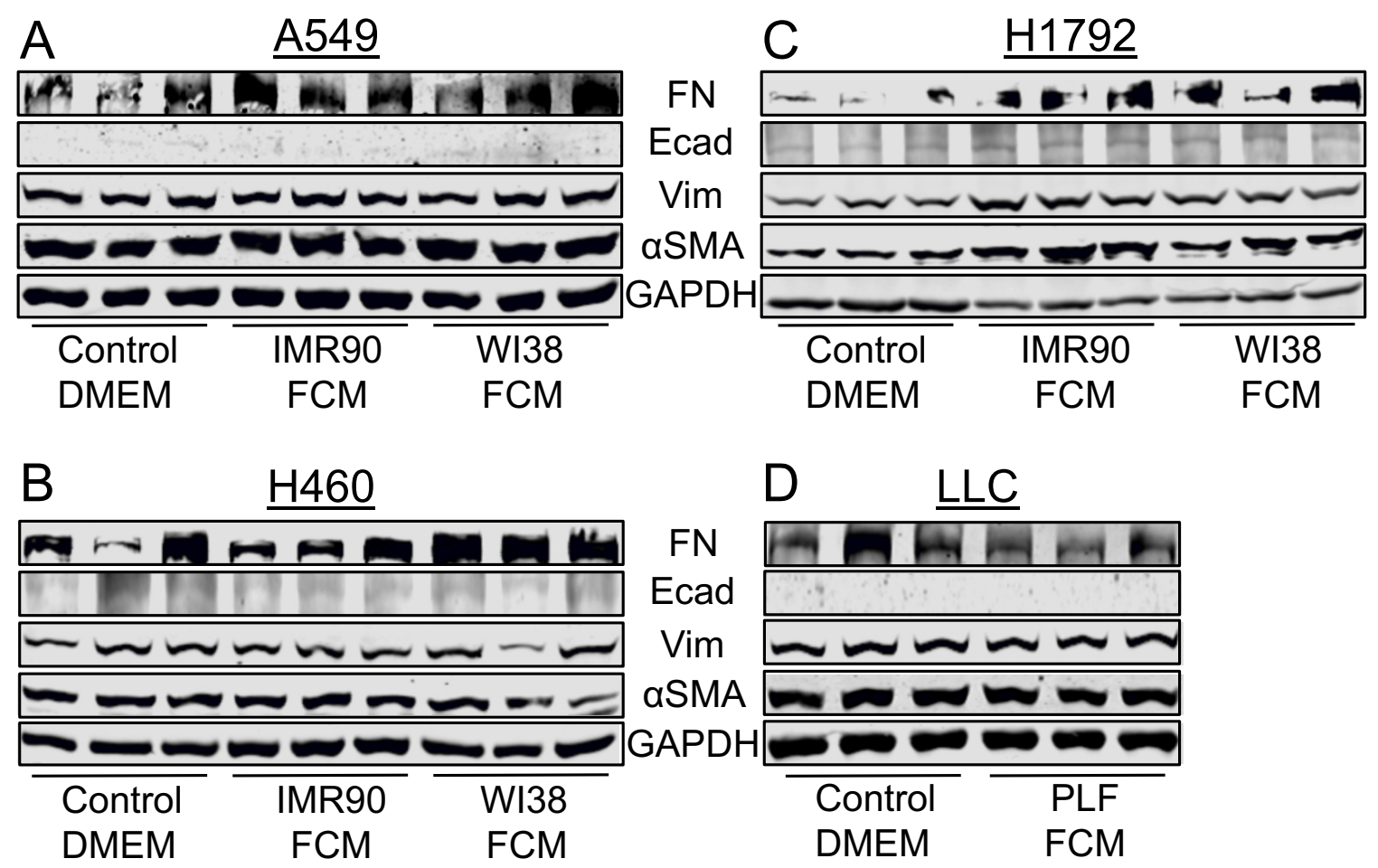

Figure 11. Effect of FCM on EMT Markers

A549, $\mathrm{H} 1792, \mathrm{H} 460$, and LLC cells were grown in 6-well plates in control DMEM or FCM for 24 hours, serum starved for 24 hours, and then grown in FCM for an additional 48 hours. Protein was isolated, followed by Western Blot analysis (20 $\mu \mathrm{g})$ for fibronectin (FN, 1:1000), E-cadherin (Ecad, 1:500), Vimentin (Vim, 1:500), alpha smooth muscle actin ( $\alpha$ SMA, 1:1000), and GAPDH (loading control, 1:10,000). 


\subsubsection{FCM has differential effects on proliferation, migration, and colony formation}

To examine the effects of FCM on lung cancer cell proliferation, cells were cultured in complete DMEM or FCM for up to 7 days. All cell lines cultured in FCM showed increased proliferation, as determined by ATP quantification, when compared to cells grown in complete DMEM (Fig. 12A-D). Likewise, Transwell migration was increased in all cell lines (Fig. 13A-D), as determined by Boyden chamber migration assays, with the greatest effect being observed in $\mathrm{H} 1792$ cells. Additionally, colony formation of A549 cells was increased by the presence of FCM (Fig. 14A) but was unchanged in H1792 and H460 cells (Fig. 14B-C), while a decrease was observed in LLC cells (Fig. 14D). Lastly, wound healing, as determined by the scratch assay, was increased in A549, H1792 and LLC cells cultured in the presence of FCM, again, with the greatest effect being observed in H1792 cells. (Fig. 15A, B and D). Interestingly, FCM had no effect on wound healing in $\mathrm{H} 460$ cells (Fig. 15C). 

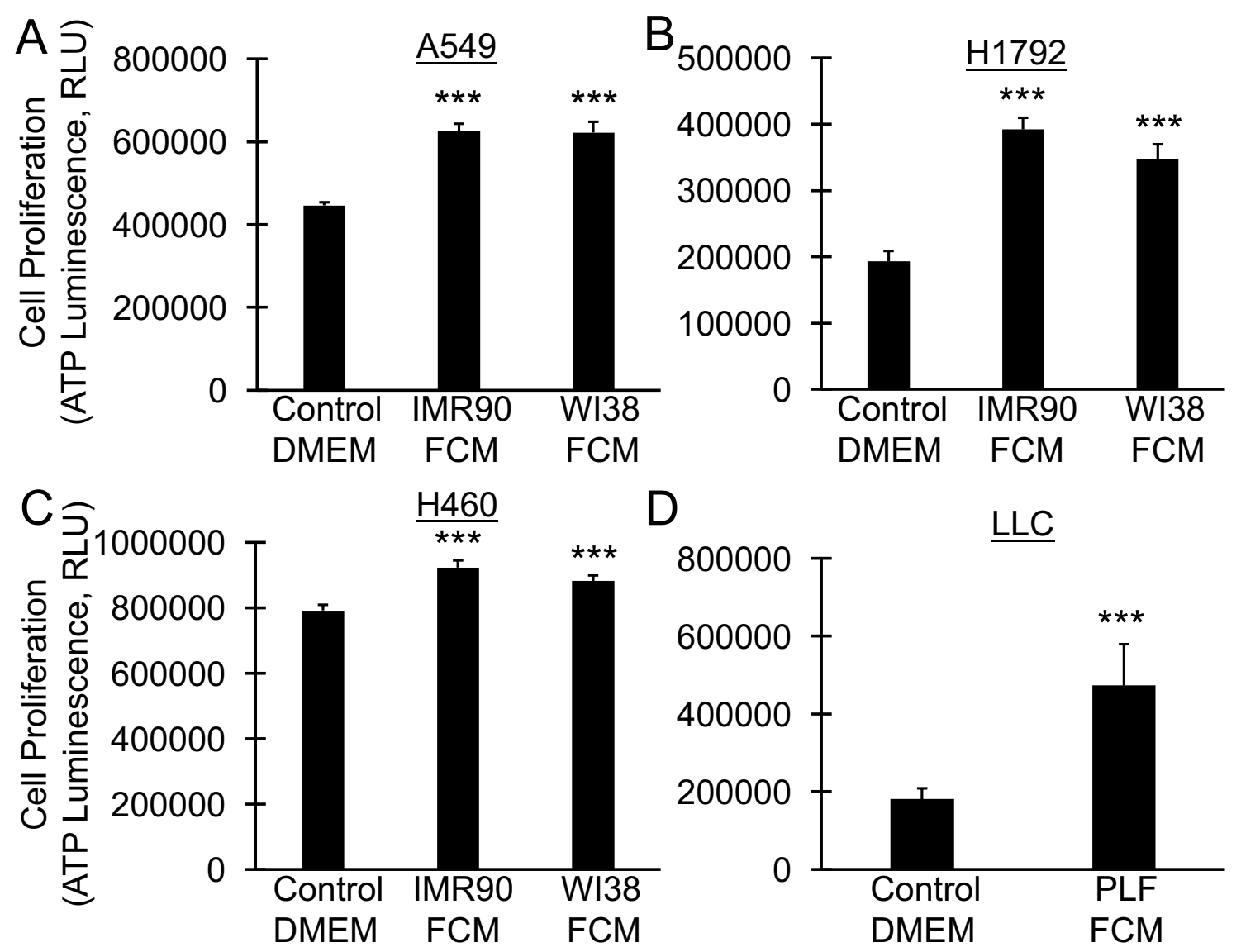

$\mathrm{D}$

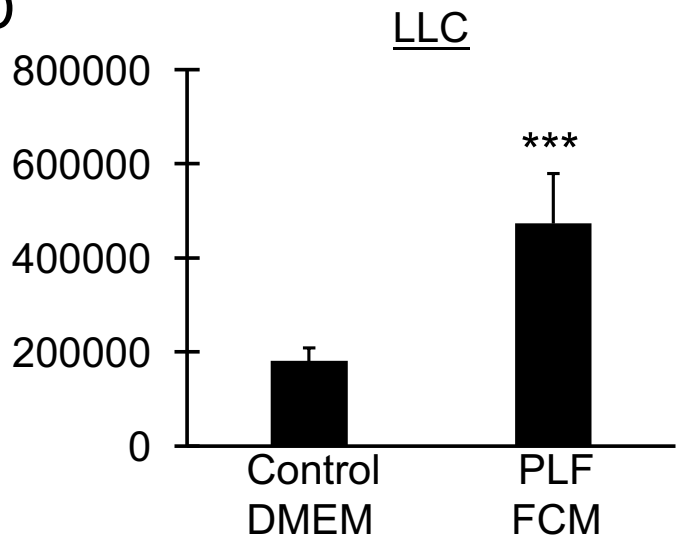

Figure 12. FCM Increases Lung Cancer Cell Proliferation

A549, $\mathrm{H} 1792, \mathrm{H} 460$, and LLC cells were grown in 48-well plates in control DMEM or FCM for 7 days. Cells were refed every 2-3 days. Cell proliferation was quantified using Cell Titer-Glo Luminescent Cell Viability Assay Kit (Promega). Graphs depict relative luciferase units (RLU). Cell proliferation was increased in all cell lines tested in response to FCM. ${ }^{* *} P<.001$. 


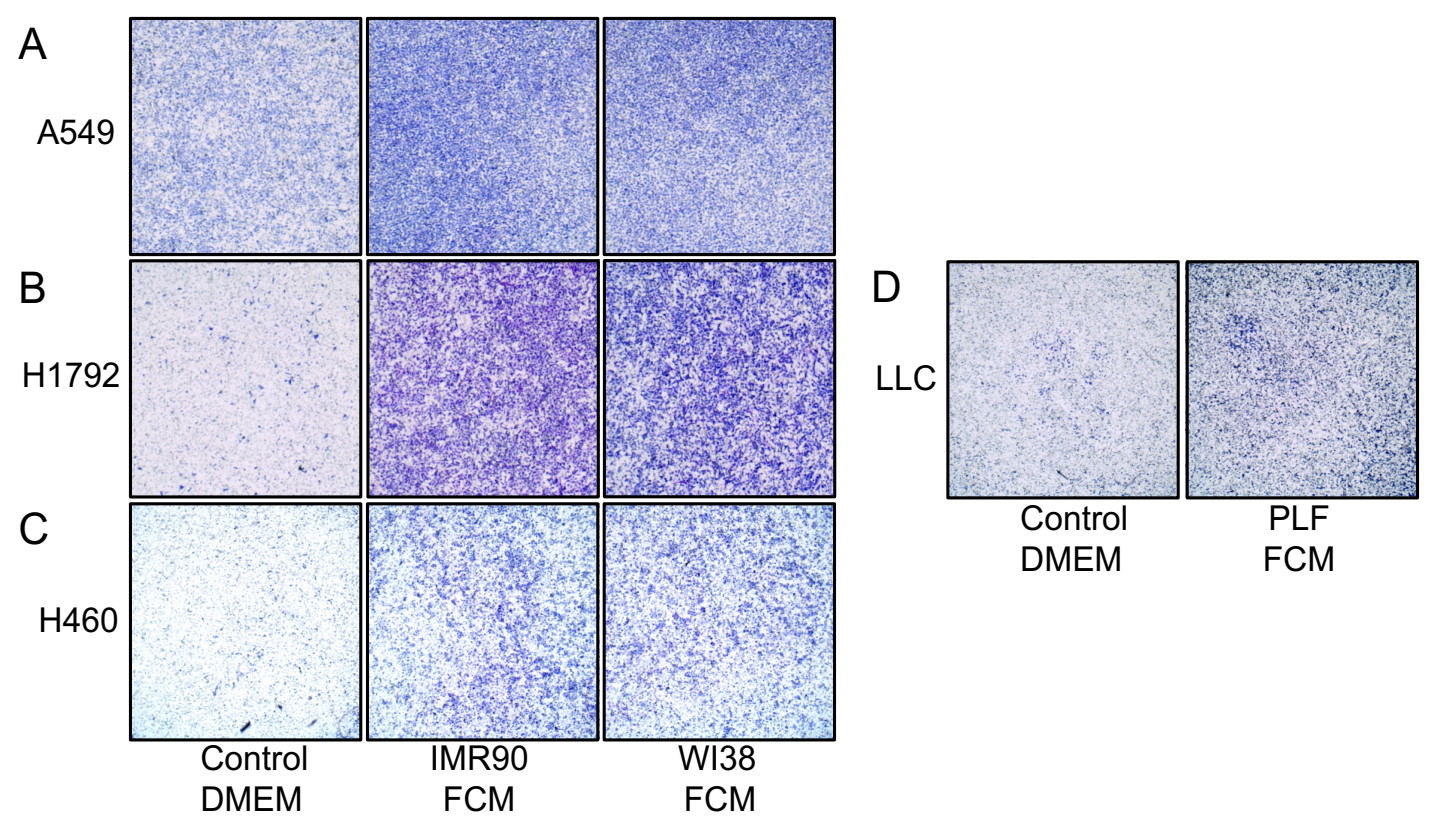

Figure 13. FCM Increases Transwell Migration

A549, H1792, H460, and LLC cells $(50,000)$ were plated in a Transwell Boyden inserts in serum- free media $(200 \mu \mathrm{L})$ with control DMEM, IMR90 FCM, or WI38 FCM in the lower well $(700 \mu \mathrm{L})$. After $20-24$ hours, cells were fixed and stained using the Kwik-Diff kit (Thermo Scientific). Inserts were then rinsed in $\mathrm{dH}_{2} \mathrm{O}$ and non-adherent cells on the inside of the insert were removed with a cotton swab and photographed. Transwell migration was increased in all cell lines tested in response to $\mathrm{FCM}$. 

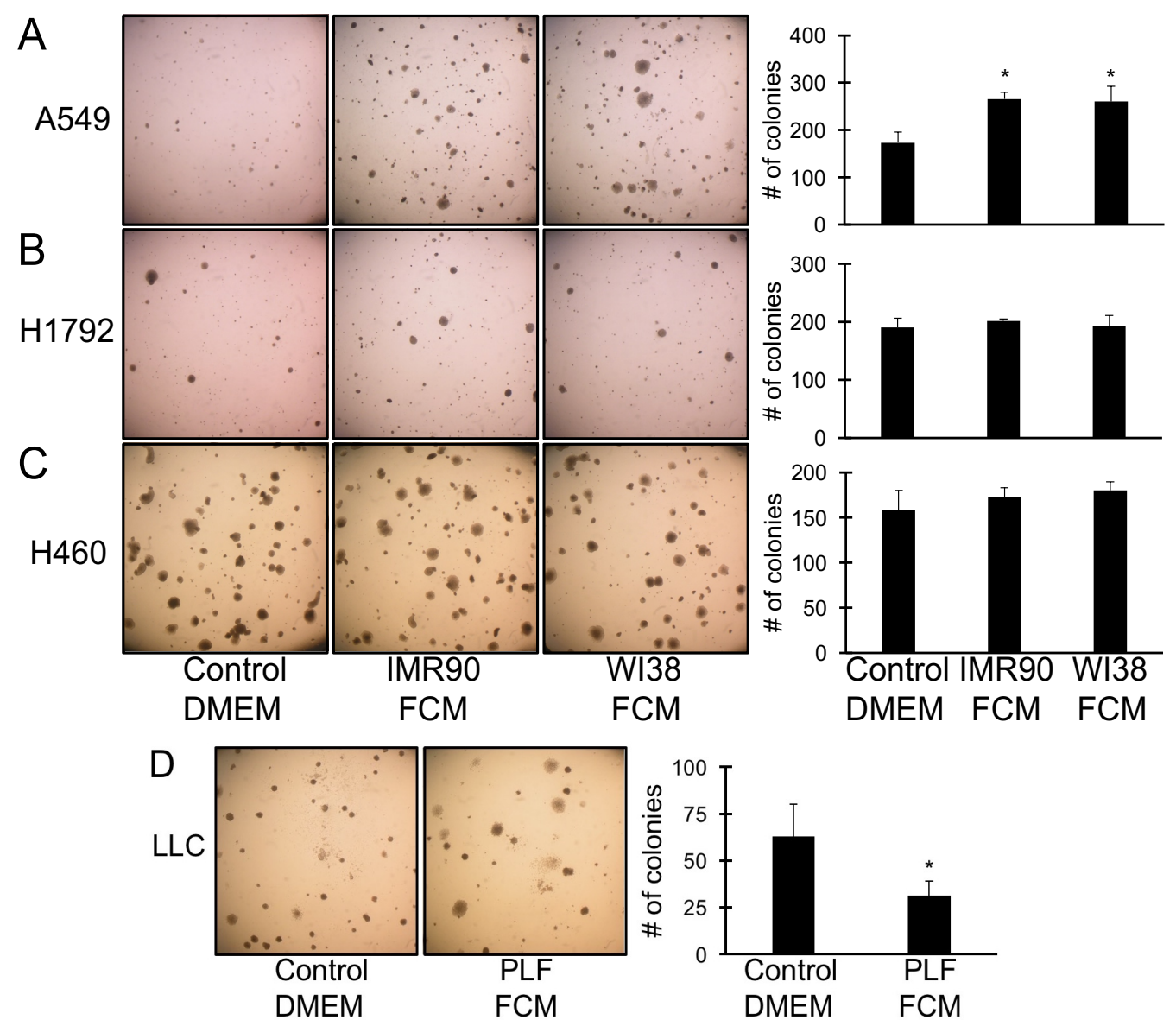

\section{Figure 14. Effect of FCM on Colony Formation}

A549, $\mathrm{H} 1792, \mathrm{H} 460$, and LLC cells plated in 24-well plates were suspended in $0.4 \%$ top agar layer and plated on a $0.8 \%$ base agar layer, which was prepared according to Millipore's instructions. Control DMEM or FCM was then added. Media was replaced every 3-4 days. Colonies were followed for 14 days and then counted and quantified using Image J software. Colony formation was increased in A549 cells and decreased in LLC cells in response to FCM, while no changes were observed in $\mathrm{H} 1792$ or $\mathrm{H} 460$ cells. ${ }^{*} P<.05$ 

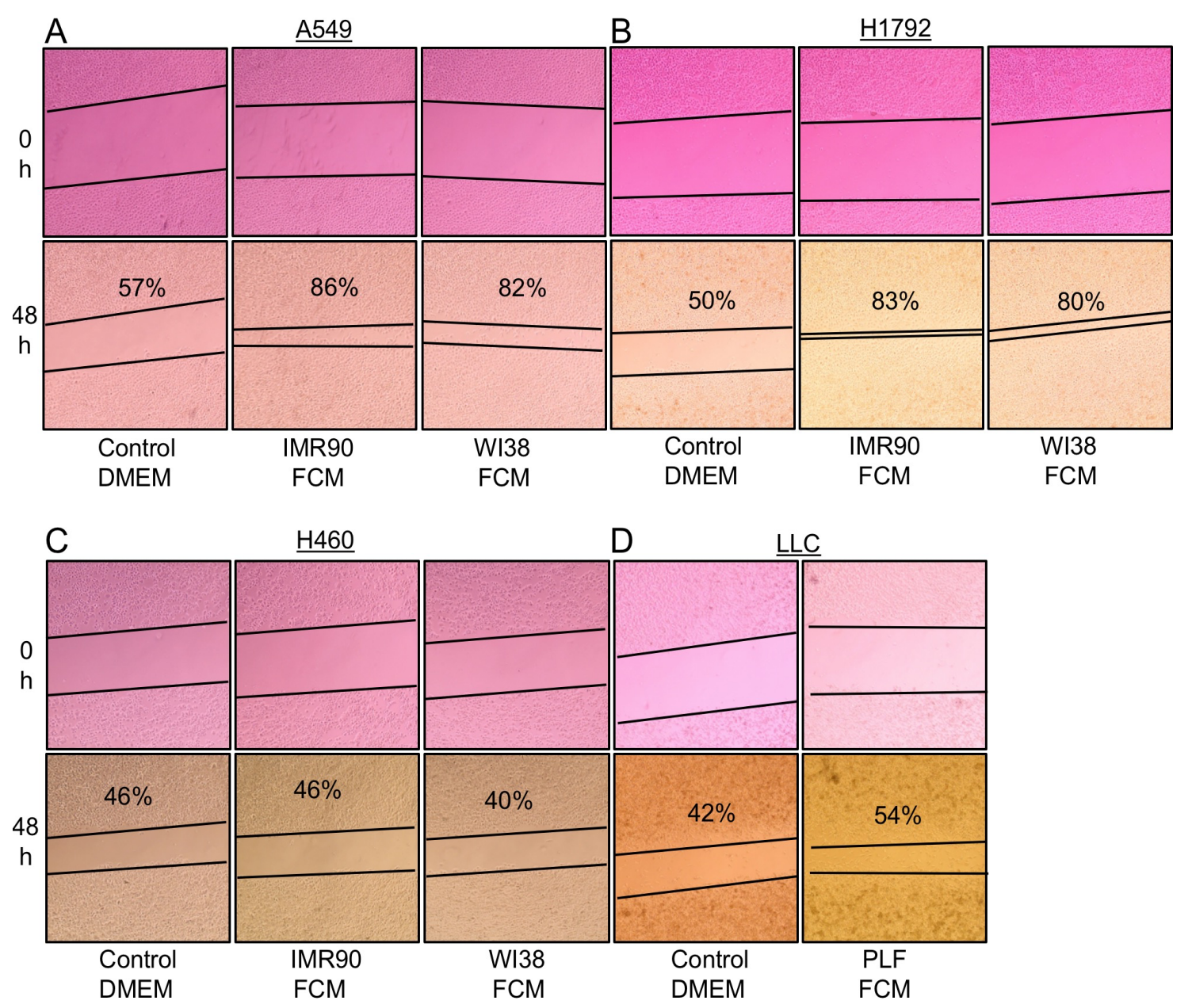

\section{Figure 15. Effect of FCM on Wound Healing}

A549, $\mathrm{H} 1792, \mathrm{H} 460$, and LLC cells were plated in 6-well plates and allowed to grow overnight. A scratch was then created using a $1 \mathrm{~mL}$ pipette tip. Media was replaced with $5 \mathrm{~mL}$ control DMEM or FCM (10 mL for LLC cells). Photographs taken at 0 and 48 hours. Quantification was performed using ImageJ software. Wound healing was increased in all cell lines tested in response to FCM, except in H460 cells. Numbers indicate \% closure after 48 hours. 


\subsubsection{FCM protects against cisplatin-induced death}

To evaluate the role of FCM in cisplatin-induced death, lung cancer cells were cultured in control DMEM or FCM for 24 hours. Cells were then exposed to cisplatin for an additional 28 hours. There was a significantly greater number of viable cells, after cisplatin exposure, when the cells were cultured in FCM compared to complete DMEM (Fig. 16A-D). FCM-induced cisplatin protection was accompanied by a decrease in the activity of caspases 3 and 7 in all cells (Fig. 17A,B and D), while no changes were observed in H460 cells (Fig. 17C). A summary of the in vitro findings is provided in Table 1.

\begin{tabular}{|l|l|l|l|l|}
\hline Table 1. Effect of FCM & A549 & $\underline{\mathrm{H} 1792}$ & $\underline{\mathrm{H} 460}$ & $\underline{\mathrm{LLC}}$ \\
\hline Morphology & Altered & Altered & No Change & Altered \\
\hline Proliferation & Increased & Increased & Increased & Increased \\
\hline Transwell Migration & Increased & Increased & Increased & Increased \\
\hline Colony Formation & Increased & No Change & No Change & Decreased \\
\hline Scratch Migration & Increased & Increased & No Change & Increased \\
\hline Apoptosis Resistance & Increased & Increased & Increased & Increased \\
\hline
\end{tabular}




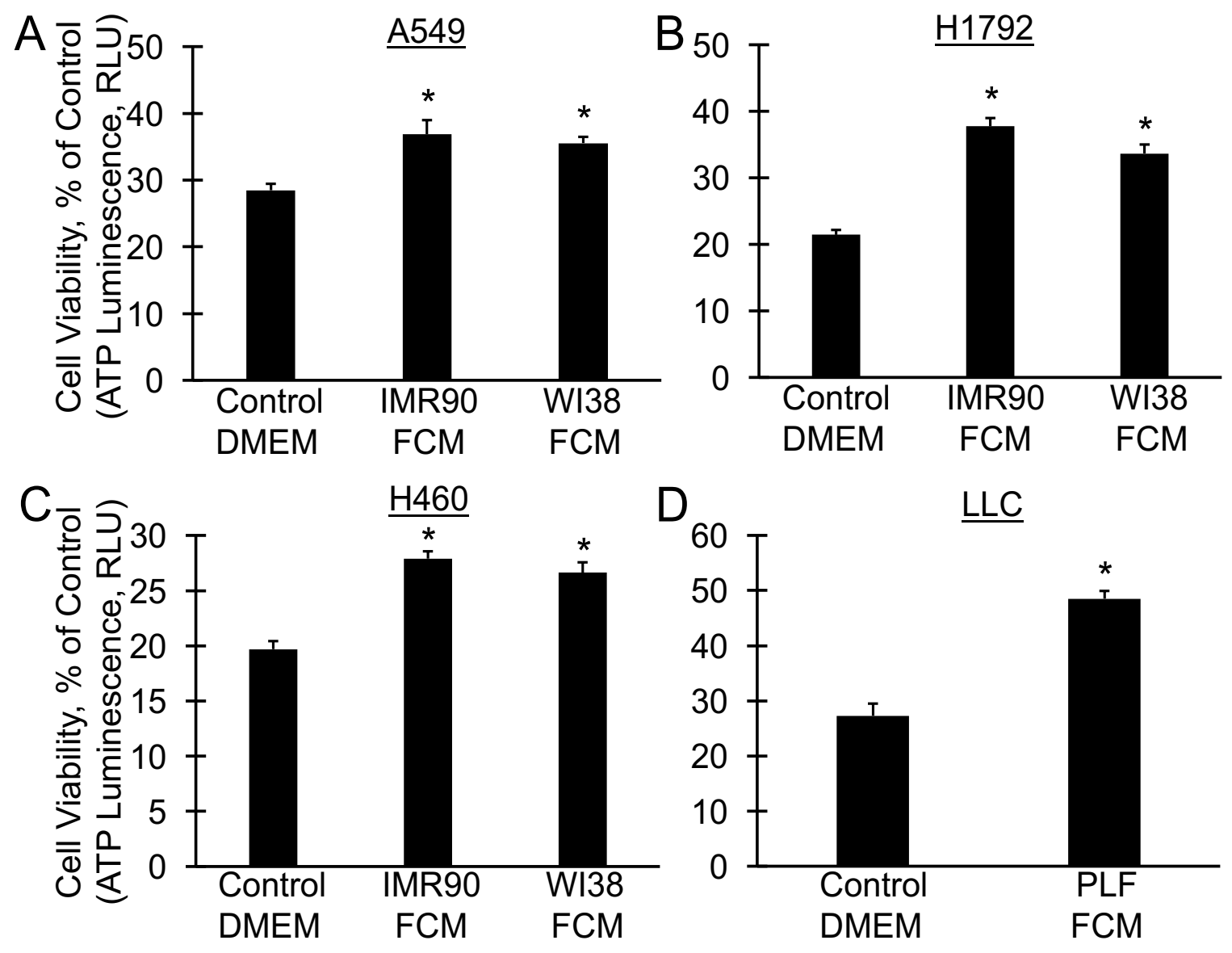

Figure 16. FCM Decreases Sensitivity of Lung Cancer Cells to Cisplatin A549, H1792, H460, and LLC cells were plated in white-walled, clear-bottom 96well plates in control DMEM or FCM and allowed to grow overnight. Cisplatin $(30 \mu \mathrm{M}, 100 \mu \mathrm{M}, 30 \mu \mathrm{M}$, and $10 \mu \mathrm{M}$, respectively) was then added and cells were allowed to grow an additional 24 hours. The remaining viable cells were quantified using Cell Titer-Glo Luminescent Cell Viability Assay Kit (Promega). Graphs depict $\%$ of control cells that did not receive cisplatin. Units are relative luciferase units (RLU). All cell lines tested showed a decreased sensitivity to cisplatin in response to FCM, with a greater effect being observed in $\mathrm{H} 1792$ and LLC cells. 

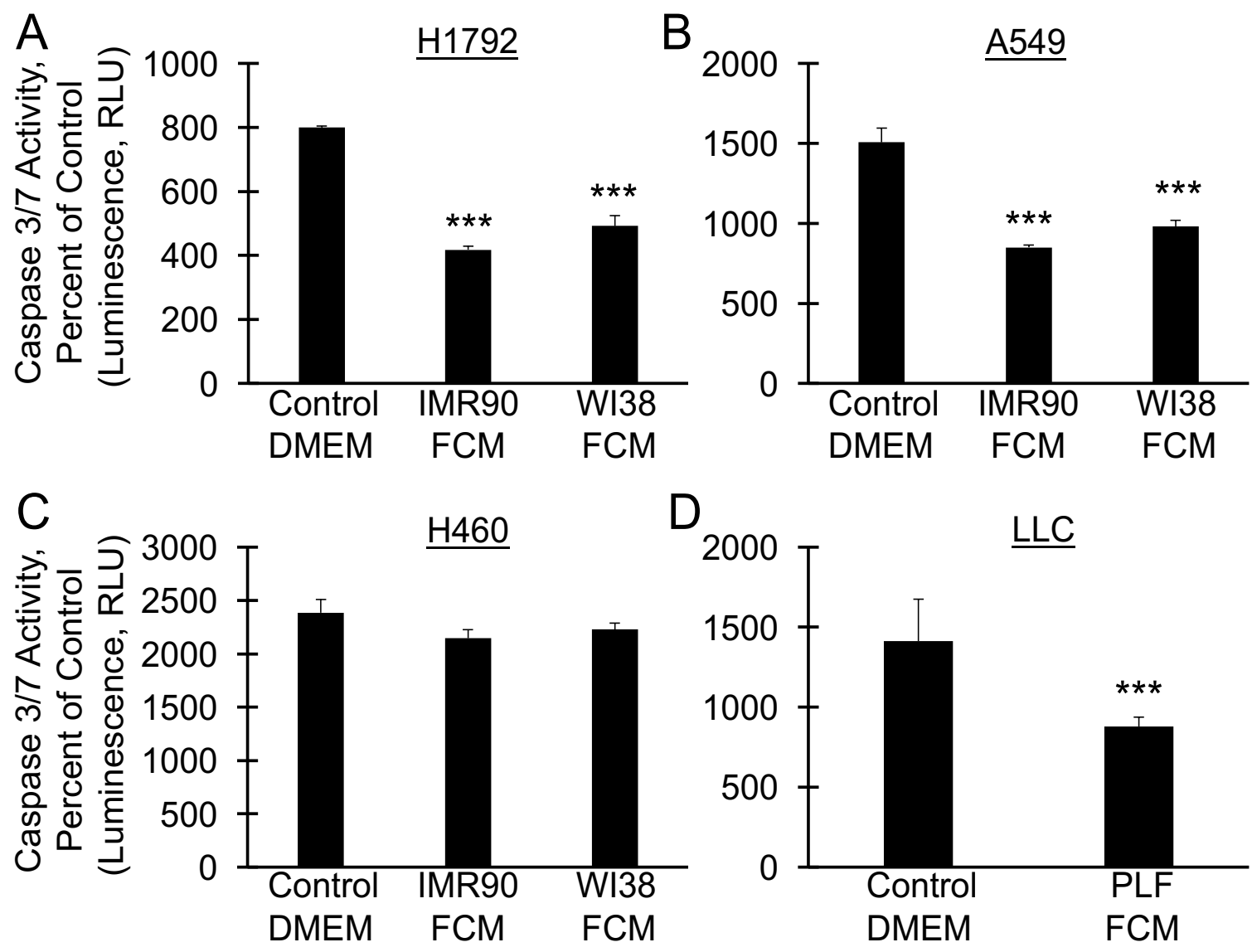

Figure 17. Effect of FCM on Caspase 3/7 Activation

A549, H1792, H460, and LLC cells were plated in white-walled, clear-bottom 96well plates in control DMEM or FCM and allowed to grow overnight. Cisplatin $(30 \mu \mathrm{M}, 100 \mu \mathrm{M}, 30 \mu \mathrm{M}$, and $10 \mu \mathrm{M}$, respectively) was then added and cells were allowed to grow an additional 24 hours. Caspase 3/7 activity was then detected using the Caspase-Glo 3/7 Assay Kit (Promega). Graphs depict \% of control cells that did not receive cisplatin. Units are relative luciferase units (RLU). Caspase 3/7 activation was decreased in all cells lines tested in response to FCM, except $\mathrm{H} 460$ cells. ${ }^{* * *} P<.001$. 


\subsubsection{Fibroblasts co-injected with LLC cells promote tumor growth, while FCM has small affect}

Having established the effects of FCM on lung cancer cells in vitro, we focused our attention on the role of fibroblasts in vivo. First, primary lung fibroblasts and LLC cells were grown separately until cells were in exponential growth phase. Cells were then co-injected into the hindflank of C57BL/6 mice. Tumor growth was followed until tumors reached a size of $15 \mathrm{~mm}$ in any direction, after which time, all animals were sacrificed and lungs were harvested and formalin fixed. Primary lung fibroblasts and LLC cells injected together caused larger tumor growth at the site of injection at 18 days (sacrifice), compared to LLC cells alone (Fig. 18A). Primary lung fibroblasts injected alone did not cause tumors at the site of injection (data not shown). To evaluate lung metastasis, lungs were processed, paraffin embedded, sectioned, and H\&E stained. As depicted in Fig. 18B, there were no differences in lung metastasis observed.

To evaluate the role that FCM plays in lung cancer metastasis, we grew LLC cells in FCM for 24 hours and then injected them into the hindflank of C57BL/6 mice in FCM or complete DMEM. Tumor growth was again followed until tumors reached a size of $15 \mathrm{~mm}$ in any direction, after which time, all animals were sacrificed and lungs were harvested and formalin fixed. Although the number of metastases in the FCM group was greater in number than those in the complete DMEM group (2.6 vs 4.5), this was not statistically significant (Fig. 18D). Tumor size at the site of injection was also unchanged (Fig. 18C). 

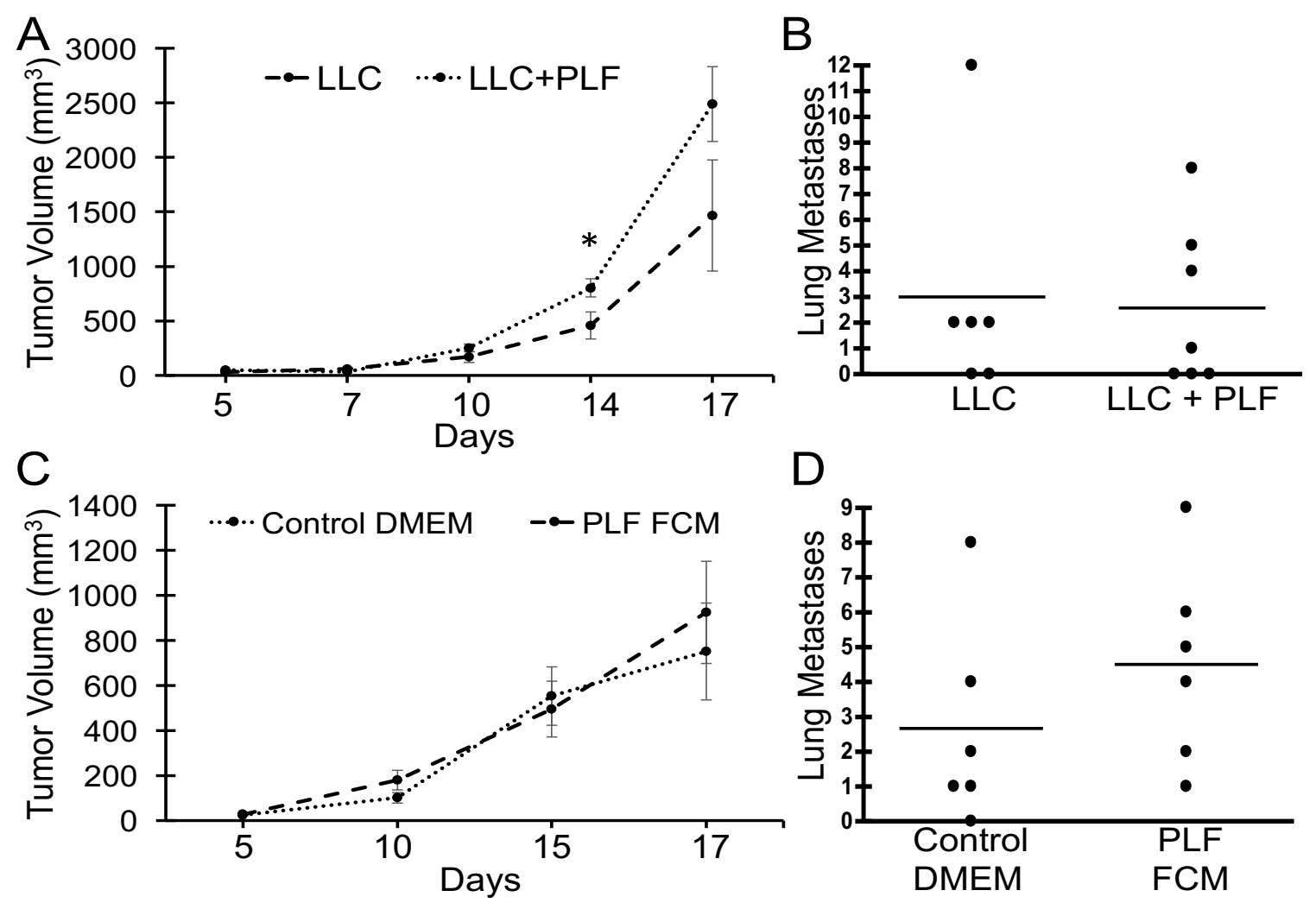

Figure 18. Effect of PLF and FCM on Tumor Growth and Lung Metastasis In Vivo

(A,B) 1E6 LLC cells (LLC, n=6) or 1E6 LLC cells with 1E6 PLF cells (LLC+PLF, $\mathrm{n}=7$ ) were injected subcutaneously into the hind flank of WT C57BL/6 mice. (C,D) LLC cells were grown in control DMEM or FCM for 24 hours and then injected subcutaneously into the hind flank of WT C57BL/6 mice. A tumor size of $\geq 15 \mathrm{~mm}$ in length or width was established as the endpoint according to IACUC regulations. Mice were then sacrificed and lungs harvested and processed for examination of metastases. Tumor volume was greater in the LLC+PLF group compared to LLC cells alone (A), while no differences in the number of lung metastases were observed (B). Tumor volume (C) and lung metastasis (D) was similar in animals injected with LLC cells grown in complete DMEM vs. FCM. ${ }^{*} P<.05$. 


\subsubsection{FCM Characterization}

In order to identify the soluble component(s) present in FCM responsible for the observed effects, we began by utilizing Corning ${ }^{\circledR}$ Spin- $X^{\circledR}$ UF Concentrators to determine the relative size of the 'active' agent. Using columns with a molecular weight cutoff of $100 \mathrm{kDa}$, we were able to block the effects of FCM, with the exception of the protection from cisplatin-induced apoptosis, which indicates that most of the effects of FCM are due to factors greater than $100 \mathrm{kDa}$ in size (not shown). Other studies suggested that the activity was not mediated by molecules capable of interacting with RGD-binding integrins, as RGD peptides (used at 500 $\mathrm{ug} / \mathrm{ml}$ ) did not block the effect. Heparin, boiling $\left(100^{\circ} \mathrm{C}, 10\right.$ minutes $)$, and proteases (PMSF), also failed to inhibit the activity suggesting that the soluble factor(s) in FCM is either not a protein, or a protein in a multiprotein complex, which protected it from degradation. Lastly, several antagonists for fibroblast growth factor receptors (SU 6668, PD161570, and FIIN1 HCl), a well characterized mitogen of fibroblasts, also failed to inhibit the activity of FCM on proliferation (not shown).

For a more targeted approach, we used RayBio AAM- BLM-1 label-based mouse antibody array, which simultaneously measures the expression of 308 soluble murine proteins. Fifteen different proteins were identified in FCM that were not present in complete DMEM (Fig. 19). One of these proteins is hepatocyte growth factor (HGF) and is $105 \mathrm{kDa}$ in size that is cleaved by serine proteases into a $69-\mathrm{kDa}$ alpha-chain and $34-\mathrm{kDa}$ beta-chain. To determine if HGF was responsible for the observed effects of FCM on lung cancer cells, we tested the effects of a commercially available hepatocyte growth factor receptor (cMet) 


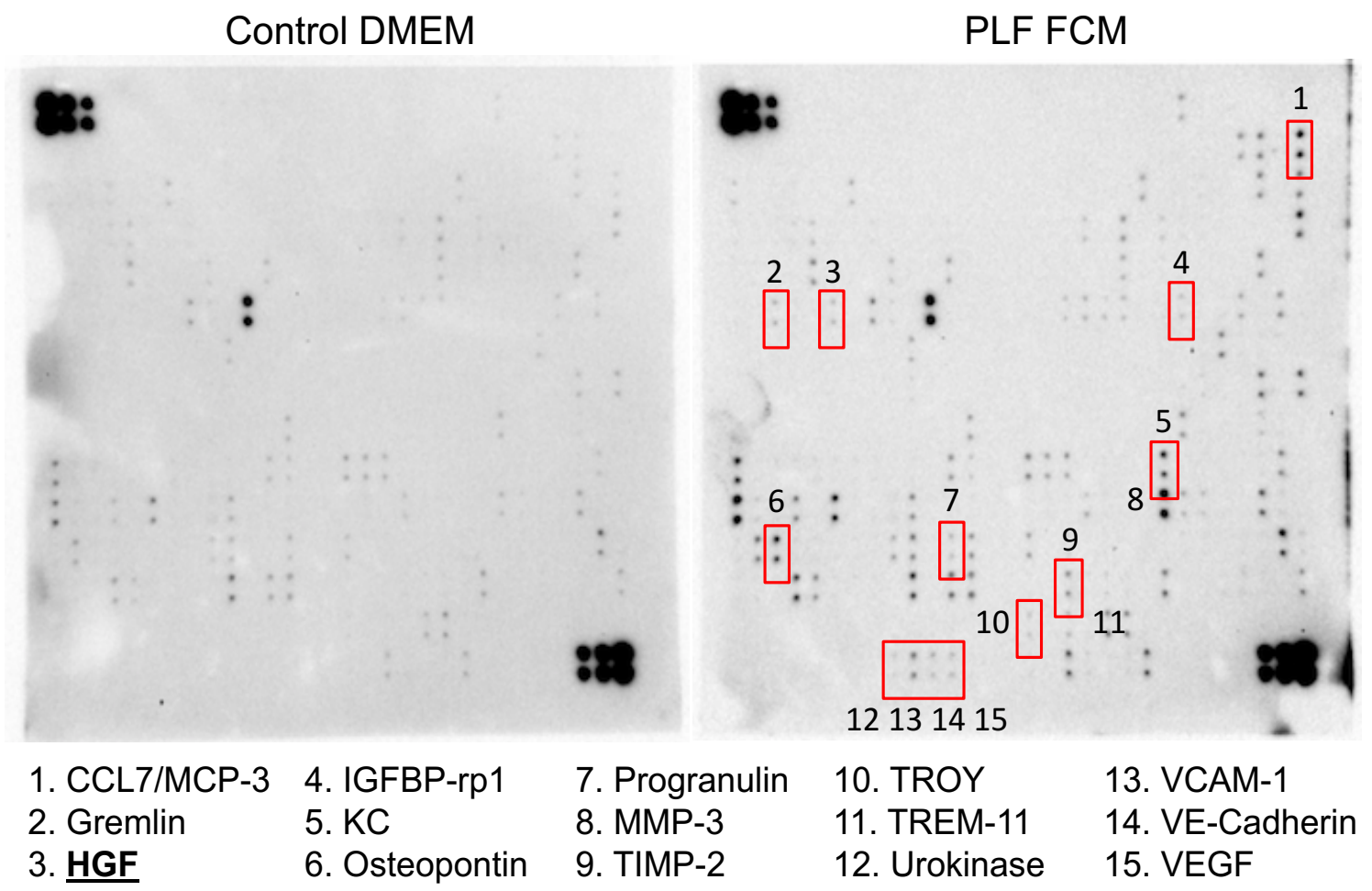

\section{Figure 19. FCM Characterization}

A RayBio label-based (L-series) mouse antibody array L-308 membrane kit (\# AAM-BLM-1-4) was used for FCM characterization. Control DMEM or FCM samples were dialyzed and biotin labeled and then incubated with membranes containing 308 soluble mouse protein antibodies. Membranes were then washed and exposed to HRP-conjugated streptavidin, followed by ECL and then imaged using Biorad's ChemiDoc ${ }^{\mathrm{TM}}$ XRS+ System. Red boxes indicate proteins present in FCM that were not present in complete DMEM (see list). 
antagonist, PF 04217903 mesylate. The presence of PF 04217903 prevented the change in tumor cell morphology induced by FCM, except for in LLC cells, and blocked many, albeit, not all, of the effects of FCM (Table 2). However, in all cell lines, it was unable to block the mitogenic effect of FCM, as well as the protective effect of FCM on cisplatin-induced apoptosis.

\begin{tabular}{|l|l|l|l|l|}
\hline $\begin{array}{l}\text { Table 2. Effect of } \\
\text { FCM + cMET } \\
\text { Antagonist }\end{array}$ & A549 & $\underline{\mathrm{H} 1792}$ & $\underline{\mathrm{H} 460}$ & $\underline{\text { LLC }}$ \\
\hline Morphology & Blocked & Blocked & No Change & No Change \\
\hline Proliferation & No Change & No Change & No Change & No Change \\
\hline $\begin{array}{l}\text { Transwell } \\
\text { Migration }\end{array}$ & Blocked & Blocked & No Change & No Change \\
\hline Colony Formation & No Change & No Change & No Change & Blocked \\
\hline Scratch Migration & Blocked & Blocked & No Change & No Change \\
\hline $\begin{array}{l}\text { Apoptosis } \\
\text { Resistance }\end{array}$ & No Change & No Change & No Change & No Change \\
\hline
\end{tabular}

To further investigate the identity of the component in FCM responsible for the effects on proliferation and cisplatin resistance, we charcoal stripped the FCM. Interestingly, the effects of FCM on cisplatin resistance were abolished with charcoal-stripped FCM (Fig. 20A-C). These data suggest that the components in FCM responsible for increasing resistance to cisplatin are non-polar materials such as lipids. 

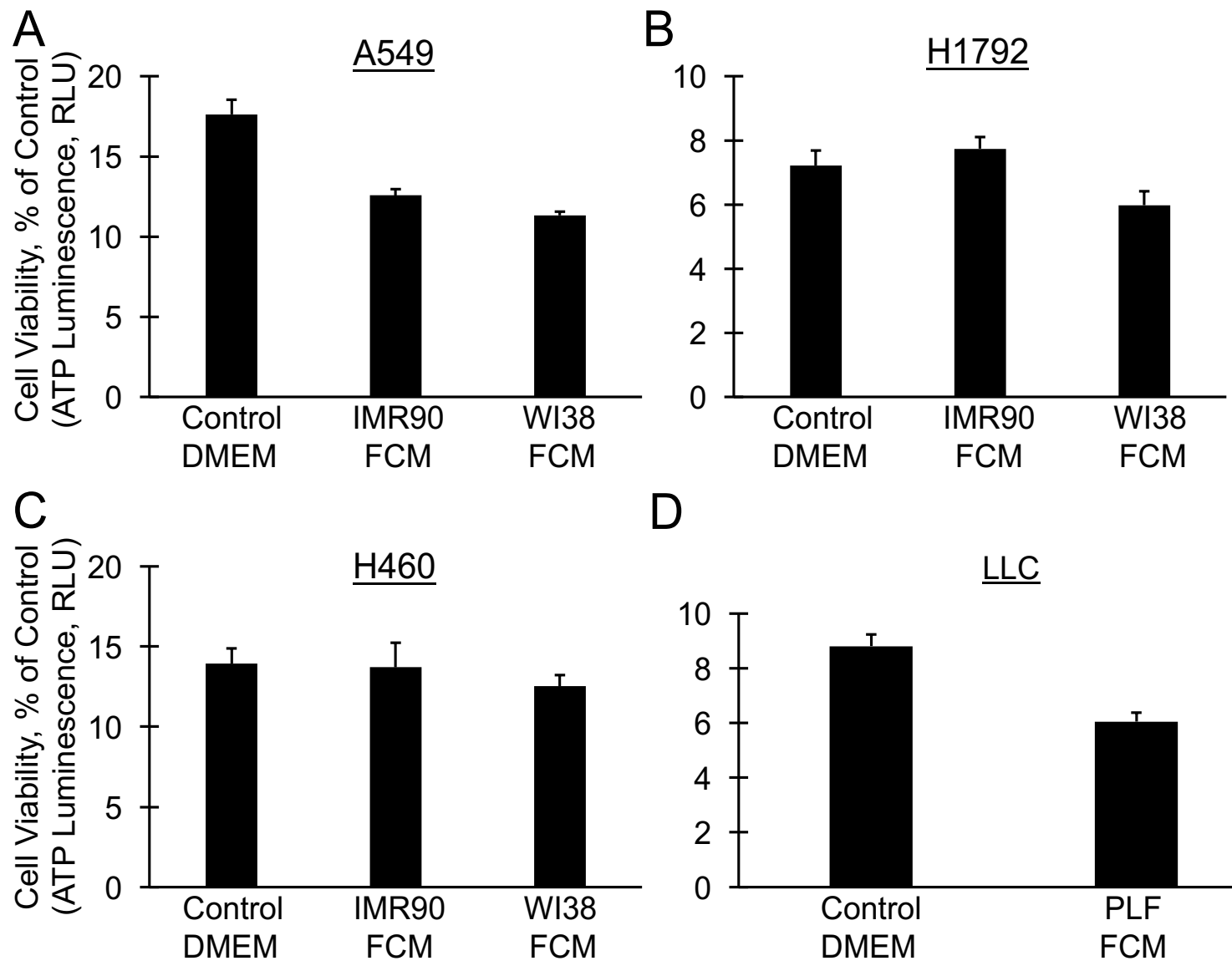

$\mathrm{D}$

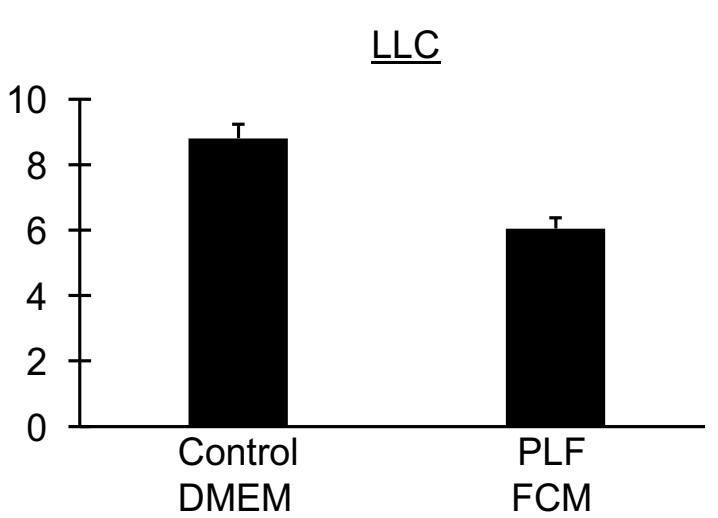

Figure 20. Charcoal-Stripped FCM Blocks Protection Against Cisplatin.

A549, H1792, H460, and LLC cells were plated in white-walled, clearbottom 96-well plates in control DMEM or FCM and allowed to grow overnight. Cisplatin $(30 \mu \mathrm{M}, 100 \mu \mathrm{M}, 30 \mu \mathrm{M}$, and $10 \mu \mathrm{M}$, respectively) was then added and cells were allowed to grow an additional 24 hours. The remaining viable cells were quantified using Cell Titer-Glo Luminescent Cell Viability Assay Kit (Promega). All cells lines tested showed a decreased sensitivity to cisplatin in response to FCM, with a greater effect being observed in $\mathrm{H} 1792$ and LLC cells. 


\subsection{Discussion}

The prevailing paradigm of cancer for decades has been that a cell acquires mutations over its lifespan that eventually lead to a malignant phenotype and the development of cancer. However, this paradigm does not tell the entire story, and we now know that stromal cells in the tumor microenvironment are not idle bystanders, but co-evolve with transformed cells and play a crucial role in cancer progression. To date, the vast majority of research in this area has focused on the role of tumor or carcinoma-associated fibroblasts [143-145], and thus it has focused on what occurs after the tumor has already developed. Fewer studies have examined the role of normal lung fibroblasts, and thus what precedes tumor development. We hypothesized that normal, unstimulated fibroblasts of the lung also represent an important component of the tumor microenvironment that helps drive tumor progression, and that old fibroblasts would have an even greater effect on lung cancer cells. Consistent with this hypothesis, our studies show that normal lung fibroblasts produce a soluble substance(s) capable of altering cancer cell morphology and stimulating proliferation, migration, and colony formation of several NSCLC lines, as well as protecting against cisplatin-induced apoptosis in vitro. We also observed an enhancement of primary tumor growth in vivo. With the exception of increased Transwell migration (not shown) however, FCM from old fibroblasts, did not show any differences compared to FCM from young fibroblasts (Table 3). 
Our observation that FCM promoted cell scattering and spreading, and a spindle-shape phenotype in three of four cell types suggested the breakdown of intercellular junctions and epithelial-mesenchymal transition (EMT). However,

\begin{tabular}{|l|l|}
\hline $\begin{array}{l}\text { Table 3. Effect of FCM from Old vs. Young PLF } \\
\text { on: }\end{array}$ & LLC \\
\hline Morphology & No Change \\
\hline Proliferation & No Change \\
\hline Transwell Migration & Increased \\
\hline Colony Formation & No Change \\
\hline Scratch Migration & No Change \\
\hline Apoptosis Resistance & No Change \\
\hline
\end{tabular}

except for increased vimentin, fibronectin and alpha smooth muscle actin levels in H1792 cells, little to no changes were observed in A549, H460 and LLC cells. These data suggest that EMT, as it is classically defined, was not responsible for the observed changes in morphology. Interestingly, at least one group has shown that the behavioral and morphological changes that accompany EMT are not necessarily linked. For example, cadherin switching is necessary for increased motility, but not the morphological changes that accompany EMT [146].

FCM affected several other processes and, as presented in Table 1, we observed differential effects of FCM on A549, H1792, H460 and LLC cells in several functional assays. For example, FCM stimulated Transwell migration in all cell lines tested, but this effect was much greater in H1792 cells. FCM increased migration across a wound in all cell lines, except H460 cells. Interestingly, colony formation was increased in $\mathrm{A} 549$ cells in response to FCM, but was unchanged in H1792 and H460 cells, and a decrease was observed in LLC cells. Lastly, FCM could protect all cell lines from cisplatin-induced death. This was accompanied by 
a decrease in the activity of caspases 3 and 7 in A549, H1792 and LLC cells, but not in $\mathrm{H} 460$ cells. There is precedent for human lung cancer cell lines behaving differently when studied in the laboratory. For example, Liang et al, demonstrated a decrease in cell proliferation in A549 cells, compared to a stimulation of cell proliferation in SK-MES-1 cells, when exposed to Budesonide, a PPAR $\alpha$ and glucocorticoid receptor agonist. This differential effect was attributed to a mutation in TP53 in SK-MES-1 cells [147]. Additionally, Ling et al, showed that overexpression of MTSS1 enhanced the invasion and proliferation abilities of H920 and $\mathrm{H} 1581$ cells, while it inhibited invasion and proliferation in SW900 cells. These differential effects were shown to be due to differences in FAK phosphorylation and activity [148]. Our observations that FCM displayed differential effects depending on what cell line was used, could explain differences observed in the literature when comparing normal fibroblasts to carcinoma-associated fibroblasts. According to the Cancer Cell Line Encyclopedia (CCLE) [149,150], a collaboration between the Broad Institute, and the Novartis Institutes for Biomedical Research and its Genomics Institute of the Novartis Research Foundation, the A549, H1792, and $\mathrm{H} 460$ cell lines used in these studies have hundreds of mutations $(785,396$, and 514, respectively). A search of the CCLE for common mutations known to NSCLC revealed interesting findings. The KRAS gene was the only gene mutated in all 3 cell lines. A mutation in the p53 gene was only observed in $\mathrm{H} 1792$ cells. STK11 was mutated in A549 and H460 cells, while STK10 was mutated in $\mathrm{H} 1792$ cells. CDKN2A is also mutated in A549 cells and $\mathrm{H} 460$ cells, but not $\mathrm{H} 1792$ cells. Lastly, there are no known mutations in the EGFR or ALK genes. The differential effects 
in response to FCM could indeed be due to these differences in the genetic profile of the cell lines used. Further research is needed in this area.

The observation that FCM protected both human cell lines and LLC cells from cisplatin-induced apoptosis through effects on caspase activity is quite intriguing as it suggests that host fibroblast-derived soluble factors, and not only physical interaction, may influence the impact of chemotherapy on tumors. Cisplatin is a recognized cornerstone in the treatment of lung cancer. Unfortunately, some tumors are unresponsive, or more quickly become resistant. To date, there are no agents in the clinic that circumvent this problem. Cisplatin acts largely by promoting the formation of DNA adducts, mainly intrastrand crosslinks, as well as inducing oxidative stress $[151,152]$. This triggers TP53 and MAPK signaling, among others, resulting in the induction of apoptosis. Thus, one must assume that the protective effects of FCM are due to inhibition of drug activity, drug uptake, or over expression of anti-apoptotic signals (e.g., bcl-2). Interestingly, our observations that FCM protected lung cancer cells from cisplatin-induced death is not in agreement with Bartling et al, who showed that conditioned media from WI38 fibroblasts could protect $\mathrm{H} 358$ cells from apoptosis induced by paclitaxel, but not by cisplatin. [153] Our data indicate that one possible approach to circumventing cisplatin resistance in the clinic would be to simultaneously target fibroblast signaling in the tumor stroma during chemotherapy. At least one group has shown that cisplatin resistance could be abrogated by inhibiting mTOR signaling [154]. 
Of all the effects of FCM, stimulation of proliferation was the most consistent in all cell lines, and interestingly, this effect was not diminished by blocking cMET (Table 2). This is intriguing because aberrant HGF/cMET signaling has been shown to promote an oncogenic phenotype in various tumor types, including lung cancers [155]. Moreover, boiling the media, blocking FGFR, and blocking the PI3K and ERK pathways also had no effect (not shown). While this proliferative effect of FCM was not observed in vivo, co-injection of fibroblasts and tumor cells together increased primary tumor growth. This is likely due to the fact that the effects of FCM are lost quickly in vivo, while fibroblasts co-injected with LLC cells persist and thus their effects are long lasting.

The activity of FCM was impressive in certain assays, but was limited in its influence in vivo in our models. Nevertheless, identifying the agent(s) present in FCM responsible for these effects might unveil potential targets for intervention that could be used in the clinic. We found that FCM was characterized by altering cancer cell morphology and stimulating proliferation, migration, and colony formation of several NSCLC lines, as well as protecting against cisplatin-induced apoptosis in vitro. We also observed an enhancement of primary tumor growth in vivo, in immunocompetent animals. Many of these effects, but importantly, not all, were due to HGF.

Altogether, these observations suggest that FCM contains not one but several factors capable of influencing tumor cell behavior. Our data showing differential effects of FCM, depending on the cell type, also indicate that the role that fibroblasts play in lung cancer progression is not as simple as a one approach 
fixes all, but is rather complex. Thus, our data suggest that targeting the tumor stroma alone, or in combination with chemotherapy, is a promising concept that warrants further study. 
CHAPTER IV

\section{THE ROLE OF REDOX AND SEX IN LUNG CANCER}

\subsection{Introduction}

Oxidative stress, classically defined as an imbalance between antioxidants and pro-oxidants, has been implicated in a number of physiological and clinical disorders ranging from aging and cardiovascular disease to pulmonary diseases, diabetes, and cancer [156-159]. However, unfortunately, large-scale interventional studies designed to shift the balance of antioxidants and prooxidants in favor of the former have failed to show significant benefits in health outcomes of several diseases [80-83]. As mentioned in the introduction to this dissertation, it was suggested that the reason for the failure of these antioxidant trials has been a misunderstanding of what oxidative stress actually is. Thus, attention towards newer and better antioxidants may not yield better results until a new definition of oxidative stress is considered, and treatment accordingly. Dean Jones at Emory University has proposed a new definition as "a disruption of redox signaling and control" [84], and has developed a way of quantifying oxidative stress as the measurement in plasma of the redox potential (Eh) for the thiol disulfide couples cysteine (Cys) and its oxidized form cystine (CySS), termed Eh Cys/CySS. This is minimally invasive and represents a measure of global redox state. Eh 
Cys/CySS has been measured in humans as well as in rats, but knowledge about the factors that influence Eh Cys/CySS in murine models is very limited, and studies in this area have used different animal models and diverse measures of oxidative stress. Taken together, these justify the use of animal models to test the impact of oxidant stress and various interventions on disease development. To gain insight into this area, we examined the effects of age, sex, fasting, and diets on the plasma Eh Cys/CySS of C57BL6 mice and what role alterations in the Eh Cys/CySS have in lung cancer progression in the LLC model of lung cancer. These studies should redirect our efforts to identify key alterations in redox signaling in oxidative stress-related diseases that will then hopefully lead to new targets for treatment.

\subsection{Materials and Methods}

\subsubsection{Reagents}

All reagents were purchased from Sigma Chemicals (St. Louis, MO) or Fisher Scientific (Pittsburgh, PA) unless otherwise noted.

\subsubsection{Cell Culture}

Lewis Lung Carcinoma (LLC; CRL-1642) cells were purchased from ATCC (Rockville, MD) and grown in DMEM supplemented with $10 \%$ FBS, at $37^{\circ} \mathrm{C}$ in a humidified $5 \% \mathrm{CO}_{2}$ incubator. The percentage of $\mathrm{CO}_{2}$ was periodically checked and recalibrated to maintain $5 \%$. Cells were used within 3 months of resuscitation. 


\subsubsection{Plasma Redox Potential Measurements}

Blood was isolated retro-orbitally under isoflurane anesthesia, using heparinized micro-hematocrit capillary tubes and immediately transferred to a 1.5 $\mathrm{mL}$ centrifuge tube containing $20 \mu \mathrm{L}$ of $\mathrm{L}$-serine, heparin, bathophenanthroline disulfonic acid, sodium iodoacetate, and $y$-glutamyl glutamate (internal standard), and spun at $16,000 \times \mathrm{g}$ for 1 minute. $100 \mu \mathrm{L}$ of supernatant were transferred to a new centrifuge tube containing $100 \mu \mathrm{L}$ boric acid and perchloric acid. Samples were mixed and frozen at $-80^{\circ} \mathrm{C}$ until further use (typically 24 hours). For analysis, samples were thawed centrifuged at $16,000 \times \mathrm{g}$ for 1 minute to remove precipitated proteins. $150 \mu \mathrm{L}$ of supernatant were then added to $30 \mu \mathrm{L}$ of iodoacetic acid in a new $1.5 \mathrm{~mL}$ Eppendorf tube and vortexed. The $\mathrm{pH}$ was then adjusted to $9.0+/-0.2$ using $1 \mathrm{M} \mathrm{KOH}$ in $\mathrm{KBO}_{4}$. Afterwards, samples were incubated at room temperature for 20 minutes after which time, $150 \mu \mathrm{L}$ dansyl chloride was added and samples vortexed and incubated 24 hours at room temperature in the dark. Lastly, $250 \mu \mathrm{L}$ $\mathrm{CHCl}_{3}$ were added and samples vortexed and analyzed by HPLC (Waters Corporation, Millford, MA) to determine molar concentrations of cysteine, cystine, glutathione, and glutathione disulfide, which were then used in the Nernst equation to determine the plasma redox potential.

\subsubsection{Animal Studies}

All experiments were approved by the Institutional Animal Care and Use Committee of the University of Louisville. LLC cells were plated out 24 hours prior to injections and were harvested at $\sim 50 \%$ confluence to ensure cells were in 
growth phase. LLC cells (1E6 /100 $\mu$ l sterile PBS) were injected subcutaneously into the hind flank of wildtype C57BL/6 mice under isoflurane anesthesia. Afterwards, tumors were monitored and measured weekly. A tumor size $>15 \mathrm{~mm}$ in any direction was considered the endpoint, per IACUC regulations. Animals were then sacrificed and tissues were harvested for analysis.

\subsubsection{Sulfur Amino Acid Diets}

Diets were custom-prepared by Harlan-Teklad and were designed to be isonitrogenous. The study was designed to evaluate the response of female mice to a diet deficient in sulfur amino acids (SAA deficient) or to a diet with excess SAA (SAA excess). The effect of these was compared to those of an SAA control diet. The deficient diet contained no cystine, and a reduced amount of methionine, while the excess diet contained $3 x$ the amount of cystine and $1.8 x$ the amount methionine compared to the SAA control diet. A fourth group of mice was fed a standard chow diet. Female mice, aged 3 months old were randomly divided into 4 groups ( $n=10$ each), and were given the following diets for 6 months: chow, SAA control, SAA deficient, SAA excess.

\subsubsection{Tissue Processing and Histological Analysis}

Animals were sacrificed by $\mathrm{CO}_{2}$ administration in a closed chamber. Lungs were flushed with PBS, inflated at standard pressure with formalin, removed, and formalin-fixed for 48 hours. Lungs were then processed through increasing ethanol solutions in an STP 120 Spin Tissue Processor (ThermoFisher Scientific, 
Waltham, MA), paraffin-embedded, and sectioned ( $6 \mu \mathrm{m})$ using a JUNG RM2055 microtome (Leica, Buffalo Groce, IL). Lung sections were then transferred onto charged, glass Colorfrost microslides (VWR Sciences, Radnor, PA) for histological analysis. Sections were deparaffinized, rehydrated, and stained with hematoxylin and eosin (HE) to evaluate lung tumors.

\subsection{Results}

\subsubsection{Plasma Eh Cys/CySS is Unchanged in Aged Mice but Females are More Oxidized Compared to Males}

Previous publications have demonstrated an oxidation of the plasma Eh Cys/CySS and Eh GSH/GSSG in aged humans [78]. To determine if this occurs in mice, plasma from young ( 3 months) and old ( 24 months) male and female mice was isolated and analyzed by HPLC for molar concentrations of Cys, CySS, GSH, and GSSG. We observed that aging did not impact the Eh Cys/CySS or the Eh GSH/GSSG in male or female mice tested at 3 vs. 24 months of age (Fig. 21AB). However, interestingly, females were more oxidized when compared to males

(Fig. 22). This was mainly due to differences in Cys concentration but not to total Cys intake. The levels of glutathione (GSH) and glutathione disulfide (GSSG) were also unchanged with regard to aging and sex. 


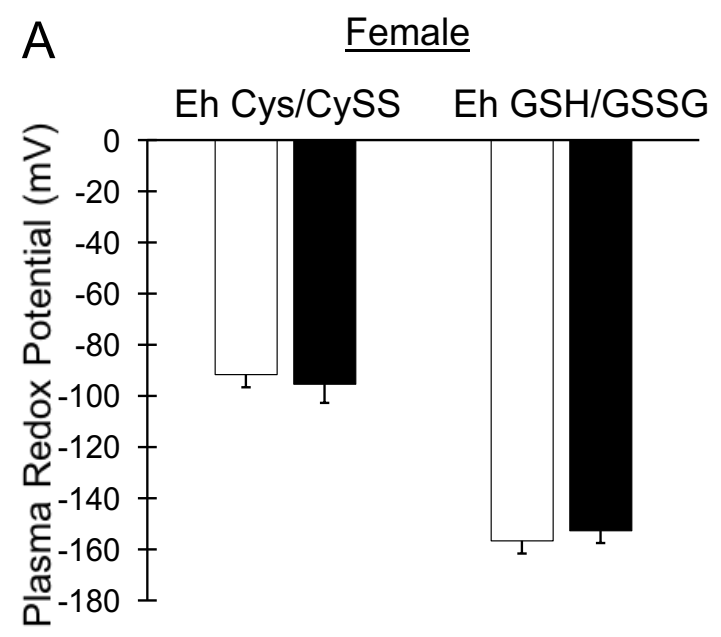

$\square$ Young $\square$ Old
B $\quad \underline{\text { Male }}$

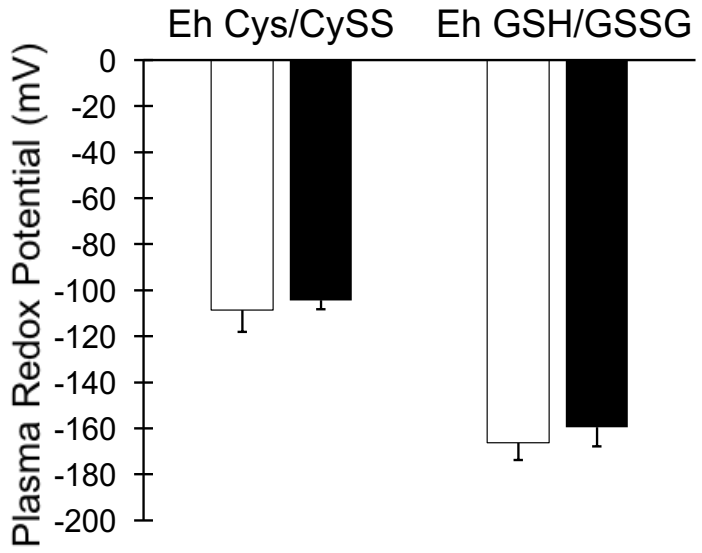

$\square$ Young $\square$ Old

Figure 21. Plasma Eh Cys/CySS and Eh GSH/GSSG are Unchanged in Old Mice

Blood was isolated retro-orbitally from young ( 3 months) and old (24 months) male and female WT C57BL/6 mice ( $\mathrm{n}=8$ in each group) under anesthesia, using heparinized micro-hematocrit capillary tubes and immediately prepared for analysis by HPLC. Plasma Eh Cys/CySS values were: young female $=-91.7+/$ $4.9 \mathrm{mV}$; old female $=-95.4+/-7.4 \mathrm{mV}$; young male $=-108.6+/-9.4 \mathrm{mV}$; old male $=-104.3+/-3.9 \mathrm{mV}$. Plasma Eh GSH/GSSG values were: young female $=-156.7$ $+/-6.6 \mathrm{mV}$; old female $=-152.7+/-4.8 \mathrm{mV}$; young male $=166.4+/-7.4 \mathrm{mV}$; old male $=-159.5+/-8.3 \mathrm{mV}$. 


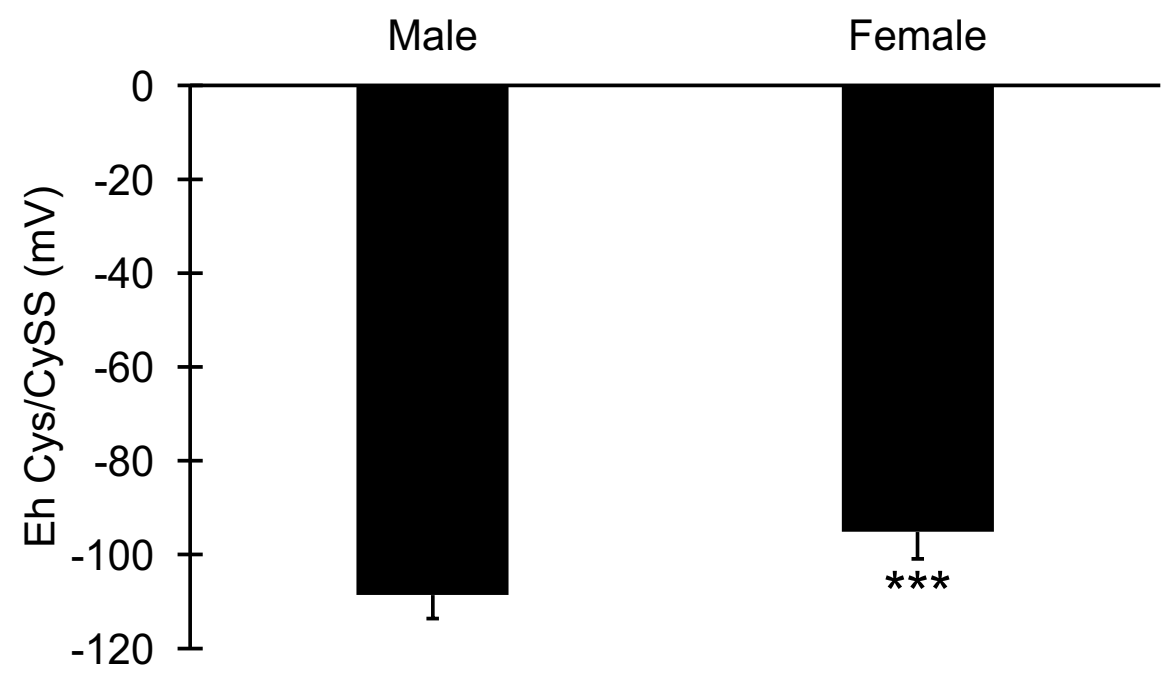

Figure 22. Female Plasma Eh Cys/CySS is More Oxidized Compared to Males Blood was isolated retro-orbitally from male $(n=10)$ and female $(n=9)$ WT C57BL/6 mice (3 months), under anesthesia, using heparinized micro-hematocrit capillary tubes and processed as described in Figure 1. Plasma $E_{h}$ Cys/CySS values were: male $=-108.6+/-5.0 \mathrm{mV}$; female $=-95.2+/-5.7 \mathrm{mV}$; Cys values were: male $=34.3$ $+/-5.9 \mu \mathrm{M}$; female $=21.5+/-3.8 \mu \mathrm{M} .{ }^{* *} P<.001$ 


\subsubsection{Female Mice are More Susceptible to LLC Lung Cancer Metastasis}

Since female mice were found to be more oxidized in their Eh Cys/CySS, and data in the literature suggests females are at an increased risk of lung cancer, we speculated they may be more susceptible to lung cancer metastasis in the LLC model. A retrospective analysis of LLC lung cancer studies in our laboratory indicated that female mice may indeed be more susceptible to lung cancer metastasis compared to males (data not shown). To test this prospectively, adult (11-12 months) male and female mice were injected subcutaneously with LLC cells and followed for tumor development. Paradoxically, tumor volume at the site of injection was smaller for female mice (Fig. 23B), while metastasis to the lung was markedly increased (Fig. 23B). 


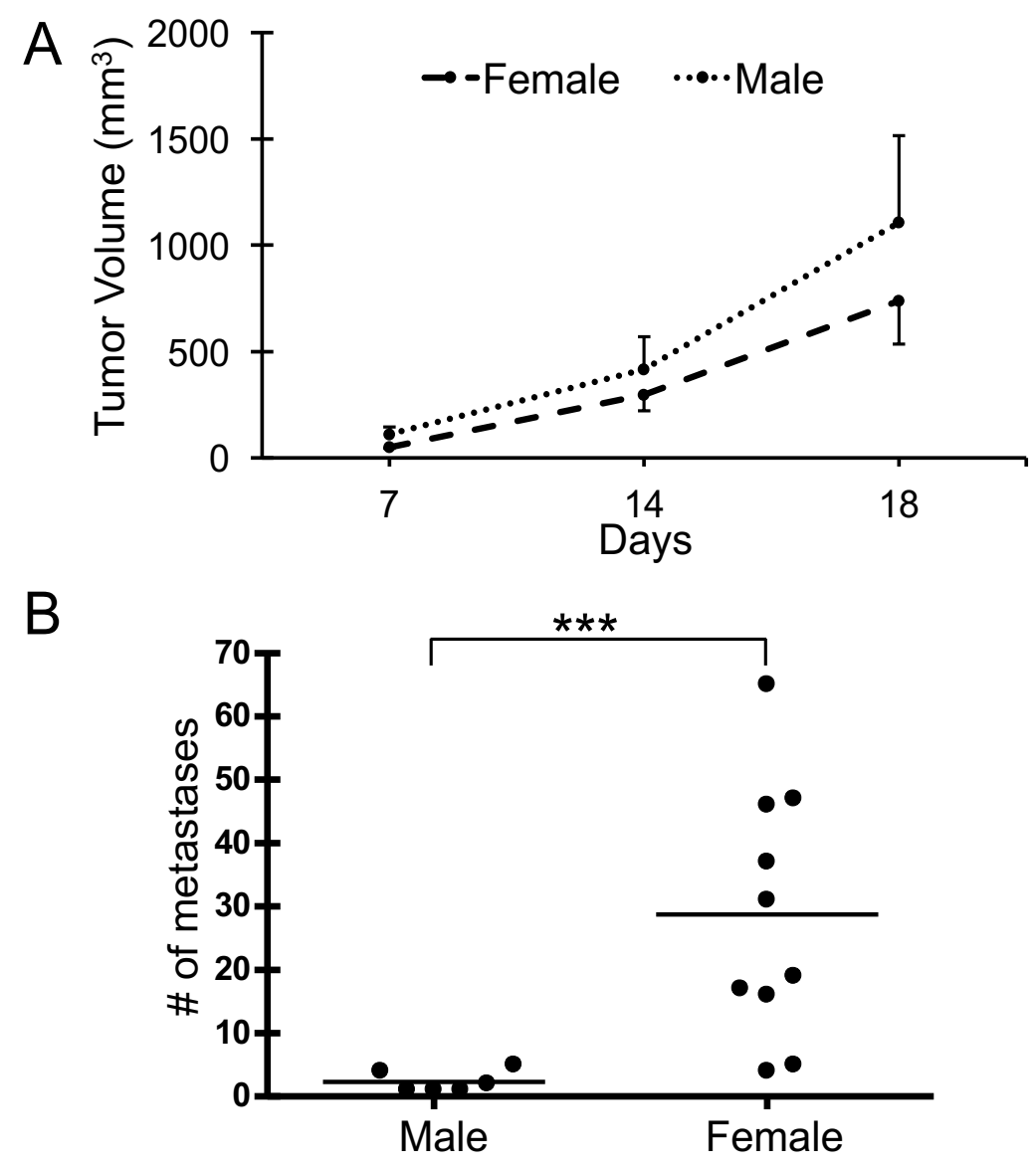

Figure 23. Female Mice are More Susceptible to LLC Lung Cancer Metastasis 1E6 LLC cells were injected subcutaneously into the hindflank of WT male (11 months, $n=6$ ) and female (12 months, $n=10)$ C57BL/6 mice. Per IACUC regulations of endpoints, tumor formation and size were followed until a tumor size of $\geq 15 \mathrm{~mm}$ in length or width was established. All mice were then sacrificed (day 18) and lungs harvested and processed for examination of metastases. Female mice developed significantly more metastases to the lung compared to male mice. ${ }^{* * *} P<.001$ 


\subsubsection{Sulfur Amino Acid Diets and Fasting Affect Plasma Eh Cys/CysS}

The observation that female mice had a more oxidized Eh Cys/CySS compared to males and were more susceptible to lung cancer metastasis in the LLC model, led us to examine whether the two were related. To test this, we first needed to determine if we could manipulate the Eh Cys/CySS in female mice. Thus, female mice were placed on diets with different concentrations of sulfur amino acids, designed to oxidize or reduce their plasm Eh Cys/CySS. Mice were placed on the diets at 3 months of age. After 6 months, plasma was harvested and processed for HPLC analysis. A diet containing excess sulfur amino acids was able to significantly reduce the plasma Eh Cys/CySS (-93.6 +/- 10.0 vs.-103.4 +/9.0 $\mathrm{mV}, P=.03$ ), while a diet deficient in sulfur amino acids was unable to significantly oxidize the mice when compared to the SAA control diet (-93.6 +/- 10.0 vs. -86.3 $+/ 6.8 \mathrm{mV}, P=.07)($ Fig. 24). There have been reports in the literature of a diurnal pattern of variation of plasma redox potential that correlated with meal intake [160].

To determine if this occurred in mice, blood was drawn from young male and female mice before and after a 24 hour fast. Interestingly, fasting did not affect Eh Cys/CySS in females, but resulted in oxidation of the males to levels similar to those of females (Eh Cys/CySS -96.2 mV vs. -98.8 mV) (Fig 25A). This oxidation was caused by a decrease in the plasma levels of Cys due to fasting $(34.3+/-5.9$ vs. $23.2+/-2.8 \mu \mathrm{M}, P<.001$ ) (Fig. 25B). 


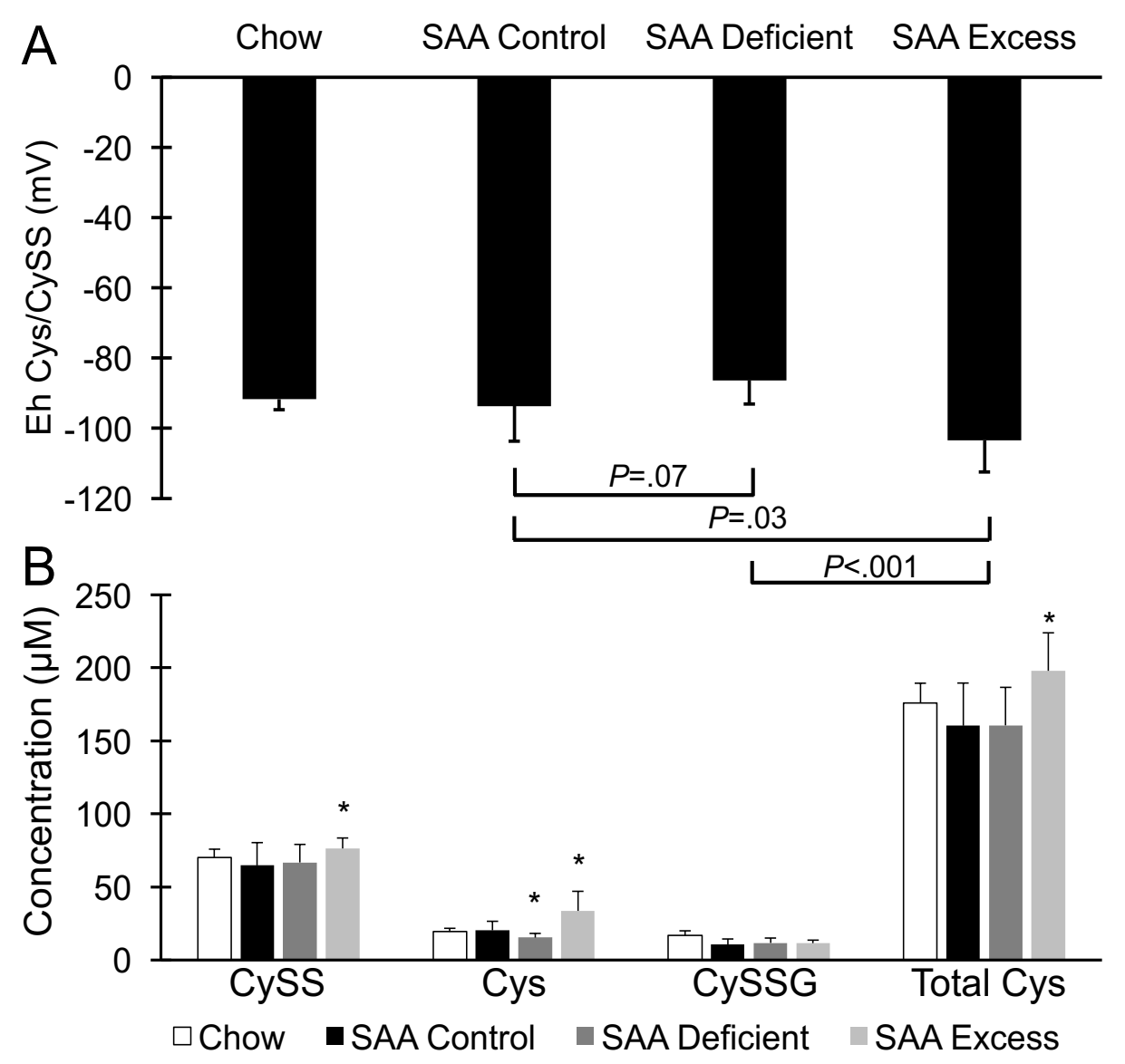

Figure 24. Diets Containing Excess Sulfur Amino Acids Reduce the Plasma Eh Cys/Cyss

Female WT C57BL/6 mice ( 3 months; $n=10$ in each group) were fed a standard chow diet, or diets with differing amounts of sulfur amino acids for 6 months. Blood was then isolated and processed as described in the methods section. (A) Plasma $E_{\mathrm{h}}$ Cys/CySS values were: chow $=-91.7+/-3.0 \mathrm{mV}$; SAA control $=-93.6+/-10.0$ $\mathrm{mV}$; SAA deficient $=-86.3+/-6.8 \mathrm{mV}$; SAA excess $=-103.4+/-9.0 \mathrm{mV}$; (B) Cys values were: chow $=19.3+/-2.4 \mu \mathrm{M}$; SAA control $=20.3+/-6.2 \mu \mathrm{M}$; SAA deficient $=15.3+/-2.9 \mu \mathrm{M} ;$ SAA excess $=33.7+/-13.4 \mu \mathrm{M}$. 

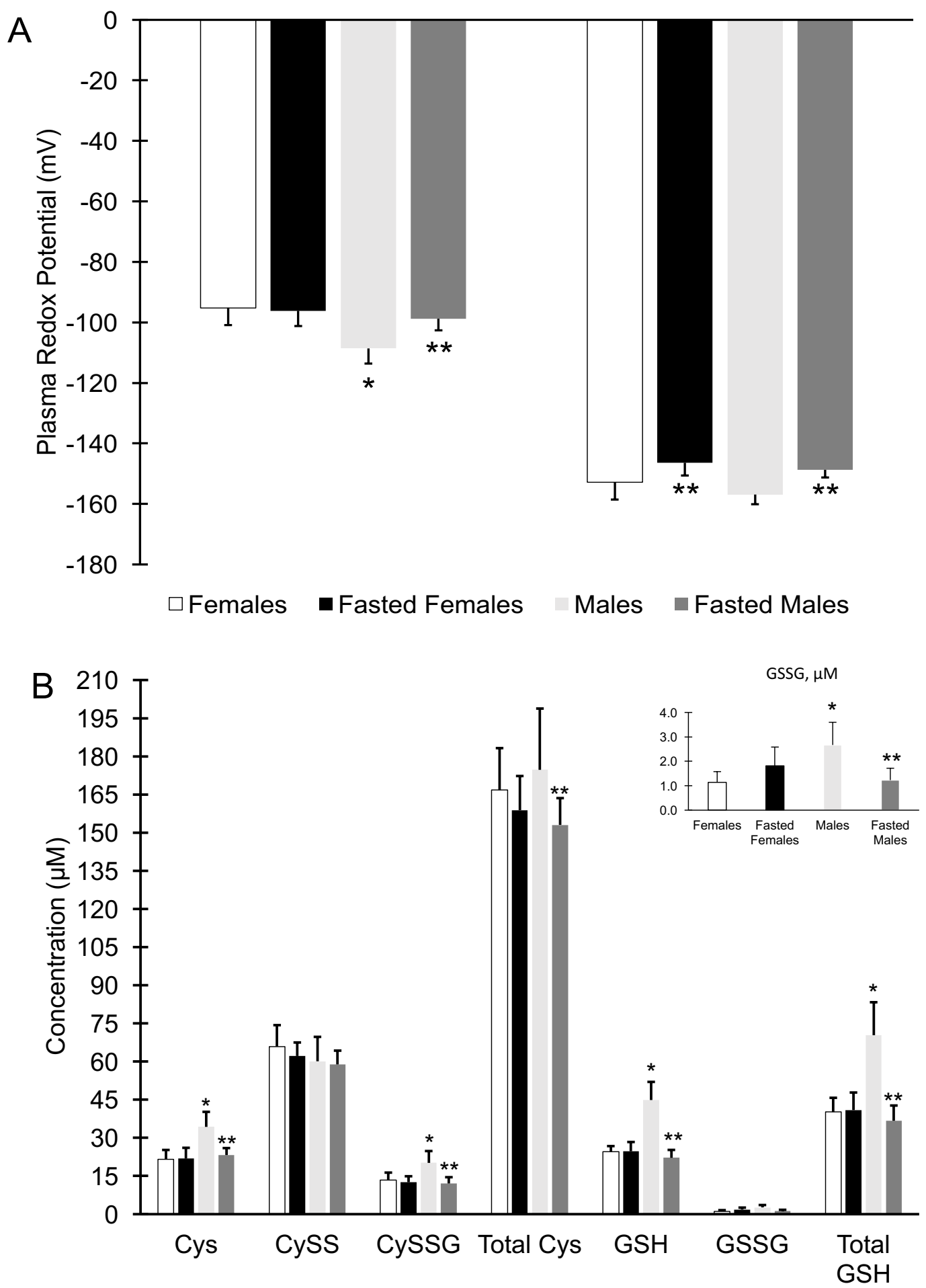

$\square$ Females $\square$ Fasted Females Males $\square$ Fasted Males 
Figure 25. Fasting Alters Plasma Eh Cys/CySS in Male Mice but Not Female Mice

Blood was isolated retro-orbitally from male $(n=10)$ and female $(n=9)$ WT C57BL/6 mice (3 months), under anesthesia, using heparinized micro-hematocrit capillary tubes and processed as described in Figure 1. Mice were allowed to recover for one week and were then fasted for 24 hours. Blood was again drawn and processed in the same manner. (A) Unfasted plasma $E_{h}$ Cys/CySS values were: male $=-108.6+/-5.0 \mathrm{mV}$; female $=-95.2+/-5.7 \mathrm{mV}$. Fasted values were: male $=$ $-98.8+/-3.8 \mathrm{mV}$; female $=-96.2+/-5.0 \mathrm{mV}$. (B) Unfasted Cys values were: male $=34.3+/-5.9 \mu \mathrm{M}$; female $=21.5+/-3.8 \mu \mathrm{M}$. Fasted Cys values were: male $=23.2$ $+/-2.7 \mu \mathrm{M}$; female $=21.8+/-5.9 \mu \mathrm{M} .{ }^{*}=$ significant difference between unfasted males and females. ${ }^{* *}=$ significant difference due to fasting. 


\subsubsection{Alterations in Plasma $E_{h}$ Cys/CysS Have No Effect on LLC Lung Cancer}

\section{Progression}

Having characterized the effects of the SAA diets in mice, we set out to determine if oxidation of the plasma Eh Cys/CySS in female mice was the cause of their increased susceptibility to lung cancer metastasis. To test this, we injected LLC cells into adult female mice on the aforementioned SAA diets. As depicted in Fig. 26, oxidation of the Eh Cys/CySS had no effect on the percentage of animals that developed lung metastases (A), or the number of metastases in the lung (B). 


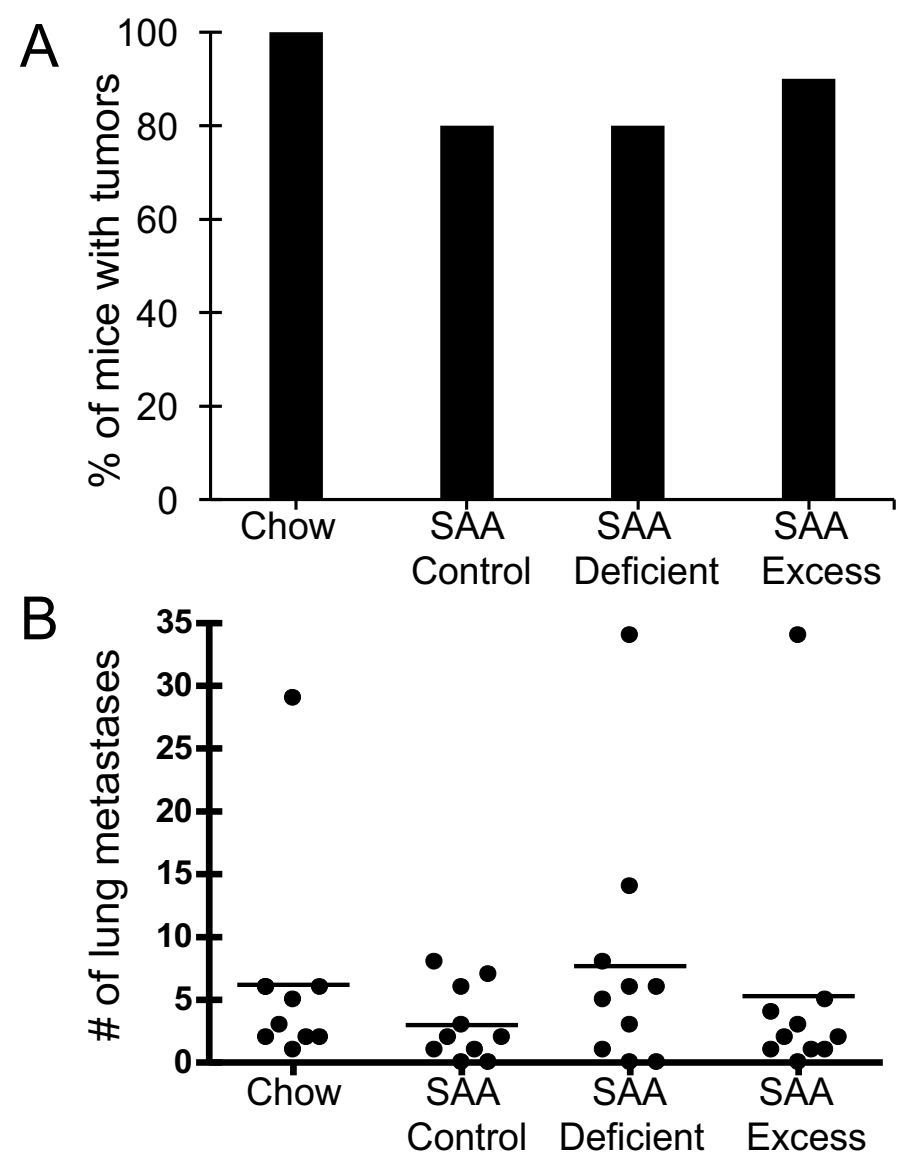

Figure 26. Alterations in Plasma $E_{h}$ Cys/CySS Have No Effect on LLC Lung Cancer Progression

Mice on SAA diets (described in Figure 4) were injected 1E6 LLC cells at 9 months of age subcutaneously into the hindflank and followed for tumor size. Once tumors reached a size of $15 \mathrm{~mm}$ in any direction, all mice sacrificed, and lungs harvested and processed for examination of metastases. No differences were observed in the percentage of mice in each group that developed tumors $(A)$, nor were differences observed in the number of metastases in the lungs of animals in each group (B). 


\subsection{Discussion}

Oxidative stress occurs with aging and is associated with multiple agerelated diseases, such as type-2 diabetes and cardiovascular disease. Noninvasive methods to quantify oxidative stress have been lacking until recently. Moreover, a misunderstanding of oxidative stress and treatment accordingly, has led to the dismal failure of clinical trials in several large-scale interventional studies. Cysteine and its disulfide form cystine, form the major low molecular weight thiol/disulfide pair in extracellular fluids. Emerging evidence has shown that the balance between cysteine and cystine, measured as their redox potential (Eh Cys/CySS), can be a marker of oxidative stress and thus an important health determinant. Dean Jones has shown that in young, healthy individuals, the Eh Cys/CySS is around $-80 \mathrm{mV}$ [161] and that this value becomes more oxidized with age [78], smoking [162] and disease, such as cardiovascular disease [79]. Taken together, these data warrant the need for the development of murine models in order to study oxidative stress further, as well as means of intervention. We thus set out to study oxidative stress in a murine model, and what role this had in lung cancer progression in the LLC model. Several observations were made as summarized below.

First, no changes were observed in either the Eh Cys/CySS or the Eh GSH/GSSG with regard to aging in male or female mice. This is interesting because the progressive oxidation of Eh Cys/CySS and the Eh GSH/GSSG in humans has been shown to occur with aging, at a pace of $0.7 \mathrm{mV}$ per year after age 45 for the Eh GSH/GSSG, and $0.2 \mathrm{mV}$ a year from age 18 onward for the Eh 
Cys/CySS [78], [163]. Eh Cys/CySS values in our studies ranged from $-91.7+/-$ $4.9 \mathrm{mV}$ to $-108.6+/-9.4 \mathrm{mV}$ which is consistent with the range reported for mouse plasma [164], but more reduced compared to human plasma [78]. Likewise, values for the Eh GSH/GSSG ranged from $-152.7+/-4.8 \mathrm{mV}$ to $166.4+/-7.4 \mathrm{mV}$, again, slightly more reduced compared to human plasma. The difference of $\sim 50 \mathrm{mV}$ between these thiol/disulfide couples indicate that they are not in equilibrium, and thus the classical definition of oxidative stress as simply an imbalance between pro-oxidants and anti-oxidants, is simple unacceptable. These data are important and suggest that murine models may not be acceptable models to study the progressive oxidation of thiol-disulfide couples that occur with aging. Although we observed no effect with aging, we did observe that female mice were oxidized in their Eh Cys/CySS, but not in their Eh GSH/GSSG when compared to males, regardless of age. Studies in humans have showed no differences in regard to sex, but these studies were not designed specifically to examine the role of sex, and are therefore not conclusive. The reasons for these differences in female mice remain unexplained.

Second, we observed that while female mice developed smaller tumors at the site of injection, they were more susceptible to lung cancer metastasis in the LLC subcutaneous model of lung cancer. It has been reported in humans that females typically have smaller tumors [165]. There are also numerous studies in the literature detailing an increased risk of lung cancer in humans in both smokers and particularly in never-smokers $[99,166-170]$. Several mechanisms have been proposed, but of particular interest is the role of estrogens, which have been 
proposed to lead to increased amounts of oxidative DNA damage [171,172]. Smoking has been shown to increase the levels of CYP1B1, which is expressed in the lung. CYP1B1 then metabolizes estrone (E1) and 17 $\beta$-estradiol (E2) into the catechol estrogens, 4-OHE1 and 4-OHE2, respectively. These catechol estrogens then lead to DNA damage $[173,174]$. It is important to note that others are not in agreement with the notion that females are more susceptible to lung cancer $[175,176]$.

Third, we showed that we were able to significantly reduce the Eh Cys/CySS in female mice using diets that were deficient in certain sulfur amino acids. We were, however, unable to significantly oxidize these same animals by using diets with excess amounts of sulfur amino acids. This has been evaluated in rats, where a diet deficient in SAA was shown to significantly oxidize the Eh Cys/CySS, and diet with excess SAA was able to significantly reduce the Eh Cys/CySS [177]. It has been shown that oxidative stress is reduced in those consuming a Mediterranean diet [178]. There is also evidence showing that tissue levels of GSH can be affected by dietary inducers [179]. Thus, there is a need to understand the dietary factors that affect Eh Cys/CySS and Eh GSH/GSSG. The data presented here are important in that they allow for interventional studies in a murine model, which will possibly help shed light on what occurs in humans [180].

Lastly, the increased susceptibility of female mice to lung cancer metastasis does not appear to be due to the fact that they are more oxidized in their Eh Cys/CySS. The canonical view of oxidative stress in terms of cancer is that ROS contribute to malignant progression of tumors by promoting, among others, 
genomic instability. Indeed, oxidative stress has been shown to promote cancer progression in several studies, evidenced by the use of antioxidants. For example, Gao et al., reported anti-tumorigenic effects of $\mathrm{N}$-acetyl cysteine (NAC) and vitamin C in multiple tumorigenic murine models. It was shown that this effect was not only due to decreased levels of DNA damage, but also to decreased levels of HIF [181]. NAC was also shown to slow tumor progression in p53-dependent mouse model of lymphomagenesis [182]. However, paradoxically, others have shown that oxidative stress can inhibit cancer metastasis. Wu et al., showed that the ability of isothiocyanates to decrease the metastatic potential of NSCLC lines was due to their induction of oxidative stress [183]. Additionally, Piskounova et al., reported that anti-oxidants promoted distant metastasis of melanoma cells in NSG mice, while having no effect on the growth of the primary tumor [184]. These latter observations, among others, have posited some to describe metastasis as an escape from oxidative stress [185]. Our studies involving SAA diets were unique, in that they could test whether or not oxidative stress could inhibit or promote metastasis. If oxidation of the Eh Cys/CySS was important in LLC lung cancer progression, the biggest difference would be observed between SAA excess and SAA deficient diet groups. However, we observed no differences in lung cancer metastasis between these groups. It could be argued that one of the reasons we failed to see differences is due to a small $\mathrm{mV}$ change due to the diets $(10-15 \mathrm{mV})$. However, a $15 \mathrm{mV}$ change in redox potential, will cause a 5-fold change in a dithiol/ disulfide motif [186]. Another explanation may be related to the short time frame 
of the studies, which cannot possibly mimic the human conditions where exposure to pro-oncogenic factors may last years.

Taken together, this work extends our understanding of redox changes with regard to aging and fasting, 2 major life processes. It was surprising that while a 24 hour fast was able to significantly oxidize male mice, aging had no effect on redox state in either sex. Interestingly, this same phenomenon has been observed in Drosophila melanogaster [187]. These data suggest that redox processes are more complicated than previously suspected and warrant additional research. 


\section{CHAPTER V}

\section{SUMMARY AND DISCUSSION}

\section{$\underline{5.1 \text { Restatement of Goals }}$}

Lung cancer occurs almost exclusively in elderly individuals. In fact, only 3$5 \%$ of lung cancers occur in individuals under the age of 40 . Aging is characterized by multiple abnormalities, such as increased oxidative stress, chronic inflammation, decreased immune function, and alterations in tissue ECM. Lung cancer also commonly occurs in those with pre-existing pulmonary diseases such as COPD and IPF (also increased in the elderly), which are marked by lung inflammation and tissue remodeling. Although the majority of lung cancers occur in former or active smokers, only $20 \%$ of lifetime smokers will acquire lung cancer. Moreover, data in the literature using old animals to study lung cancer are scarce, contradictory, and usually evaluated only primary tumor growth at the site of injection [188]. For this reason, we set out to explore what host factors in the elderly are responsible for the increased susceptibility to lung cancer, by testing the following hypothesis: while smoking and other environmental exposures can lead to lung cancer development in a genetically susceptible individual, increased oxidation of the Eh Cys/CySS in the aging lung creates an oncogenic microenvironment, specifically by increased fibronectin EDA levels, that renders 
the host susceptible to lung cancer progression (Figure 1). Several observations were made as summarized below.

\subsection{Main Findings of This Dissertation}

Through both subcutaneous and intravenous injection of LLC cells, we showed that aged $\mathrm{C} 57 \mathrm{BI} / 6$ mice were more susceptible to lung cancer progression, marked by increased metastases to the lung in the subcutaneous model, and an increased number of tumors in the lung in the intravenous model. This effect of aging is in agreement with those of Gozez and Trainin who showed tumor incidence and growth rate of the primary tumor was increased in direct proportion to age in C57BI/6 mice injected subcutaneously with LLC cells (metastasis was not evaluated) [189]. Yuhas and Ulrich also showed an increase in lung tumors with aging using Line 1 cells [190]. In contrast, Ershler found decreased survival and increased metastasis in younger animals using LLC cells and B16 melanoma cells [191]. Lastly, Anisimov and Zhukovskaya, using LLC cells, showed no effect of age on the growth of the primary tumor or survival (metastasis was not evaluated). [192]. These contradictory reports suggest differences in animal models and methodology, while emphasizing the need for further research in this area. Interestingly, one of the proposed causes of these discrepancies has been the sex of mice used, as many of the earlier studies did not indicate what sex was tested. In this dissertation, we have outlined that female mice are indeed more susceptible to lung cancer metastasis in the LLC model when compared to males, and develop larger tumors at the site of injection. Our data clearly showed that aging renders 
the host susceptible to lung cancer progression in the LLC model. This 'aging effect' does not appear related to tumor implantation, growth, or metastasis from the primary tumor, and the effects of immunity appear limited. Instead, the aging effect appears to be 'lung dependent'. Our lab has previously shown that the aged murine lung is characterized by a pro-fibrotic phenotype. Considering this, we hypothesized that the aging effect related to the extracellular matrix deposited in the microenvironment. To test this, we engaged in studies using fibronectin EDA KO mice. However, we showed that fibronectin EDA was not important for lung cancer progression in uninjured lungs.

Fibronectin EDA is increased in the aged lung and has been shown to be a vascular marker for solid tumors and metastases. Moreover, immunization against fibronectin EDA decreases tumor burden and lung metastases in the MMTV-PyMT transgenic model of metastatic mammary carcinoma. This and other observations justify testing fibronectin EDA. Nevertheless, we observed no differences in primary tumor growth, or metastases to the lung in the LLC model when using fibronectin EDA KO mice. As mentioned in the Future Studies section, studies are ongoing using KRAS mice to determine if EDA has a role in lung cancer development.

Third, by using the bleomycin model of pulmonary fibrosis, followed by injection of LLC cells, we showed that lung inflammation/tissue remodeling increased metastases to the lung, but only in aged mice, and not young mice. Due to reports that fibronectin EDA KO mice were protected from bleomycin-induced pulmonary fibrosis, we chose to use these animals to begin to determine the 
mechanisms increased tissue remodeling in the lung played in LLC lung cancer progression. In our hands, fibronectin EDA KO mice were found to develop the same degree of pulmonary fibrosis as WT mice. We repeated these experiments several times in both male and female mice. Surprisingly, despite the presence of pulmonary fibrosis, bleomycin was unable to increase metastases to the lung in fibronectin EDA KO mice, suggesting that EDA plays a crucial role for lung cancer progression in the setting of aging and lung injury. In WT animals treated with bleomycin, we observed that $\sim 90 \%$ of metastases to the lung occurred in areas of fibrosis. This was not observed in fibronectin EDA KO mice, which suggests that EDA acts a scaffold for the recruitment and organization of tumor cells in the lung. This is consistent with our observation that most metastatic lesions co-localized with areas of tissue remodeling. Additionally, in vitro, we observed that fibronectin EDA increased proliferation and migration of LLC cells.

Fourth, we found that immunity played an important role in age-related susceptibility to lung cancer progression in the LLC model. The differences in young vs. old WT mice were abolished in NSG mice. Young NSG mice developed metastases to the lung while young WT animals did not, suggesting that young WT animals are able to successfully mount a defense against lung cancer progression. While the number of metastases to the lung in aged NSG mice was still greater than those in young NSG mice, this was not statistically significant. However, importantly, the size of the lung tumors in the aged NSG mice were significantly larger than those observed in young NSG mice. These data support our hypothesis that the microenvironment of the aged lung (specifically alterations in ECM 
proteins) itself renders the host susceptible to lung cancer progression. The cause of the differences in location of lung metastases in WT vs. NSG mice remain unexplained.

Fifth, we observed no changes in the oxidation of either the Eh Cys/CySS or the Eh GSH/GSSG with aging in mice. Oxidation of these thiol/disulfide couples has been shown to occur in humans, and our lab has previously reported that oxidation of the Eh Cys/CySS in lung fibroblasts alters matrix gene expression, specifically, increased expression of fibronectin and the growth factor TGF $\beta$. For these reasons, we hypothesized that the increased susceptibility of old mice to lung cancer progression was due to oxidation of the Eh Cys/CySS, which led to altered matrix composition in the old lung. While this was not found to be the case, we observed that female mice were more oxidized in their Eh Cys/CySS, but not in their Eh GSH/GSSG, when compared to males. We also observed that female mice were more susceptible to lung metastases in the LLC model. To determine if these were related, we engaged in studies using SAA diets. We were able to significantly reduce the Eh Cys/CySS in females to levels observed in males. However, this had no effect on lung metastasis to lung, suggesting that oxidation of thiol/disulfide couples has no role in aging or lung cancer progression in mice. We suspect that the time frame of the experiments prevented us from observing a differential effect. Our studies were performed within weeks of the intervention, while humans are likely oxidized for years prior to the latter promoting alterations in ECM composition and having a pro-oncogenic effect. Either way, it remains to be determined why aged, female WT mice are more susceptible to lung cancer 
progression in the LLC model. Interestingly, females were found to have increased levels of fibronectin EDA in whole lung homogenates (Fig. 27).

Lastly, we showed that normal, untransformed lung fibroblasts play an important role in lung cancer progression. Fibroblasts are the predominant cell type in the tissue stroma and are the main source of ECM proteins. As such, they play prominent roles in tissue remodeling and thus pulmonary fibrosis. Our lab has also shown that old fibroblasts have defects in control of their redox state. This was found to be due to a 10-fold decreased expression of the Slc7a11 subunit of the xCT cystine-glutamate transporter in primary lung fibroblasts harvested from 24month old mice. For this reason, we engaged in studies evaluating the role that young and old fibroblasts played in lung cancer progression. Based on the vast number of reports in the literature studying cancer-associated fibroblasts (albeit few in the lung), we hypothesized that 'normal' young fibroblasts would play little to no role in lung cancer progression and that old fibroblasts would. Surprisingly, FCM from normal young fibroblasts was found to alter the morphology of several lung cancer cell lines, as well as increase their proliferation, confer resistance to cisplatin, increase colony formation, increase Transwell migration, and increase wound healing. Little differences were observed between the effect of FCM from young and old fibroblasts. Despite large differences observed in vitro in response to FCM, we observed no differences in vivo in metastases to the lung or growth of the primary tumor. We did, however, observe larger tumors at the site of injection when LLC cells were co-injected with PLF. 

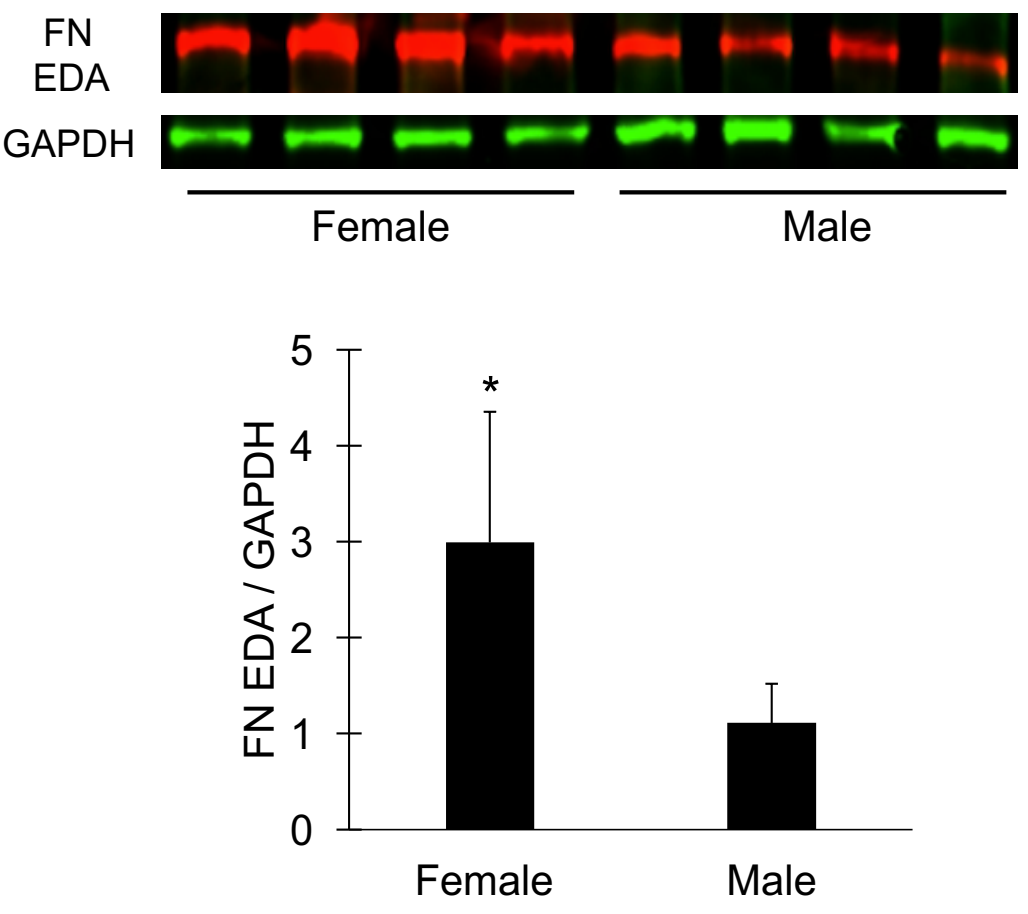

Figure 27. FNA EDA Protein Levels in Female and Male Whole Lung Homogenates

Protein was isolated from female $(n=4)$ and male $(n=4)$ murine whole lung homogenates followed by Western Blot analysis for FN EDA (Abcam, ab6328; 1:400) and GAPDH (Sigma, G9545; 1:10,000). Blots were scanned on a LI-COR Odyssey CLx imaging system and analyzed in Image Studio (LI-COR). Quantification was performed using ImageStudioLite software. ${ }^{*} P<.05$ 
Fewer people are dying today from lung cancer than ever before, a fact to be celebrated, but one that is due largely to a decreased incidence of lung cancer due to fewer smokers, rather than better treatment and early detection strategies. The dismal five-year survival rate for lung cancer remains below $20 \%$ and over one million people will still die worldwide from lung cancer every year. While the number of lung cancers due to tobacco use is declining, smoking rates remain over $30 \%$ for most countries worldwide, and the use of e-cigs is increasing each year at an alarming pace. While the vast majority of lung cancers occur in those who have histories of, or who currently are, smoking, only $20 \%$ of smokers will acquire lung cancer. There are also a large number of individuals who develop lung cancer who have never smoked a day in their lives. These data suggest that other factors are also important in predisposing individuals to the development of lung cancer. This observation formed the basis for this work. The data presented in this dissertation can be summarized by the following: age-dependent host factors, including immunity and fibroblast-derived factors, influence lung cancer progression. Importantly, lung inflammation/tissue remodeling augments pulmonary metastasis in the aging lung, but not in young lungs, through mechanisms involving fibronectin EDA, which perhaps provides a scaffold for tumor cell proliferation, organization, and migration. These events seem to be amplified in females, suggesting a role for sex. We could find no role for redox oxidation in lung cancer progression. These data point to an interplay between lung aging and inflammation/remodeling in lung tumor progression. This dissertation underscores the need for further studies in the role of the host to unveil new anti-lung cancer therapies. 


\subsection{Strengths and Weaknesses}

\section{Strengths}

The work presented here has several strengths that have helped shed light on how age-dependent host factors influence lung cancer progression. First, this works unveils a previously unknown role for fibronectin EDA in lung cancer progression. Of particular interest is that EDA only plays a role in the aged lung, in the setting of lung injury. In our model, it did not play a role in uninjured lungs in young or old animals.

Second, the use of multiple assays, several lung cancer and lung fibroblast cell lines as well as primary fibroblasts, and the complementary use of in vitro and in vivo models, allowed us to address an area for which there is no perfect model. All models, by nature, simplify the complexity human diseases. Of particular importance is our use of both immunocompetent and immunocompromised animals. While xenografts in immunocompromised animals are important in being able to study human cell lines by avoiding host rejection, they rarely metastasize and they do not allow one to dissect the role of host immunity in tumor growth and metastasis. This is a major drawback, as metastasis is what often kills patients. Studies often focus on the primary tumor, which is usually resected in the clinic. Our use of NSG mice was not to study human cell lines, but to determine what role, if any, immunity had in observations in immunocompetent animals.

Lastly, the work presented here allowed for the careful characterization of the murine model of lung cancer by addressing a diverse range of host factors 
ranging from age to redox to sex to tissue remodeling, many of which are observed in humans.

\section{Weaknesses}

The work described here is by no means perfect. Science is based on experiments and observations, both of which can be flawed, which can then lead to flawed conclusions. Thus, it is imperative that the work be replicated and expanded to test mechanisms of action and potential interventions.

One weakness of this work is the use of the Lewis Lung Carcinoma model of lung cancer. While this model has been used extensively over the years, and much is known about it, it does not completely represent lung cancer development in the human. This is the case for all syngeneic and xenograft models. For this reason, studies in are lab our ongoing using the KRAS model of spontaneous lung cancer development (see future directions).

Another weakness is that, other than the studies utilizing isolated primary lung fibroblasts, fibronectin EDA KO mice, and CMET inhibitors, there are limited mechanistic data. This is understandable as studies characterizing the model had to be completed first. Studies evaluating receptor function and intracellular signaling pathways will need to be performed in the future.

Fibronectin EDA was shown to be necessary for the increased susceptibility of the injured, aged lung to lung cancer metastasis. Admittedly, strategies for targeting fibronectin would be limited due to the high concentration of fibronectin in the plasma and other organs, but much work is being done in this area. Perhaps 
a better approach would be to target fibronectin recognition by blocking its association with its various integrins [193].

\subsection{Future Directions}

Good science always raises more questions than it answers, and the work presented here is no different. There are several observations that remain unexplained in three keys areas presented in this dissertation:

\subsubsection{How does aging impact cancer progression?}

While we were able to show, in studies utilizing NSG mice, that immunity played a role in the increased susceptibility to lung cancer progression in the aged mice, there were still differences observed with aging (larger tumors in the lung), suggesting that other factors besides immunity play a role. In addition to the role of fibronectin EDA, it would be interesting to test which integrins mediate this effect and what other ECMs, the various collagens, for example, influence cancer progression.

We also plan to perform additional studies as outlined here, but with the B16 melanoma cell line. These studies will be important to determine if the effect of aging that we observed is truly due to intrinsic factors in the host, or to intrinsic properties specific to LLC cells.

As mentioned previously, there are limitations to using syngeneic and xenograft models, as they do not fully recapitulate the human condition (e.g. angiogenesis and tissue microenvironment). For this reason, we plan to perform 
additional studies using the KRAS model of spontaneous lung cancer development. KRAS is a potent oncogene that is mutated in $30 \%$ of human NSCLC cases [194]. This leads to a constitutively active pathway and the spontaneous development of lung carcinomas, which more closely resembles the human condition. By breeding fibronectin EDA mice with KRAS mice, we have developed animals that are lacking fibronectin EDA and that also spontaneously develop tumors. This will allow to evaluate the role of fibronectin EDA in lung cancer development. Studies are ongoing in our lab in this area.

Lastly, one must consider the role that epigenetics plays, not only in the aging process itself, but also in age-related disease susceptibility. Epigenetics refers to the study of inheritable changes in gene function without alterations to the underlying DNA sequence. This is important as it provides a target for intervention. At present, changes to the DNA sequence in humans are irreversible. The deterioration of cellular functions that occur with aging are characterized by epigenetic changes, which may be due to both internal and/or external stimuli [195]. Several epigenetic changes occur in aging including chromatin remodeling $[196,197]$, but one of the best characterized modifications involve alterations in DNA methylation patterns at CpG sites in gene promoter regions, which typically become hypomethylated (hypermethylation has been observed in certain regions [198]) with age, and ultimately affect gene expression by preventing access of RNA polymerase II [199]. This age-associated CpG hypomethylation is similar to global hypomethylation observed in most cancers and may provide a potential link between epigenetics and age-related cancer susceptibility in the elderly population 
[200]. Indeed, it was recently shown that standardized measures of intrinsic epigenetic age acceleration (IEAA) were significantly associated with lung cancer incidence in aged females, suggesting that IEAA might serve as a useful biomarker for determining lung cancer susceptibility [201].

\subsubsection{What is the identity of soluble factor(s) in FCM that promote lung cancer?}

We were able to identify and determine that HGF was responsible for several, but importantly not all, of the effects of FCM we observed in vitro. We were also able to rule out several components. Of interest were our data showing that charcoal-stripping of the FCM was able to prevent the protection from cisplatin in several NSCLC lines tested in vitro, although it was unable to block the mitogenic effect of FCM. This indicates that a non-polar, possibly lipid-based molecule is responsible for these effects. Additional work will need to be performed to discover the identity of this molecule(s).

\subsubsection{What is the role of sex in lung cancer progression?}

In these studies, female mice were found to be more oxidized in their Eh Cys/CySS and were more susceptible to lung cancer progression in the LLC model. Our studies with the SAA diets suggested that these two were not related. This could however be due to limitations inherent in the SAA diets or the timing of the experiments. To investigate this further, we plan to treat female mice with sulforaphane, an isothiocyanate compound obtained from cruciferous vegetables 
that has been shown to reduce the Eh Cys/CySS by increasing the levels of Slc7a11, a cystine-glutamate transporter. We also plan to repeat studies with the SAA diets in males, as we only performed studies using females.

One observation that remains unexplained is the increased oxidation of the Eh Cys/CySS in female mice. It is unknown if this also occurs in humans, or if this is simply a murine phenomenon. There is at least one report in the literature detailing increased oxidative stress in female C57BL/6 mice compared to males, as determined by electron para-magnetic resonance spectrometry and dihydroethidium oxidation in the brain [202]. Nevertheless, the factors responsible for this observation could explains other differences in female humans, such as an increased incidence of COPD in never-smokers.

Lastly, we observed that aged female mice had more fibronectin EDA protein levels in whole lung homogenates when compared to males. Whether this plays a role in their increased susceptibility to lung cancer progression in the LLC model remains to be seen.

Whenever the topic of sex is being investigated as a biological variable, one must take into account the obvious: the role of sex hormones. For this, we plan to repeat many of the studies described here, but in ovariectomized females, or castrated males. If differences are observed, then studies will again be repeated with hormone replacement using estradiol in females and testosterone in males. These studies will shed light on the role that sex hormones play in lung cancer progression and oxidative stress in males and females. 


\subsubsection{Could SAA diets play a role in prevention?}

While our studies using SAA diets suggested that neither oxidation of the Eh Cys/CySS or the Eh GSH/GSSG played no role in lung cancer progression, this could be due to limitations of the LLC model. For this reason, we plan to repeat experiments with the SAA diets in KRAS mice, which spontaneously develop lung tumors, to determine what role, if any, thiol/disulfide couples play in lung cancer development. Exposure of animals to the diets for prolonged periods of time would also help further define this observation.

\subsubsection{What is the role of the lung microbiome?}

An emerging and exciting area of research pertains to the role of the microbiome (used synonymously with microbiota) in both normal and diseased states. The microbiome refers to the abundant and diverse bacterial, fungal, viral, and archaea populations that exist on and within the human body. In 2008 , the $\mathrm{NIH}$ launched the Human Microbiome Project (HMP), which was tasked with studying how changes in the human microbiome associated with health and disease. The microbiome indeed has been shown to play crucial roles in maintaining normal homeostasis in the body, but has also been found to be altered in several disease states [203]. The most extensively studied microbiome is in the gut, which has the highest density of microorganisms in the body, with approximately $10^{14}$ bacteria [204]. Astonishingly, it has been reported that every human is host to trillions of bacterial cells, whose genome, in the gut, for example, contains at least 100 times as many genes as our own genome [205]. Alterations in the microbiome of the gut 
(referred to as gut dysbiosis) are thought to be responsible for gastrointestinal diseases such as irritable bowel syndrome (IBS), peptic ulcers, and many gastric malignancies [206]. Of interest to this dissertation are studies indicating an effect of gut dysbiosis on the lung, a relationship referred to as the "gut-lung axis." For example, individuals suffering from IBS often have impaired lung function [207]. A strong correlation between decreased microbial diversity in infancy and the development of asthma later in life has also been noted [208]. A variety of other lung disorders, such as COPD and cystic fibrosis, have also been linked to microbial dysbiosis [209-211]. In terms of cancer, a Danish population-based cohort study found that individuals with Crohn's disease, but not ulcerative colitis, had an increased risk of lung cancer that was associated with female gender and smoking [212]. While research in this area is still in its infancy, there have been several promising studies detailing how we might take advantage of the microbiome and its effect, for example, on immunity, in our fight to eradicate cancer [213-215]. 


\section{REFERENCES}

1. American Cancer Society. Cancer Facts \& Figures 2017. Atlanta: American Cancer Society. 2017.

2. Siegel RL, Miller KD, Jemal A. Cancer statistics, 2015. CA Cancer J Clin. 2015;65:5-29.

3. Mariotto AB, Robin Yabroff K, Shao Y, Feuer EJ, Brown ML. Projections of the cost of cancer care in the United States: 2010-2020. J Natl Cancer Inst. 2011;103:117-128.

4. Rodgman A, Perfetti T. The Chemical Components of Tobacco and Tobacco Smoke. 2009 CRC Press.

5. Hecht SS. Research opportunities related to establishing standards for tobacco products under the family smoking prevention and tobacco control act. Nicotine Tob Res. 2012;14:18-28.

6. Denissenko MF, Pao A, Tang M, Pfeifer GP. Preferential Formation of Benzo[a]pyrene Adducts at Lung Cancer Mutational Hotspots in P53. Science. 1996;274:430-432.

7. Sato M, Vaughan MB, Girard L, Peyton M, Lee W, Shames DS, Ramirez RD, Sunaga N, Gazdar AF, Shay JW, Minna JD. Multiple oncogenic changes (K-RAS(V12), p53 knockdown, mutant EGFRs, p16 bypass, telomerase) are not sufficient to confer a full malignant phenotype on 
human bronchial epithelial cells. Cancer Res. 2006;66:2116-2128.

8. Koo L, Ho J. Worldwide epidemiological patterns of lung cancer in nonsmokers. Int J Epidemiol. 1990;19:S14-23.

9. Toh CK, Gao F, Lim WT, Leong SS, Fong KW, Yap SP, Hsu AAL, Eng P, Koong HN, Thirugnanam A, Tan EH. Never-smokers with lung cancer: Epidemiologic evidence of a distinct disease entity. J Clin Oncol. 2006;24:2245-2251.

10. Darby S, Hill D, Auvinen A, Barros-Dios J, Baysson H, Bochicchio F, Deo H, Falk R, Forastiere F, Hakama M, Heid I. Radon in homes and risk of lung cancer: collaborative analysis of individual data from 13 European case-control studies. Bmj. 2005;330:223-228.

11. Krewski D, Lubin JH, Zielinski JM, Alavanja M, Catalan VS, Field RW, Klotz JB, L??tourneau EG, Lynch CF, Lyon JI, Sandler DP, Schoenberg JB, Steck DJ, Stolwijk JA, Weinberg C, Wilcox HB. Residential Radon and Risk of Lung Cancer: A Combined Analysis of 7 North American CaseControl Studies Daniel. Epidemiology. 2005;16:137-145.

12. Scott BR. Residential radon appears to prevent lung cancer. DoseResponse. 2011;9:444-464.

13. Sun S, Schiller JH, Gazdar AF. Lung cancer in never smokers - a different disease. Nat Rev Cancer. 2007;7:778-790.

14. Howlader N, Noone A, Krapcho M, Garshell J, Miller D, Altekruse S, Kosary C, Yu M, Ruhl J, Tatalovich Z, Mariotto A, Lewis D, Chen H, Feuer E, Cronin K. SEER Cancer Statistics Review, 1975-2008, National Cancer 
Institute. Bethesda, MD. 2010.

15. US Department of Health and Human Services. The Health Consequences of Smoking: 50 Years of Progress A Report of the Surgeon Genera Atlanta, GA. US Department of Health and Human Services Centers, Centers for Disease Control and Prevention, Natational Center for Chronic Disease Prevention and Health Promotion, Office on Smoking and Health, 2014.

16. Jemal A, Ma J, Rosenberg PS, Siegel R, Anderson WF. Increasing lung cancer death rates among young women in southern and midwestern states. J Clin Oncol. 2012;30:2739-2744.

17. Schoenborn C, Gindi R. Electronic cigarette use among adults: United States, 2014. Natl Cent Heal Stat. 2015;217:1-7.

18. Herzog B, Gerberi J. E-Cigs Revolutionizing The Tobacco Industry-Equity Research. Wells Fargo Secur LLC Equity Res Dep. 2013:1-14.

19. Goniewicz ML, Knysak J, Gawron M, Kosmider L, Sobczak A, Kurek J, Prokopowicz A, Jablonska-Czapla M, Rosik-Dulewska C, Havel C, Jacob P, Benowitz N. Levels of selected carcinogens and toxicants in vapour from electronic cigarettes. Tob Control. 2013;0:1-7.

20. Williams M, Villarreal A, Bozhilov K, Lin S, Talbot P. Metal and Silicate Particles Including Nanoparticles Are Present in Electronic Cigarette Cartomizer Fluid and Aerosol. PLoS One. 2013;8:e57987.

21. Brambilla E, Travis WD, Colby T V., Corrin B, Shimosato Y. The new World Health Organization classification of lung tumours. Eur Respir J. 2001;18:1059-1068. 
22. Kreuzer M, Kreienbrock L, Müller KM, Gerken M, Wichmann E. Histologic types of lung carcinoma and age at onset. Cancer. 1999;85:1958-1965.

23. Gajra A, Akbar SA, Din NU. Management of Lung Cancer in the Elderly. Clin Geriatr Med. 2016;32:81-95.

24. Liam C-K, Andarini S, Lee P, Ho JC-M, Chau NQ, Tscheikuna J. Lung cancer staging now and in the future. Respirology. 2015;20:526-534.

25. Pinsky PF, Church TR, Izmirlian G, Kramer BS. The National Lung Screening Trial: Results Stratified by Demographics, Smoking History and Lung Cancer Histology. 2013;119:1-20.

26. The National Lung Screening Trial Research Team. Reduced Lung-Cancer Mortality with Low-Dose Computed Tomographic Screening. N Engl J Med. 2011;365:395-409.

27. Welch HG, Schwartz LM, Woloshin S. Are increasing 5-year survival rates evidence of success against cancer? JAMA. 2000;283:2975-2978.

28. United Nations, Department of Economic and Social Affairs, Population Division (2011). World Population Prospects: The 2010 Revision, Volume I: Comprehensive Tables. ST/ESA/SER.A/313.

29. Rossen L, Osterman M, Hamilton B, Martin J. Quarterly provisional estimates for selected birth indicators. Natl Cent Heal Stat Natl Vital Stat Syst Vital Stat Rapid Release Progr. 2017.

30. Benjamin RM. Public Health Reports. 2010;125:626-629.

31. Geneva World Health Orginzation. World Health Organization. Global surveillance, prevention and control of chronic respiratory diseases: a 
comprehensive approach. 2007

http://www.who.int/gard/publications/GARD_Manual/e.

32. World Health Organization. World Health Statistics 2008. Geneva World Health Organization. 2008

http://www.who.int/gho/publications/world_health_statistics/EN_WHS08_F ull.pdf

33. Navaratnam V, Fleming KM, West J, Smith CJP, Jenkins RG, Fogarty A, Hubbard RB. The rising incidence of idiopathic pulmonary fibrosis in the UK. Thorax. 2011;66:462-467.

34. Kohansal R, Martinez-Camblor P, Agustí A, Sonia Buist A, Mannino DM, Soriano JB. The natural history of chronic airflow obstruction revisited: An analysis of the Framingham Offspring Cohort. Am J Respir Crit Care Med. 2009;180:3-10.

35. Bhatt NY, Wood KL. What defines abnormal lung function in older adults with chronic obstructive pulmonary disease? Drugs Aging. 2008;25:717728.

36. Sueblinvong V, Neujahr DC, Mills ST, Roser-page S, Ritzenthaler JD, Guidot D, Rojas M, Roman J. Predisposition for Disrepair in the Aged Lung. Am J Med Sci. 2012;344:41-51.

37. Matulionis $\mathrm{DH}$. Chronic cigarette smoke inhalation and aging in mice: 1. Morphologic and functional lung abnormalities. Exp Lung Res. 1984;7:237256.

38. Nin N, Lorente JA, De Paula M, Fernández-Segoviano P, Peñuelas O, 
Sánchez-Ferrer A, Martínez-Caro L, Esteban A. Aging increases the susceptibility to injurious mechanical ventilation. Intensive Care Med. 2008;34:923-931.

39. Gloyne S. Two cases of squamous carcinoma of the lung occurring in asbestosis. Tubercle. 1935;17:5-10.

40. Haddad R, Massaro D. Idiopathic diffuse interstitial pulmonary fibrosis (fibrosing alveolitis), atypical epithelial proliferation and lung cancer. Am J Med. 1968;45:211-219.

41. Hubbard R, Venn A, Lewis S, Britton J. Lung cancer and cryptogenic fibrosing alveolitis. A population-based cohort study. Am J Respir Crit Care Med. 2000;161:5-8.

42. Järveläinen $\mathrm{H}$, Sainio A, Koulu M, Wight TN, Penttinen R. Extracellular matrix molecules: potential targets in pharmacotherapy. Pharmacol Rev. 2009;61:198-223.

43. Frantz C, Stewart K, Weaver V. The Extracellular Matrix at a Glance. J Cell Sci. 2010;123 (pt24):4195-4200.

44. Kranenburg AR, Willems-Widyastuti A, Moori WJ, Sterk PJ, Alagappan VKT, de Boer WI, Sharma HS. Enhanced bronchial expression of extracellular matrix proteins in chronic obstructive pulmonary disease. Am J Clin Pathol. 2006;126:725-735.

45. Cottin V, Nunes H, Brillet PY, Delaval P, Devouassaoux G, Tillie-Leblond I, Israel-Biet D, Court-Fortune I, Valeyre D, Cordier JF. Combined pulmonary fibrosis and emphysema: A distinct underrecognised entity. Eur Respir J. 
2005;26:586-593.

46. Meltzer EB, Noble PW. Idiopathic pulmonary fibrosis. Orphanet J Rare Dis. 2008;3:1-15.

47. Bartram U, Speer CP. The Role of Transforming Growth Factor Beta in Lung Development and Disease. Chest. 2004;125:754-765.

48. Parameswaran K, Willems-Widyastuti A, Alagappan VKT, Radford K, Kranenburg AR, Sharma HS. Role of Extracellular Matrix and Its Regulators in Human Airway Smooth Muscle Biology. Cell Biochem Biophys. 2006;44:139-146.

49. Hernnas J, Nettelbladt O, Bjermer L, Sarnstrand B, Malmstrom A, Hallgren R. Alveolar accumulation of fibronectin and hyaluronan precedes bleomyininduced pulmonary fibrosis in the rat. Eur Respir J. 1992;5:404-410.

50. Limper $\mathrm{AH}$, Roman J. Fibronectin. A versatile matrix protein with roles in thoracic development, repair and infection. Chest. 1992;101:1663-1673.

51. Roman J. Fibronectin and Fibronectin Receptors in Lung Development. Exp Lung Res. 1997;23:147-159.

52. Kurtz A, Oh S-J. Age related changes of the extracellular matrix and stem cell maintenance. Prev Med. 2012;54:S50-S56.

53. Virchow R. Die Cellularpathologie in Ihrer Begruendung auf Physiologische und Pathologische Gewebelehre. Hirschwald, A, Berlin, Ger. 1858.

54. Duvall M. Atlas d'Embryologie. Masson, Paris. 1879.

55. Lazarides E, Balzer Jr. DR. Specificity of desmin to avian and mammalian muscle cells. Cell. 1978;14:429-438. 
56. Goldsmith EC, Hoffman A, Morales MO, Potts JD, Price RL, McFadden A, Rice M, Borg TK. Organization of fibroblasts in the heart. Dev Dyn. 2004;230:787-794.

57. Wei Y, Kim TJ, Peng DH, Duan D, Gibbons DL, Yamauchi M, Jackson JR, Le Saux CJ, Calhoun C, Peters J, Derynck R, Backes BJ, Chapman HA. Fibroblast-specific inhibition of TGF- $\beta 1$ signaling attenuates lung and tumor fibrosis. J Clin Invest. 2017;127:3675-3688.

58. Yamauchi Y, Izumi Y, Asakura K, Kawai K, Wakui M, Ohmura M, Suematsu M, Nomori H. Lewis lung carcinoma progression is facilitated by TIG-3 fibroblast cells. Anticancer Res. 2013;33:3791-3798.

59. Mishra DK, Compean SD, Thrall MJ, Liu X, Massarelli E, Kurie JM, Kim MP. Human Lung Fibroblasts Inhibit Non-Small Cell Lung Cancer Metastasis in Ex Vivo 4D Model. Ann Thorac Surg. 2015;100:1167-1174.

60. Tamkun JW, Hynes RO. Plasma fibronectin is synthesized and secreted by hepatocytes. J Biol Chem. 1983;258:4641-4647.

61. McDonald J. Extracellular matrix assembly. Annu Rev Cell Biol. 1988;4:183-207.

62. Kornblihtt AR, Vibe-Pedersen K, Baralle FE. Human fibronectin: molecular cloning evidence for two mRNA species differing by an internal segment coding for a structural domain. EMBO J. 1984;3:221-226.

63. Zardi L, Carnemolla B, Siri A, Petersen TE, Paolella G, Sebastio G, Baralle FE. Transformed human cells produce a new fibronectin isoform by preferential alternative splicing of a previously unobserved exon. EMBO J. 
$1987 ; 6: 2337-2342$.

64. Schwarzbauer JE, Patel RS, Fonda D, Hynes RO. Multiple sites of alternative splicing of the rat fibronectin gene transcript. Embo J. $1987 ; 6: 2573-2580$.

65. Roman J. Fibronectin and fibronectin receptors and lung development. Exp Lung Res. 1997;23:147-159.

66. Georges-Labouesse EN, George EL, Rayburn H, Hynes RO. Mesodermal development in mouse embryos mutant for fibronectin. Dev Dyn. 1996;207:145-156.

67. Grinnell F. Cellular adhesiveness and extracellular substrata. Int Rev Cytol. 1978;53:65-144.

68. Kleinman HK, Klebe RJ, Martin GR. Role of collagenous matrices in the adhesion and growth of cells. J Cell Biol. 1981;88:473-485.

69. Grinnell F, Feld M, Minter D. Fibroblast adhesion to fibrinogen and fibrin substrata: Requirement for cold-insoluble globulin (plasma fibronectin). Cell. 1980;19:517-525.

70. Culp L. Biochemical determinants of cell adhesion. Curr Top Membr Transp. 1978;11:327-396.

71. Sakai T, Johnson KJ, Murozono M, Sakai K, Magnuson M a, Wieloch T, Cronberg T, Isshiki A, Erickson HP, Fässler R. Plasma fibronectin supports neuronal survival and reduces brain injury following transient focal cerebral ischemia but is not essential for skin-wound healing and hemostasis. Nat Med. 2001;7:324-330. 
72. Muro AF, Chauhan AK, Gajovic S, laconcig A, Porro F, Stanta G, Baralle FE. Regulated splicing of the fibronectin EDA exon is essential for proper skin wound healing and normal lifespan. J Cell Biol. 2003;162:149-160.

73. Nam JM, Onodera Y, Bissell MJ, Park CC. Breast cancer cells in threedimensional culture display an enhanced radioresponse after coordinate targeting of integrin alpha5beta1 and fibronectin. Cancer Res. 2010;70:5238-5248.

74. Lou X, Han X, Jin C, Tian W, Yu W, Ding D, Cheng L, Huang B, Jiang H, Lin B. SOX2 Targets Fibronectin 1 to Promote Cell Migration and Invasion in Ovarian Cancer: New Molecular Leads for Therapeutic Intervention. Omi A J Integr Biol. 2013;17:510-518.

75. Rybak JN, Roesli C, Kaspar M, Villa A, Neri D. The extra-domain A of fibronectin is a vascular marker of solid tumors and metastases. Cancer Res. 2007;67:10948-10957.

76. Femel J, Huijbers EJM, Saupe F, Cedervall J, Zhang L, Roswall P, Larsson E, Olofsson H, Pietras K, Hellman L, Olsson A. Therapeutic vaccination against fibronectin ED-A attenuates progression of metastatic breast cancer. Oncotarget. 2014;5:12418-12427.

77. Sies H. Oxidative Stress. Acad Press London. 1985:1-507.

78. Jones DP, Mody VC, Carlson JL, Lynn MJ, Sternberg P. Redox analysis of human plasma allows separation of pro-oxidant events of aging from decline in antioxidant defenses. Free Radic Biol Med. 2002;33:1290-1300.

79. Abramson JL, Hooper WC, Jones DP, Ashfaq S, Rhodes SD, Weintraub 
WS, Harrison DG, Quyyumi AA, Vaccarino V. Association between novel oxidative stress markers and C-reactive protein among adults without clinical coronary heart disease. Atherosclerosis. 2005;178:115-121.

80. Shalansky SJ, Pate GE, Levin A, Webb JG. N-acetylcysteine for prevention of radiocontrast induced nephrotoxicity: the importance of dose and route of administration. Heart. 2005;91:997-999.

81. Trial ARC. Effects of Long-term Vitamin E Supplementation on Cardiovascular Events. 2005;293:1338-1347.

82. Goodman GE, Thornquist MD, Balmes J, Cullen MR, Meykens FL, Omenn GS, Valanis B, Williams JH. The Beta-Carotene and Retinol Efficacy Trial: Incidence of lung cancer and cardiovascular disease mortality during 6year follow-up after stopping $\beta$-carotene and retinol supplements. J Natl Cancer Inst. 2004;96:1743-1750.

83. Scott JA, King GL. Oxidative stress and antioxidant treatment in diabetes. Ann N Y Acad Sci. 2004;1031:204-213.

84. Jones DP. Redefining Oxidative Stress. Antioxid Redox Signal. 2006;8:1865-1879.

85. Ramirez A, Ramadan B, Ritzenthaler JD, Rivera HN, Jones DP, Roman J. Extracellular cysteine/cystine redox potential controls lung fibroblast proliferation and matrix expression through upregulation of transforming growth factor- $\beta$. Am J Physiol Lung Cell Mol Physiol. 2007;293:L972-981.

86. Beery A, Zucker I. Sex Bias in Neuroscience and Biomedical Research. Neurosci Biobehav. 2011;35:565-572. 
87. Mielke M, Vemuri P, Rocca W. Clinical epidemiology of Alzheimer's disease: assessing sex and gender differences. Clin Epidemiol. 2014;6:3748.

88. America's Bone Health: The State of Osteoporosis and Low Bone Mass in Our Nation. Washington, DC: National Osteoporsis Foundation; 2010.

89. Mannino DM, Homa DM, Akinbami LJ, Ford ES, Redd SC. Chronic obstructive pulmonary disease surveillance: United States, 1971-2000. In: Surveillance Summaries, August 2, 2002. MMWR 2002;51:1-16.

90. Han MK, Postma D, Mannino DM, Giardino ND, Buist S, Curtis JL, Martinez FJ. Gender and Chronic Obstructive Pulmonary Disease. Am J Respir Crit Care Med. 2007;176:1179-1184.

91. Birring SS, Brightling CE, Bradding P, Entwisle JJ, Vara DD, Grigg J, Wardlaw AJ, Pavord ID. Clinical, Radiologic, and Induced Sputum Features of Chronic Obstructive Pulmonary Disease in Nonsmokers: A Descriptive Study. Am J Respir Crit Care Med. 2002;166:1078-1083.

92. Voltz JW, Card JW, Carey MA, DeGraff LM, Ferguson CD, Flake GP, Bonner JC, Korach KS, Zeldin DC. Male sex hormones exacerbate lung function impairment after bleomycin-induced pulmonary fibrosis. Am J Respir Cell Mol Biol. 2008;39:45-52.

93. Gharaee-kermani M, Hatano K, Nozaki Y, Phan SH. Gender-based differences in bleomycin-induced pulmonary fibrosis. Am J Pathol. 2005;166:1593-1606.

94. Brass DM, McGee SP, Dunkel MK, Reilly SM, Tobolewski JM, Sabo- 
Attwood T, Fattman CL. Gender influences the response to experimental silica-induced lung fibrosis in mice. Am J Physiol Lung Cell Mol Physiol. 2010;299:L664-671 .

95. Ashley DJ. A male-female differential in tumour incidence. $\mathrm{Br} \mathrm{J}$ Cancer. $1969 ; 23: 21-25$.

96. Edgren G, Liang L, Adami HO, Chang ET. Enigmatic sex disparities in cancer incidence. Eur J Epidemiol. 2012;27:187-196.

97. Mitchell C, Richards S, Harrison CJ, Eden T. Long-term follow-up of the United Kingdom Medical Research Council protocols for childhood acute Lymphoblastic leukaemia, 1980-2001. Leukemia. 2010;24:406-418.

98. Devarahally SR, Severson RK, Chuba P, Thomas R, Bhambhani K, Hamre MR. Second malignant neoplasms after primary central nervous system malignancies of childhood and adolescence. Pediatr Hematol Oncol. 2003;20:617-625.

99. Kiyohara C, Ohno Y. Sex Differences in Lung Cancer Susceptibility: A Review. Gend Med. 2010;7:381-401.

100. International Early Lung Cancer Action Program Investigators. Women's susceptibility to tobacco carcinogens and survival after diagnosis of lung cancer. Jama. 2006;296:180-184.

101. Gazdar AF, Thun MJ. Lung cancer, smoke exposure, and sex. J Clin Oncol. 2007;25:469-471.

102. American Cancer Society. Cancer Facts \& Figures 2015. Atlanta: American Cancer Society. 2015. 
103. Harman D. Aging: a theory based on free radical and radiation chemistry. $J$ Gerontol. 1956;11:298-300.

104. Krishnan KJ, Greaves LC, Reeve AK, Turnbull D. The ageing mitochondrial genome. Nucleic Acids Res. 2007;35:7399-7405.

105. Makinodan T, Marguerite K. Age Influence on the Immune System. Adv Immunol. 1980;29:287-330.

106. Campisi J. Cancer and ageing: rival demons? Nat Rev Cancer. 2003;3:339-349.

107. Kirkwood TBL. Understanding the odd science of aging. Cell. $2005 ; 120: 437-447$.

108. Yao H, Rahman I. Current concepts on the role of inflammation in COPD and lung cancer. Curr Opin Pharmacol. 2009;9:375-383.

109. Park CC, Bissell MJ, Barcellos-Hoff MH. The influence of the microenvironment on the malignant phenotype. Mol Med Today. 2000;6:324-329.

110. Weaver VM, Petersen OW, Wang F, Larabell CA, Briand P, Damsky C, Bissell MJ. Reversion of the Malignant Phenotype of Human Breast Cells in Three-Dimensional Culture and In Vivo by Integrin Blocking Antibodies. J Cell Biol. 1997;137:231-245.

111. Wang F, Hansen RK, Radisky D, Yoneda T, Barcellos-Hoff MH, Petersen OW, Turley EA, Bissell MJ. Phenotypic Reversion or Death of Cancer Cells by Altering Signaling Pathways in Three-Dimensional Contexts. J Natl Cancer. 2002;94:1494-1503. 
112. Tockman MS, Anthonisen NR, Wright EC, Donithan MG. Airways obstruction and the risk for lung cancer. Ann Intern Med. 1987;106:512518.

113. Yang H, Bocchetta M, Kroczynska B, Elmishad AG, Chen Y, Liu Z, Bubici C, Mossman BT, Pass HI, Testa JR, Franzoso G, Carbone M. TNF-alpha inhibits asbestos-induced cytotoxicity via a NF-kappaB-dependent pathway, a possible mechanism for asbestos-induced oncogenesis. Proc Natl Acad Sci U S A. 2006;103:10397-10402.

114. Philip M, Rowley D a., Schreiber H. Inflammation as a tumor promoter in cancer induction. Semin Cancer Biol. 2004;14:433-439.

115. Giardiello FM, Hamilton SR, Krush AJ, Piantadosi S. Treatment of Colonic and Rectal Adenomas with Sulindac in Familial Adenomatous Polyposis. N Engl J Med. 1993;328:1313-1316.

116. Martins-Green M, Boudreau N, Bissell MJ. Inflammation is responsible for the development of wound-induced tumors in chickens infected with Rous sarcoma virus. Cancer Res. 1994;54:4334-4341.

117. Aoshiba K, Nagai A. Chronic lung inflammation in aging mice. FEBS Lett. 2007;581:3512-3516.

118. Calabresi C, Arosio B, Galimberti L, Scanziani E, Bergottini R, Annoni G, Vergani C. Natural aging, expression of fibrosis-related genes and collagen deposition in rat lung. Exp Gerontol. 2007;42:1003-1011.

119. Zheng Y, Ritzenthaler JD, Roman J, Han S. Nicotine stimulates human lung cancer cell growth by inducing fibronectin expression. Am J Respir 
Cell Mol Biol. 2007;37:681-690.

120. Malik G, Knowles LM, Dhir R, Xu S, Yang S, Ruoslahti E, Pilch J. Plasma fibronectin promotes lung metastasis by contributions to fibrin clots and tumor cell invasion. Cancer Res. 2010;70:4327-4334.

121. Pontiggia O, Sampayo R, Raffo D, Motter A, Xu R, Bissell MJ, De Kier Joffé EB, Simian M. The tumor microenvironment modulates tamoxifen resistance in breast cancer: A role for soluble stromal factors and fibronectin through $\beta 1$ integrin. Breast Cancer Res Treat. 2012;133:459471.

122. George EL, Georges-Labouesse EN, Patel-King RS, Rayburn H, Hynes RO. Defects in mesoderm, neural tube and vascular development in mouse embryos lacking fibronectin. Development. 1993;119:1079-1091.

123. Muro AF, Moretti FA, Moore BB, Yan M, Atrasz RG, Wilke CA, Flaherty KR, Martinez FJ, Tsui JL, Sheppard D, Baralle FE, Toews GB, White ES. An essential role for fibronectin extra type III domain A in pulmonary fibrosis. Am J Respir Crit Care Med. 2008;177:638-645.

124. Ashcroft T, Simpson JM, Timbrell V. Simple method of estimating severity of pulmonary fibrosis on a numerical scale. J Clin Pathol. 1988;41:467-470.

125. Balducci L, Extermann M. Cancer and aging. An Evolving Panorama. Hematol Oncol Clin North Am. 2000;14:1-16.

126. Hecht SS. Tobacco smoke carcinogen and lung cancer. J Natl Cancer Inst. 1999;91:1194-1210.

127. Goodman SA, Makinodan T. Effect of age on cell-mediated immunity in 
long-lived mice. Clin Exp Immunol. 1975;19:533-542.

128. Girard JP, Paychère M, Cuevas M, Fernandes B. Cell-mediated immunnity in an ageing population. Clin Exp Immunol. 1977;27:85-91.

129. Arenberg D, Luckhardt TR, Carskadon S, Zhao L, Amin MA, Koch AE. Macrophage migration inhibitory factor promotes tumor growth in the context of lung injury and repair. Am J Respir Crit Care Med. 2010;182:1030-1037.

130. Rossnagl S, Altrock E, Sens C, Kraft S, Rau K, Milsom MD, Giese T, Samstag Y, Nakchbandi IA. EDA-Fibronectin Originating from Osteoblasts Inhibits the Immune Response against Cancer. PLOS Biol. 2016;14:1-32.

131. Wang JP, Hielscher A. Fibronectin: How Its Aberrant Expression in Tumors May Improve Therapeutic Targeting. J Cancer. 2017;8:674-682.

132. Roman J, Ritzenthaler JD, Roser-Page S, Sun X, Han S. Alpha5Beta1Integrin Expression Is Essential for Tumor Progression in Experimental Lung Cancer. Am J Respir Cell Mol Biol. 2010;43:684-691.

133. World Cancer Research Fund / American Institute for Cancer Research. Food, Nutrition, Physical Activity, and the Prevention of Cancer: a Global Perspective. Washington DC: AICR, 2007

134. Farber E. The Multistep Nature of Cancer Development. Cancer Res. 1984;44:4217-4223.

135. Tsao AS, Kim ES, Hong WK. Chemoprevention of cancer. A Cancer J Clin. 2004;54:150-180.

136. Bange J, Zwick E, Ullrich A. Molecular targets for breast cancer therapy 
and prevention. Nat Med. 2001;7:548-552.

137. Fidler I, Ellis L. The implications of angiogenesis for the biology and therapy of cancer metastasis. Cell. 1994;79:185-188.

138. Rønnov-Jessen L, Petersen OW, Bissell MJ. Cellular changes involved in conversion of normal to malignant breast: importance of the stromal reaction. Physiol Rev. 1996;76:69-125.

139. Kanaji N, Yokohira M, Nakano-Narusawa Y, Watanabe N, Imaida K, Kadowaki N, Bandoh S. Hepatocyte growth factor produced in lung fibroblasts enhances non-small cell lung cancer cell survival and tumor progression. Respir Res. 2017;18:1-10.

140. Stabile LP, Lyker JS, Land SR, Dacic S, Zamboni BA, Siegfried JM. Transgenic mice overexpressing hepatocyte growth factor in the airways show increased susceptibility to lung cancer. Carcinogenesis. 2006;27:1547-1555.

141. Takeuchi S, Wang W, Li Q, Yamada T, Kita K, Donev IS, Nakamura T, Matsumoto K, Shimizu E, Nishioka Y, Sone S, Nakagawa T, Uenaka T, Yano S. Dual inhibition of met kinase and angiogenesis to overcome HGFinduced EGFR-TKI resistance in EGFR mutant lung cancer. Am J Pathol. 2012;181:1034-1043.

142. Yano S, Wang W, Li Q, Matsumoto K, Sakurama H, Nakamura T, Ogino H, Kakiuchi S, Hanibuchi M, Nishioka Y, Uehara H, Mitsudomi T, Yatabe Y, Nakamura T, Sone S. Hepatocyte growth factor induces gefitinib resistance of lung adenocarcinoma with epidermal growth factor receptor-activating 
mutations. Cancer Res. 2008;68:9479-9487.

143. Ding S, Chen G, Zhang W, Xing C, Xu X, Xie H, Lu A, Chen K, Guo H, Ren Z, Zheng S, Zhou L. MRC-5 fibroblast-conditioned medium influences multiple pathways regulating invasion, migration, proliferation, and apoptosis in hepatocellular carcinoma. J Transl Med. 2015;13:1-13.

144. Erez N, Truitt M, Olson P, Hanahan D. Cancer-Associated Fibroblasts Are Activated in Incipient Neoplasia to Orchestrate Tumor-Promoting Inflammation in an NF-??B-Dependent Manner. Cancer Cell. 2010;17:135147.

145. Shiga K, Hara M, Nagasaki T, Sato T, Takahashi H, Takeyama H. Cancerassociated fibroblasts: Their characteristics and their roles in tumor growth. Cancers. 2015;7:2443-2458.

146. Maeda M, Johnson KR, Wheelock MJ. Cadherin switching: essential for behavioral but not morphological changes during an epithelium-tomesenchyme transition. J Cell Sci. 2005;118:873-887.

147. Liang H, Kowalczyk P, Junco JJ, Klug-De Santiago HL, Malik G, Wei SJ, Slaga TJ. Differential effects on lung cancer cell proliferation by agonists of glucocorticoid and PPARa receptors. Mol Carcinog. 2014;53:753-763.

148. Ling DJ, Chen ZS, Liao Q De, Feng JX, Zhang XY, Yin TY. Differential effects of MTSS1 on invasion and proliferation in subtypes of non-small cell lung cancer cells. Exp Ther Med. 2016;12:1225-1231.

149. Stransky N, Ghandi M, Kryukov G V., Garraway LA, Lehár J, Liu M, Sonkin D, Kauffmann A, Venkatesan K, Edelman EJ, Riester M, Barretina J, 
Caponigro G, Schlegel R, Sellers WR, Stegmeier F, Morrissey M, Amzallag A, Pruteanu-Malinici I, Haber DA, Ramaswamy S, Benes $\mathrm{CH}$, Menden MP, lorio F, Stratton MR, McDermott U, Garnett MJ, Saez-Rodriguez J.

Pharmacogenomic agreement between two cancer cell line data sets. Nature. 2015;528:84-87.

150. Barretina J, Caponigro G, Stransky N, et al. The Cancer Cell Line Encyclopedia enables predictive modeling of anticancer drug sensitivity. Nature. 2012;483:603-607.

151. Jamieson E, Lippard S. Structure, Recognition, and Processing of Cisplatin - DNA Adducts. Chem Rev. 1999;99:2467-2498.

152. Santos NAG, Catão CS, Martins NM, Curti C, Bianchi MLP, Santos AC. Cisplatin-induced nephrotoxicity is associated with oxidative stress, redox state unbalance, impairment of energetic metabolism and apoptosis in rat kidney mitochondria. Arch Toxicol. 2007;81:495-504.

153. Bartling B, Hofmann H-S, Silber R-E, Simm A. Differential impact of fibroblasts on the efficient cell death of lung cancer cells induced by paclitaxel and cisplatin. Cancer Biol Ther. 2008;7:1250-1261.

154. Wu C, Wangpaichitr M, Feun L, Kuo MT, Robles C, Lampidis T, Savaraj N. Overcoming cisplatin resistance by mTOR inhibitor in lung cancer. Mol Cancer. 2005;4:1-10.

155. Trusolino L, Bertotti A, Comoglio PM. MET signalling: principles and functions in development, organ regeneration and cancer. Nat Rev Mol cell Biol. 2010;11:834-848. 
156. Stocker R, Keaney JF. Role of Oxidative Modifications in Atherosclerosis. Physiol Rev. 2004;84:1381-1478.

157. Berger MM. Can oxidative damage be treated nutritionally? Clin Nutr. 2005;24:172-183.

158. Cantin AM. Potential for antioxidant therapy of cystic fibrosis. Curr Opin Pulm Med. 2004;10:531-536.

159. Bonnefont-Rousselot, Dominique D. The role of antioxidant micronutrients in the prevention of diabetic complications. Treat Endocrinol. 2004;3:41-52.

160. Blanco RA, Ziegler TR, Carlson BA, Cheng PY, Park Y, Cotsonis GA, Accardi CJ, Jones DP. Diurnal variation in glutathione and cysteine redox states in human plasma. Am J Clin Nutr. 2007;86:1016-1023.

161. Jones DP, Carlson JL, Mody Jr. VC, Cai J, Lynn MJ, Sternberg Jr. P. Redox State of Glutathione in Human Plasma. Free Radic Biol Med. 2000;28:625-635.

162. Moriarty SE, Shah JH, Lynn M, Jiang S, Openo K, Jones DP, Sternberg P. Oxidation of glutathione and cysteine in human plasma associated with smoking. Free Radic Biol Med. 2003;35:1582-1588.

163. Degeneration AM. Glutathione in human plasma: decline in association with aging, age-related macular degeneration, and diabetes. Free Radic Biol Med. 1998;24:699-704.

164. Iyer SS, Ramirez AM, Ritzenthaler JD, Torres-gonzalez E, Roser-page S, Mora AL, Brigham KL, Jones DP, Roman J, Rojas M. Oxidation of extracellular cysteine / cystine redox state in bleomycin-induced lung 
fibrosis. Am J Physiol Lung Cell Mol Physiol. 2009;296:37-45.

165. Pendleton N, Jefferson MF, Dixon GR, Myskow MW, Horan MA. Correlates of tumor size, gender, cell type, and metastasis of resected non-small cell lung cancer and age. J Gerontol. 1996;51:B50-B53.

166. Pope M, Ashley M, Ferrence R. The carcinogenic and toxic effects of tobacco smoke: are women particularly susceptible? J Gend Spec Med. $1999 ; 2: 45-51$

167. Osann KE, Anton-Culver H, Kurosaki T, Taylor T. Sex Differences in Lung Cancer Risk Associated with Cigarette Smoking. Int J Cancer. 1993;54:4448.

168. Risch H, Howe G, Jain M, Burch J, Holowaty E, Miller A. Are female smokers at higher risk for lung cancer than male smokers? a case-control analysis by histologic type. Am J Epidemiol. 1993;138:281-293.

169. Wakelee HA, Chang ET, Gomez SL, Keegan TH, Feskanich D, Clarke CA, Holmberg L, Yong LC, Kolonel LN, Gould MK, West DW. Lung cancer incidence in never-smokers. J Clin Oncol. 2007;25:472-478.

170. Payne S. "Smoke like a man, die like a man"?: A review of the relationship between gender, sex and lung cancer. Soc Sci Med. 2001;53:1067-1080.

171. Taoli E W. Endocrine factors and adenocarcinoma of the lung in women. $J$ Natl Cancer Inst. 1994;86:869-870.

172. Mooney LVA, Perera FP, Van Bennekum AM, Blaner WS, Karkoszka J, Covey L, Hsu Y, Cooper TB, Frenkel K. Gender differences in autoantibodies to oxidative DNA base damage in cigarette smokers. 
Cancer Epidemiol Biomarkers Prev. 2001;10:641-648.

173. Liehr J, Fang W, Sirbasku D, Ari-Ulubelen A. Carcinogenicity of catechol estrogens in Syrian hamsters. J Steroid Biochem. 1986;24:353-356.

174. Meireles SI, Esteves GH, Hirata R, Peri S, Devarajan K, Slifker M, Mosier SL, Peng J, Vadhanam M V., Hurst HE, Neves EJ, Reis LF, Gairola CG, Gupta RC, Clapper ML. Early changes in gene expression induced by tobacco smoke: Evidence for the importance of estrogen within lung tissue. Cancer Prev Res. 2010;3:707-717.

175. Prescott E, Osler M, Ole Hein H, Borch-Johnsen K, Lange P, Schnohr P. Gender and smoking-related risk of lung cancer. Epidemiology. 1997;9:7983.

176. Bain C, Feskanich D, Speizer FE, Thun M, Hertzmark E, Rosner BA, Colditz GA. Lung Cancer Rates in Men and Women With Comparable Histories of Smoking. J Natl Cancer Inst. 2004;96:826-834.

177. Nkabyo YS, Gu LH, Jones DP, Ziegler TR. Thiol/disulfide redox status is oxidized in plasma and small intestinal and colonic mucosa of rats with inadequate sulfur amino acid intake. J Nutr. 2006;136:1242-1248.

178. Dai J, Jones DP, Goldberg J, Ziegler TR, Bostick RM, Wilson PW, Manatunga AK, Shallenberger L, Jones L, Vaccarino V. Association between adherence to the Mediterranean diet and oxidative stress. Am J Clin Nutr. 2008;88:1364-1370.

179. Martínez Alvarez JR, Bellés VV, López-Jaén AB, Marín AV, CodoñerFranch P. Effects of alcohol-free beer on lipid profile and parameters of 
oxidative stress and inflammation in elderly women. Nutrition. 2009;25:182187.

180. Jones DP, Park Y, Gletsu-Miller N, Liang Y, Yu T, Accardi CJ, Ziegler TR. Dietary sulfur amino acid effects on fasting plasma cysteine/cystine redox potential in humans. Nutrition. 2011;27:199-205.

181. Gao P, Zhang H, Dinavahi R, Li F, Xiang Y, Raman V, Bhujwalla ZM, Felsher DW, Cheng L, Pevsner J, Lee LA, Semenza GL, Dang C V. HIFDependent Antitumorigenic Effect of Antioxidants In Vivo. Cancer Cell. $2007 ; 12: 230-238$.

182. Sablina A a, Budanov A V, llyinskaya G V, Larissa S, Kravchenko JE, Chumakov PM. The antioxidant function of the p53 tumor suppressor Anna. Nat Med. 2005;11:1306-1313.

183. Wu X, Zhu Y, Yan H, Liu B, Li Y, Zhou Q, Xu K. Isothiocyanates induce oxidative stress and suppress the metastasis potential of human non-small cell lung cancer cells. BMC Cancer. 2010;10:1-11.

184. Piskounova E, Agathocleous M, Murphy MM, Hu Z, Huddlestun SE, Zhao Z, Leitch AM, Johnson TM, DeBerardinis RJ, Morrison SJ. Oxidative stress inhibits distant metastasis by human melanoma cells. Nature. 2015;527:186-191.

185. Pani G, Galeotti T, Chiarugi P. Metastasis: Cancer cell's escape from oxidative stress. Cancer Metastasis Rev. 2010;29:351-378.

186. Jones DP. Redox Potential of GSH/GSSG Couple: Assay and Biological Signficance. Methods Enzymol. 2002;348:93-112. 
187. Menger KE, James AM, Cochemé HM, Harbour ME, Chouchani ET, Ding S, Fearnley IM, Partridge L, Murphy MP. Fasting, but Not Aging, Dramatically Alters the Redox Status of Cysteine Residues on Proteins in Drosophila melanogaster. Cell Rep. 2015;11:1856-1865.

188. Anisimov VN. Effect of host age on tumor growth rate in rodents. Front Biosci. 2006;11:412-422.

189. Gozes $\mathrm{Y}$, Trainin N. Enhancement of Lewis lung carcinoma in a syngeneic host by spleen cells of C57BL/6 old mice. Eur J Immunol. 1977;7:159-164.

190. Yuhas J, Ulrich R. Responsiveness of senescent mice to the antitumor properties of Corynebacterium parvum. Cancer Res. 1976;36:161-166.

191. Ershler W. Explanations for Reduced Tumor Proliferative Capacity with Age. Exp Gerontol. 1992;27:551-558.

192. Anisimov VN, Zhukovskaya N. Effect of age on the growth of transplantable tumors in mice. Vopr Onkol. 1981;27:52-59.

193. Jarvelainen H, Sainio A, Koulu M, Wight TN, Penttinen R. Extracellular Matrix Molecules : Potential Targets in Pharmacotherapy. Pharmacol Rev. 2009;61:198-223.

194. Bos JL. ras Oncogenes in Human Cancer : A Review. Cancer Res. 1989;49:4682-4689.

195. Oberdoerffer P, Sinclair DA. The role of nuclear architecture in genomic instability and ageing. Nat Rev Mol Cell Biol. 2007;8:692-702.

196. O'Sullivan RJ, Karlseder J. The great unravelling: chromatin as a modulator of the aging process. Trends Biochem. 2012;37:466-476. 
197. Feser J, Tyler J. Chromatin structure as a mediator of aging. FEBS Lett. 2011;585:2041-2048.

198. Rakyan VK, Down TA, Maslau S, Andrew T, Yang TP, Beyan H, Whittaker P, McCann OT, Finer S, Valdes AM, Leslie RD, Deloukas P, Spector TD. Human aging-associated DNA hypermethylation occurs preferentially at bivalent chromatin domains. Genome Res. 2010;20:434-439.

199. Bollati V, Schwartz J, Wright R, Litonjua A, Tarantini L, Suh H, Sparrow D, Vokonas $\mathrm{P}$, Baccarelli A. Decline in genomic DNA methylation through aging in a cohort of elderly subjects. Mech Aging Dev. 2010;130:234-239.

200. Gautrey HE, Van Otterdijk SD, Cordell HJ, Bond J, Collerton J, Davies K, Eccles M, Jagger C, James O, Kirkwood T, Martin-Ruiz C, Robinson L, Von Zglinicki T, Mathers JC, Strathdee G. DNA methylation abnormalities at gene promoters are extensive and variable in the elderly and phenocopy cancer cells. FASEB J. 2014;28:3261-3272.

201. Levine ME, Hosgood HD, Chen B, Absher D, Assimes T, Horvath S. DNA methylation age of blood predicts future onset of lung cancer in the women's health initiative. Aging (Albany NY). 2015;7:690-700.

202. Ali SS, Xiong C, Lucero J, Behrens MM, Dugan LL, Quick KL. Gender differences in free radical homeostasis during aging: Shorter-lived female C57BL6 mice have increased oxidative stress. Aging Cell. 2006;5:565-574.

203. Cho I, Blaser MJ. The human microbiome: at the interface of health and disease. Nat Rev Genet. 2012;13:260-270.

204. Savage D. Microbial ecology of the gastrointestinal tract. Annu Rev 
Microbiol. 1977;31:107-133.

205. Gill S, Pop M, Deboy RT, Eckburg PB, Turnbaugh PJ, Samuel BS, Gordon JI, Relman DA, Fraser-Ligget CM, Nelson KE. Metagenomic analysis of the human distal gut microbiome. Science. 2006;312:1355-1359.

206. Anand JK. Helicobacter pylori infection. N Engl J Med. 2010;363:180.

207. Keely S, Talley NJ, Hansbro PM. Pulmonary-intestinal cross-talk in mucosal in ammatory disease. Muscosal Immunol. 2012;5:7-18.

208. Abrahamsson TR, Jakobsson HE, Andersson AF, Björkstén B, Engstrand L, Jenmalm MC. Low gut microbiota diversity in early infancy precedes asthma at school age. Clin Exp Allergy. 2014;44:842-850.

209. Sze MA, Dimitriu PA, Hayashi S, Elliott WM, McDonough JE, Gosselink J V., Cooper J, Sin DD, Mohn WW, Hogg JC. The lung tissue microbiome in chronic obstructive pulmonary disease. Am J Respir Crit Care Med. 2012;185:1073-1080.

210. van der Gast CJ, Walker AW, Stressmann FA, Rogers GB, Scott P, Daniels TW, Carroll MP, Parkhill J, Bruce KD. Partitioning core and satellite taxa from within cystic fibrosis lung bacterial communities. ISME J. 2011;5:780-791.

211. Marsland BJ, Trompette A, Gollwitzer ES. The gut-lung axis in respiratory disease. Ann Am Thorac Soc. 2015;12:S150-S156.

212. Jess T, Horváth-Puhó E, Fallingborg J, Rasmussen HH, Jacobsen BA. Cancer Risk in Inflammatory Bowel Disease According to Patient Phenotype and Treatment: A Danish Population-Based Cohort Study. Am J 
Gastroenterol. 2013;108:1869-1876.

213. Gui QF, Lu HF, Zhang CX, Xu ZR, Yang YM. Well-balanced commensal microbiota contributes to anti-cancer response in a lung cancer mouse model. Genet Mol Res. 2015;14:5642-5651.

214. Sivan A, Corrales L, Hubert N, Williams J, Aquino-Michaels K, Earley ZM, Benyamin FW, Lei YM, Jabri B, Alegre L, Chang EB, Gajewski TF. Commensal Bifidobacterium promotes antitumor immunity and facilitates anti-PD-L1 efficacy. 2015;350:1084-1089.

215. Bingula R, Filaire M, Radosevic-Robin N, Bey M, Berthon J-Y, BernalierDonadille A, Vasson M-P, Filaire E. Desired Turbulence? Gut-Lung Axis, Immunity, and Lung Cancer. J Oncol. 2017;2017:1-15. 


\section{LIST OF ABBREVIATIONS}

\begin{tabular}{|c|c|}
\hline aSMA & Alpha Smooth-Muscle Actin \\
\hline BAL & Bronchoalveolar Lavage \\
\hline BLEO & Bleomycin \\
\hline CCLE & Cancer Cell Line Encyclopedia \\
\hline $\mathrm{cFN}$ & Cellular Fibronectin \\
\hline cMET & Hepatocyte Growth Factor Receptor \\
\hline CAFs & Cancer-Associated Fibroblasts \\
\hline $\mathrm{CO}_{2}$ & Carbon Dioxide \\
\hline COPD & Chronic Obstructive Pulmonary Disease \\
\hline Cys & Cysteine \\
\hline Cyss & Cystine \\
\hline DAPI & 4',6-diamidino-2-phenylindole \\
\hline DMEM & Dulbecco's Modified Eagle Medium \\
\hline E1 & Estrone \\
\hline E2 & $17 \beta$-Estradiol \\
\hline ECAD & E-Cadherin \\
\hline cig & Electronic Cigarette \\
\hline ECM & Extracellular Matrix \\
\hline
\end{tabular}




$\begin{array}{ll}\text { EDA } & \text { Extra Domain A } \\ \text { EDB } & \text { Extra Domain B } \\ \text { Eh } & \text { Redox Potential } \\ \text { EMT } & \text { Epithelial Mesenchymal Transition } \\ \text { ERK } & \text { Extracellular Signal-Regulated Kinase } \\ \text { FCM } & \text { Fibroblast Conditioned Media } \\ \text { FBS } & \text { Fetal Bovine Serum } \\ \text { FGF } & \text { Fibroblast Growth Factor } \\ \text { FN } & \text { Fibronectin } \\ \text { GAPDH } & \text { Glyceraldehyde 3-phosphate dehydrogenase } \\ \text { GSH } & \text { Glutathione } \\ \text { GSSG } & \text { Glutathione Disulfide } \\ \text { HE } & \text { Hematoxylin and Eosin } \\ \text { HGF } & \text { Hepatocyte Growth Factor } \\ \text { HIF } & \text { Hypoxia-Inducible Factor } \\ \text { HMP } & \text { Human Microbiome Project } \\ \text { HPLC } & \text { High-Performance Liquid Chromatography } \\ \text { IACUC } & \text { Institutional Animal Care and Use Committee } \\ \text { IBS } & \text { Irritable Bowel Syndrome } \\ \text { IEAA } & \text { Intrinsic Epigenetic Age Acceleration } \\ \text { IPF } & \text { Idiopathic Pulmonary Fibrosis } \\ \text { KV } & \text { Intravenous Injection } \\ \text { Knockout }\end{array}$




\begin{tabular}{|c|c|}
\hline LLC & Lewis Lung Carcinoma \\
\hline mTOR & Mammalian Target of Rapamycin \\
\hline $\mathrm{mV}$ & Millivolts \\
\hline NAC & N-Acetyl Cysteine \\
\hline NCDs & Noncommunicable diseases \\
\hline $\mathrm{NIH}$ & National Institutes of Health \\
\hline NNK & 4-(Methylnitrosamino)-1-(3-pyridyl)-1-butanone \\
\hline NNN & N'-nitrosonornicotine \\
\hline NSCLC & Non-Small Cell Lung Cancer \\
\hline NSG & NOD scid gamma \\
\hline PAHs & Polycyclic Aromatic Hydrocarbons \\
\hline PBS & Phosphate Buffered Saline \\
\hline PBST & Phosphate Buffered Saline with Tween \\
\hline pFN & Plasma Fibronectin \\
\hline $\mathrm{PI} 3 \mathrm{~K}$ & Phosphatidylinositol-3-Kinases \\
\hline PLF & Primary Lung Fibroblasts \\
\hline RPM & Revolutions Per Minute \\
\hline RNS & Reactive Nitrogen Species \\
\hline ROS & Reactive Oxygen Species \\
\hline SAA & Sulfur Amino Acid \\
\hline SCLC & Small Cell Lung Cancer \\
\hline SDS & Sodium Dodecyl Sulfate \\
\hline TGF $\beta$ & Transforming Growth Factor $\beta$ \\
\hline
\end{tabular}




$\begin{array}{ll}\text { TSNAs } & \text { Tobacco Specific Nitrosamines } \\ \text { US } & \text { United States } \\ \text { VIM } & \text { Vimentin } \\ \text { WT } & \text { Wildtype } \\ \text { xg } & \text { Relative Centrifugal Force }\end{array}$

